Aus der Klinik für Neurologie

(Prof. Dr. med. M. Bähr)

im Zentrum Neurologische Medizin

der Medizinischen Fakultät der Universität Göttingen

\title{
Einfluss des zellulären Prion-Proteins auf die LDH-Expression unter oxidativen Stressbedingungen
}

\author{
INAUGURAL - DISSERTATION
}

zur Erlangung des Doktorgrades

der Medizinischen Fakultät der

Georg-August-Universität zu Göttingen

vorgelegt von

Sara Schenkel, geb. Schumann aus

Göttingen

Göttingen 2015 
Dekan:

I. Berichterstatterin:

II. Berichterstatter:

III. Berichterstatter:

Tag der mündlichen Prüfung:
Prof. Dr. rer. nat. H. K. Kroemer

Prof. Dr. med. I. Zerr

Prof. Dr. Michael Müller

Prof. Dr. Rainer Mausberg

23.11.2015 


\section{Inhaltsverzeichnis}

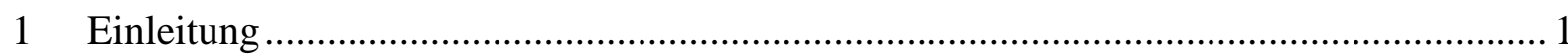

1.1 Prionen-Erkrankungen .................................................................................. 1

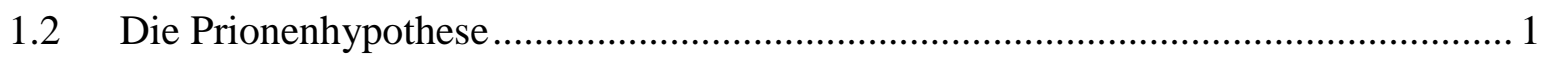

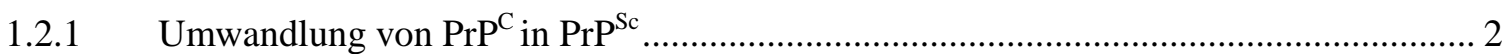

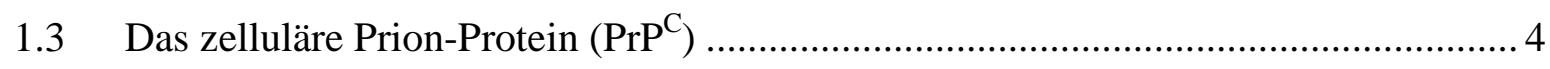

1.3.1 Struktur, Biosynthese und Prozessierung des zellulären Prion-Proteins ........................... 4

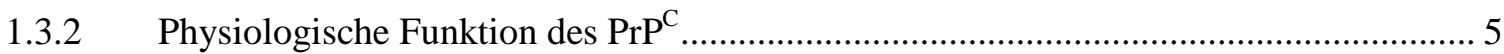

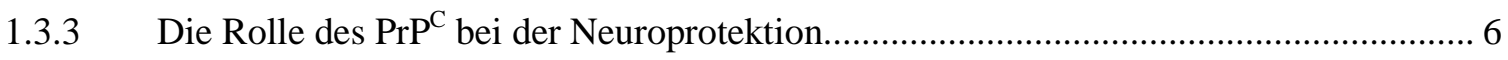

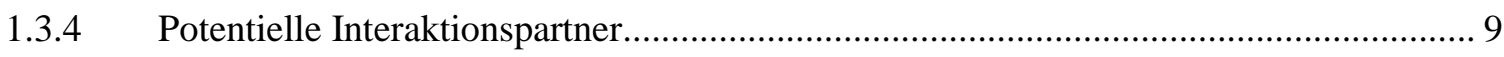

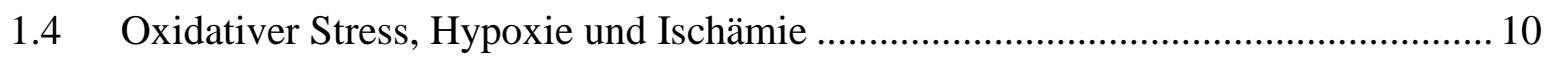

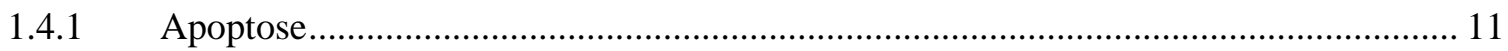

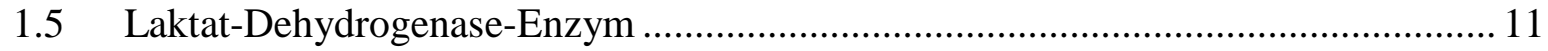

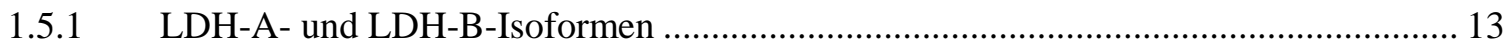

1.5.2 LDH und das zelluläre Prion-Protein ....................................................................... 13

1.5.3 Der Monocarboxylase-Transporter 1 (MCT1) …...................................................... 14

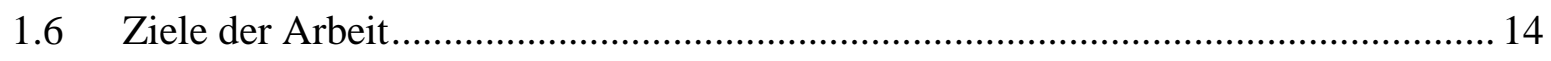

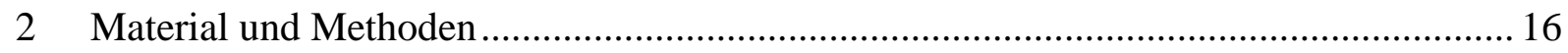

2.1 Material und Geräte ................................................................................. 16

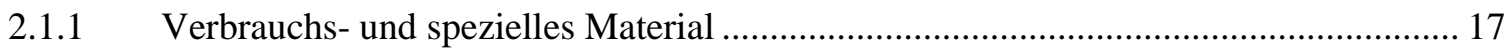

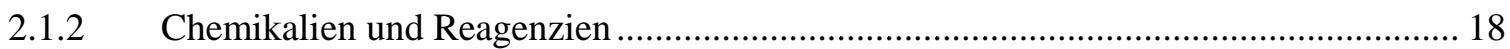

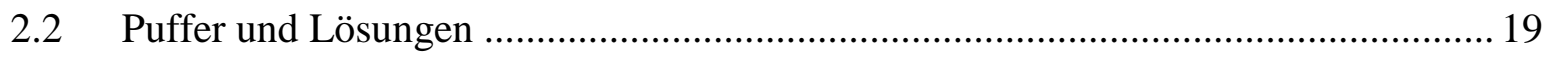

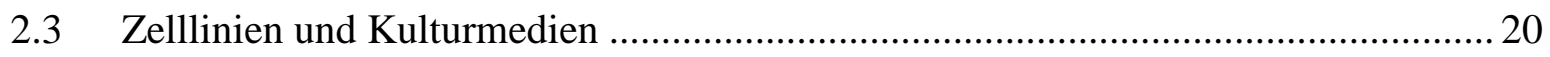

2.3.1 Human-embryonic-kidney-293-Zellen (HEK-293-Zellen) .......................................... 20

2.3.2 Präparation und Pflege der primären kortikalen Zellen von Prnp ${ }^{0 / 0}$-Knock-Out-Mäusen

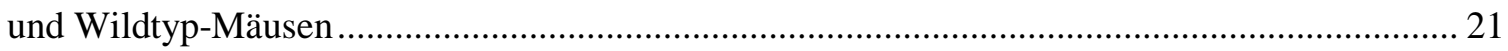

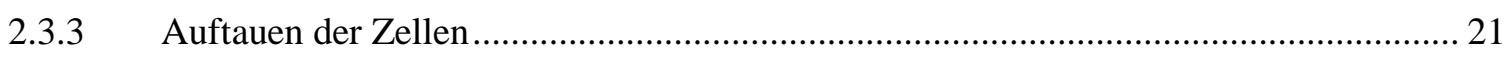

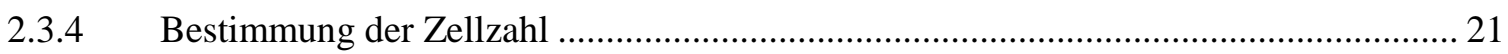




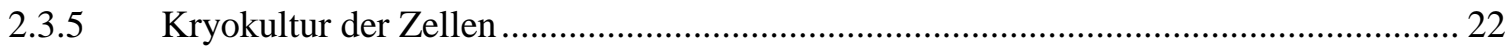

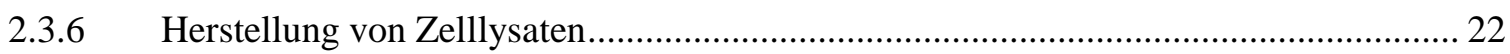

2.4 Transfektion der Zelllinien mit pCMS-PRNP-EGFP-Vektor ................................... 22

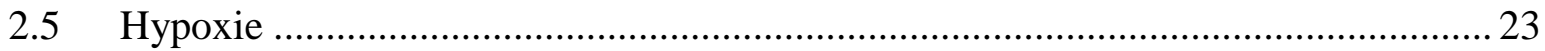

2.6 Bakterienstämme und Kulturmedium.............................................................. 23

2.6.1 Transformation von Plasmiden in E. coli-Bakterien ...................................................... 23

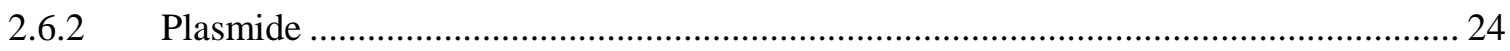

2.6.3 Plasmid-DNA-Extraktion (Minipräparation) …………................................................. 25

2.6.4 Plasmid-DNA-Extraktion (Midipräparation) …............................................................. 26

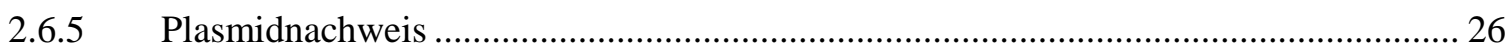

2.7 Bestimmung der Proteinkonzentration nach Bradford ......................................... 27

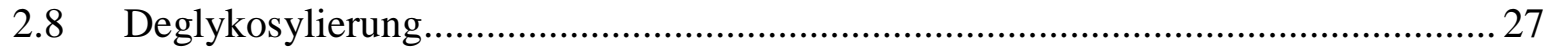

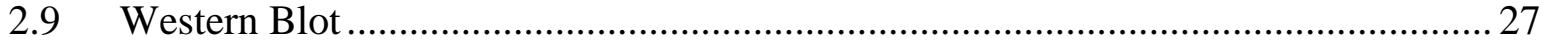

2.9.1 Sodiumdodecylsulfat-Polyacrylamid-Gelelektrophorese (SDS-PAGE) ....................... 28

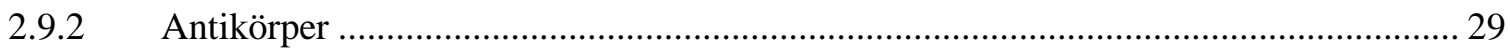

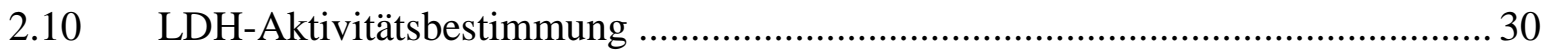

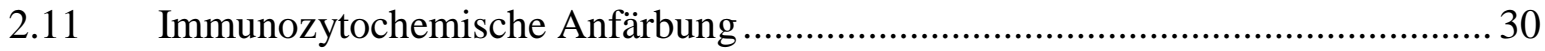

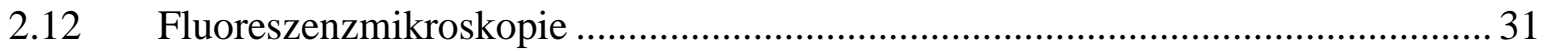

2.12.1 Anfärbung der DNA mit 4',6-Diamidin-2-Phenylindol (DAPI) ..................................... 31

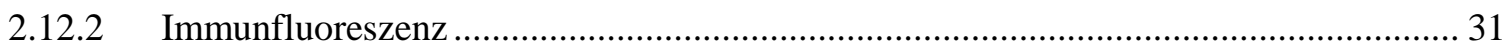

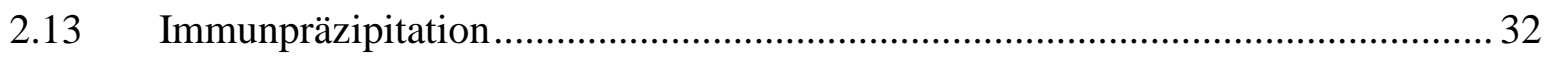

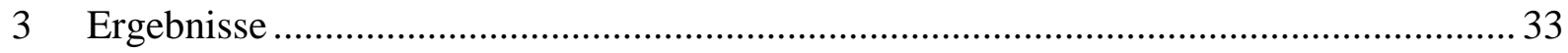

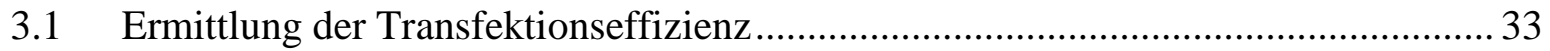

3.2 Deglykosylierung des $\operatorname{PrP}^{\mathrm{C}}$ bei HEK-293-Zellen durch N-Glykosidase F ............... 34

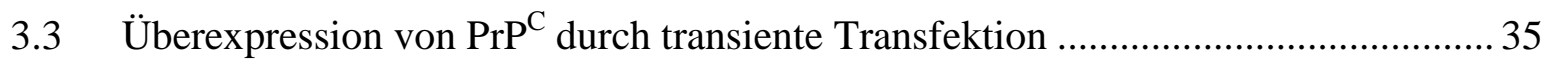

3.3.1 Transfektion von HEK-293-Zellen mit dem pCMS-PRNP-EGFP-Plasmid führt zu einer

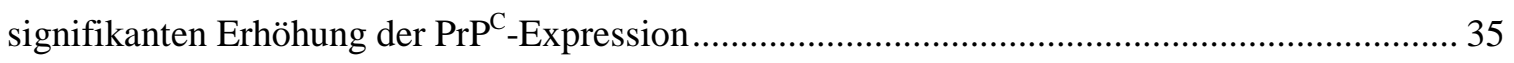

3.3.2 Transfektion von Prnp ${ }^{0 / 0}$-Zellen mit dem pCMS-PRNP-EGFP-Vektor führt zu einer Induktion der $\operatorname{PrP}^{\mathrm{C}}$-Expression 
3.4 Immunpräzipitation der beiden Proteine LDH-A und $\operatorname{PrP}^{\mathrm{C}}$ 38

3.5 Bestimmung der LDH-Expression vor und nach Hypoxie in verschiedenen Zelllinien 40

3.5.1 Regulation der LDH-Expression durch $\operatorname{PrP}^{\mathrm{C}}$ in kortikalen Neuronen in Folge einer Hypoxie 40

3.5.2 Regulation von LDH nach Hypoxie in $\operatorname{PrP}^{\mathrm{C}}$ überexprimierenden HEK-293-Zellen .... 42

3.5.3 Erhöhung der LDH-Expression in Abhängigkeit vom $\mathrm{PrP}^{\mathrm{C}}$-Level in $\mathrm{PRNP}^{+/+}$transfizierten Prnp ${ }^{0 / 0}$-Zellen nach Hypoxie

3.5.4 Hypoxie führt zu einer größeren Schädigung des Tubulinzytoskelettes in Prnp ${ }^{0 / 0}$-Zellen im Vergleich zu WT-Zellen. 45

4 Diskussion 48

4.1 Interaktion von $\mathrm{LDH}$ und $\mathrm{PrP}^{\mathrm{C}}$ 48

4.1.1 PrP ${ }^{\mathrm{C}}$-vermittelte Hochregulation der LDH-Expression unter zellulären Stressbedingungen .49

4.1.2 Laktat als Energiesubstrat. 50

4.2 $\operatorname{PrP}^{\mathrm{C}}$ wirkt neuroprotektiv bei einer Ischämie in Mäusen. 51

4.3 Relevanz von LDH in der Humanmedizin 52

5 Zusammenfassung. 55

6 Literaturverzeichnis 56 


\section{Abbildungsverzeichnis}

Abbildung 1: Das Umfaltungsmodell von $\operatorname{PrP}^{\mathrm{C}}$ zu $\operatorname{PrP}^{\mathrm{Sc}}$ 3

Abbildung 2: Das Keimbildungsmodell für die Umwandlung von $\operatorname{PrP}^{\mathrm{C}} \mathrm{zu} \operatorname{PrP}^{\mathrm{Sc}}$ 4

Abbildung 3: Die Struktur des Prion-Proteins

Abbildung 4: Verschiedene Schnitte durch die zerebrale Infarktregion von $\operatorname{PrP}^{0 / 0}$ - und WTMäusen nach Hypoxie, angefärbt durch 2,3,5-Triphenyl-Tetrasoliumchlorid. 8

Abbildung 5: Schematische Darstellung des pCMS-EGFP-Plasmids 25

Abbildung 6: Bestimmung der Transfektionseffizienz und immunozytochemische Anfärbung von $\mathrm{PrP}^{\mathrm{C}}$ in HEK-293-Zellen 34

Abbildung 7: Expressionsmuster des $\mathrm{PrP}^{\mathrm{C}}$ in HEK-293-Zellen vor und nach Deglykosylierung 35

Abbildung 8: Hochregulation der $\operatorname{PrP}^{\mathrm{C}}$-Expression in den $\mathrm{PRNP}^{+/+}$-transfizierten Zellen nach transienter Transfektion mittels $\mathrm{PRNP}^{+/+}$-Vektor.... 37

Abbildung 9: Induktion von $\operatorname{PrP}^{\mathrm{C}}$ mittels Transfektion mit pCMS-PRNP-EGFP- Vektor in Prnp $^{0 / 0}$-Zellen 38

Abbildung 10: Co-Immunpräzipitation von LDH-A und $\operatorname{PrP}^{\mathrm{C}}$ in HEK-293-Zellen 39

Abbildung 11: $\operatorname{PrP}^{\mathrm{C}}$ induziert eine Hochregulation der LDH-Expression in primären Neuronen nach Hypoxie.

Abbildung 12: LDH-A-Expression in Kontroll- und $\mathrm{PrP}^{\mathrm{C}}$-überexprimierenden HEK-293Zellen unter normalen und hypoxischen Bedingungen.

Abbildung 13: LDH-A-Expression vor und nach Hypoxie in $\mathrm{PRNP}^{+/+}$- und $\mathrm{PRNP}^{-/-}$transfizierten $\operatorname{Prnp}^{0 / 0}$-Zellen. 45

Abbildung 14: Immunozytochemische Darstellung des Tubulinzytoskeletts in primären kortikalen Neuronen von WT- und Prnp ${ }^{0 / 0}$-Zellen vor und nach Hypoxie .46 


\section{Tabellenverzeichnis}

Tabelle 1: Unterschiede zwischen $\operatorname{PrP}^{\mathrm{C}}$ und $\mathrm{PrP}^{\mathrm{Sc}}$ bezogen auf Struktur, Halbwertszeiten und Eigenschaften. 2

Tabelle 2: Mögliche Funktionen von $\operatorname{PrP}^{\mathrm{C}}$ und deren Einfluss auf die Apoptose.................... 11

Tabelle 3: Varianten der LDH und deren Vorkommen........................................................ 13

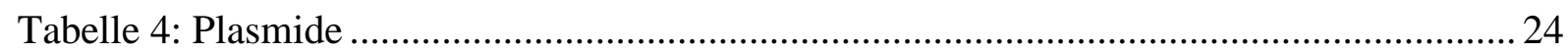

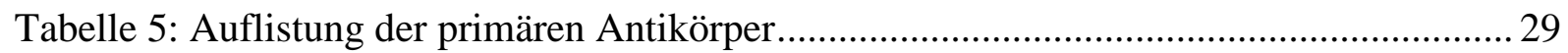

Tabelle 6: Auflistung der sekundären Antikörper.............................................................. 30 


\section{Abkürzungsverzeichnis}

\begin{tabular}{|c|c|}
\hline Abkürzung & Bedeutung \\
\hline A & Ampere \\
\hline Abb. & Abbildung \\
\hline$A \beta$ & Amyloid $\beta$ \\
\hline APP & Amyloid-Vorläufer-Protein (engl.: Amyloid precursor protein) \\
\hline$\beta-$ & Beta \\
\hline BSA & Rinderserumalbumin (engl.: bovine serum albumine) \\
\hline BSE & Bovine spongiforme Enzephalopathien \\
\hline${ }^{\circ} \mathrm{C}$ & Grad Celsius \\
\hline CJK & Creutzfeldt-Jakob-Krankheit \\
\hline CJD & engl.: Creutzfeldt-Jakob-Disease \\
\hline C-Terminus & carboxyterminales Ende von Proteinen \\
\hline $\mathrm{d}$ & Tag \\
\hline GSS & Gerstmann-Sträussler-Scheinker-Syndrom \\
\hline DMEM & engl.: Dulbecco's modified Eagle’s medium \\
\hline DNA & Desoxyribonukleinsäure (engl.: deoxyribonucleic acid) \\
\hline ECL & engl.: enhanced chemiluminescence \\
\hline EDTA & Ethylendiamintetraessigsäure \\
\hline EGFP & engl.: enhanced green fluorescent protein \\
\hline engl. & englisch \\
\hline FBS & engl.: fetal bovine serum \\
\hline g & Gramm \\
\hline
\end{tabular}




\begin{tabular}{|c|c|}
\hline G & mittlere Erdbeschleunigung \\
\hline $\mathrm{h}$ & Stunde \\
\hline HEK-293 & engl.: human embryonic kidney cell line \\
\hline $\mathrm{H}_{2} \mathrm{O}$ & Wasser \\
\hline $\mathrm{kDa}$ & Kilodalton \\
\hline l & Liter \\
\hline LDH & Laktat-Dehydrogenase \\
\hline MW & Molekulargewicht (engl.: molecular weight) \\
\hline $\min$ & Minute \\
\hline $\mathrm{ml}$ & Milliliter \\
\hline$\mu-$ & mikro $\left(1 \times 10^{-6}\right)$ \\
\hline PAGE & Polyacrylamid-Gelelektrophorese \\
\hline PBS & phosphatgepufferte Kochsalzlösung (engl.: phosphat buffered saline) \\
\hline PFA & Paraformaldehyd \\
\hline $\mathrm{pH}$ & negativ dekadischer Logarithmus der Protonenkonzentration \\
\hline PRNP & Prion-Protein-Gen (Mensch) \\
\hline Prnp & Prion-Protein-Gen (Maus) \\
\hline $\operatorname{PrP}$ & Prion-Protein \\
\hline $\operatorname{PrP}^{\mathrm{c}}$ & zelluläres Prion-Protein (engl.: c-cellular) \\
\hline $\operatorname{PrP}^{\mathrm{sc}}$ & pathogenes Prion-Protein (engl.: Sc-Scrapie) \\
\hline Prnp ${ }^{0 / 0}$-Maus & Prion-Protein-Knockout-Maus \\
\hline PS & Penicilin-Streptomycin \\
\hline rpm & engl.: revolutions per minute \\
\hline
\end{tabular}




\begin{tabular}{l|l} 
RT & Raumtemperatur \\
S & Sekunde \\
SDS & Neite \\
Tab. & Tatriumdodecylsulfat (engl.: sodium dodecylsulfate) \\
TEMED & Tetramethylendiamin \\
TRIS & Tris-hydroxymethyl-aminomethan \\
TSE & Transmissible spongiforme Enzephalopathie \\
Tween & Polyoxyethylensorbitanmonolaurat \\
V & Volt \\
WB & Western Blot \\
WT & Wildtyp
\end{tabular}




\section{Einleitung}

\subsection{Prionen-Erkrankungen}

Prionen-Erkrankungen werden auch als übertragbare (transmissible) spongiforme Enzephalopathien (TSE's) bezeichnet. Sie sind tödlich verlaufende neurodegenerative Erkrankungen bei Menschen und Tieren. Histologisch findet sich eine Degeneration von Neuronen sowie eine Entzündungsreaktion infolge einer Aktivierung von Astrozyten und schwammartigen (spongiformen) Veränderungen im Nervensystem. Auf Grund der langen Inkubationszeit wurde früher davon ausgegangen, dass es sich um ein sogenanntes slow Virus handelt (Gajdusek et al. 1977). Jedoch zeigten Versuche, die sowohl Bakterien (Autoklavieren) als auch Viren (Detergenzien, Bestrahlen mit UV-Licht) zerstören sollten, keine Wirkung (Bellinger-Kawahara et al. 1987; McKinley et al. 1983; Prusiner 1989; Prusiner 1991; Prusiner und DeArmond 1987). Es konnten zudem keine Nukleinsäuren isoliert werden (Meyer et al. 1991). Bei humanen Prionen-Erkrankungen unterscheidet man die im Jahr 1921 erstmals beschriebene Creutzfeldt-Jakob-Krankheit (CJK), das GerstmannSträussler-Scheinker-Syndrom (GSS), die fatale familiäre Insomnie (Griffith 1967) und Kuru (Collinge 2001). TSE's beim Menschen werden eingeteilt in sporadische, hereditäre (genetisch bedingte) und erworbene (iatrogene). Die Mehrheit der TSE-Fälle treten sporadisch auf. Bei den Tieren sind die bekanntesten Formen die Bovine Spongiforme Enzephalopathie (BSE) bei Rindern und Scrapie bei Schafen und Ziegen.

\subsection{Die Prionenhypothese}

Die Prionenhypothese wurde 1982 von Stanley B. Prusiner aufgestellt (Prusiner 1982). Prusiner ging davon aus, dass nur ein einziges Protein oder ein proteinähnlicher Bestandteil das infektiöse Agens darstellt. In Anlehnung an die Abkürzung seiner Hypothese (proteinaceous infectious particle) nannte Prusiner das infektiöse Agens „Prion“. Die von ihm formulierte protein-only-Hypothese besagt, dass das Prion-Protein in einer zellulären $\left(\operatorname{PrP}^{\mathrm{C}}\right)$ und einer infektiösen, abnormal gefalteten ( $\mathrm{PrP}^{\mathrm{Sc}}$ ) Form vorkommt (Prusiner, 1998). Beide unterscheiden sich lediglich in ihrer Konformation (Pan et al. 1993). Während sich $\operatorname{PrP}^{\mathrm{C}} \mathrm{zu}$ $42 \%$ aus $\alpha$-Helixstruktur zusammensetzt und nur zu 3\% $\beta$-Faltblattstruktur aufweist, besteht $\operatorname{PrP}^{\mathrm{Sc}} \mathrm{zu} 30 \%$ aus $\alpha$-Helixstruktur und zu 54\% aus $\beta$-Faltblattstruktur (Pan et al. 1993). Bei Kontakt der beiden Konformere kommt es zur Konversion von $\operatorname{PrP}^{\mathrm{C}}$ in $\operatorname{PrP}^{\mathrm{Sc}}$ (Griffith 1967) (Prusiner und DeArmond 1987). Das infektiöse Agens vermehrt sich so ohne direkte Beteiligung von Nukleinsäuren (Prusiner 1998). Desweiteren ist eine Entstehung von $\mathrm{PrP}^{\mathrm{Sc}}$ 
durch zufällige Fehlfaltung des Prion-Proteins möglich und es wird vermutet, dass Mutationen die Konformationsänderung fördern können (Prusiner 1993; Prusiner 1998).

\subsubsection{Umwandlung von $\operatorname{PrP}^{\mathrm{C}}$ in $\operatorname{PrP}^{\mathrm{Sc}}$}

Beide Formen des Prion-Proteins sind bezüglich ihrer Aminosäuresequenz identisch. Es bestehen aber Unterschiede in der Sekundär- und Tertiärstruktur (Baldwin et al. 1995; Stahl et al. 1993). In der pathogenen Form konnten keine Modifikationen nachgewiesen werden, die es nicht auch in der zellulären Form gibt (Stahl et al. 1993). Jedoch unterscheiden sich die biosphysikalischen Eigenschaften deutlich. Während $\operatorname{PrP}^{\mathrm{C}}$ vollständig durch die zelleigene Proteinase $\mathrm{K}$ hydrolysiert wird, ist $\mathrm{PrP}^{\mathrm{Sc}}$ resistent gegenüber dem Verdau durch Proteinase $\mathrm{K}$ (Bolton et al. 1982; McKinley et al. 1983). Infolge des hohen $\beta$-Faltblatt-Anteils sowie der starken Aggregationsneigung von $\operatorname{PrP}^{\mathrm{Sc}}$ bilden sich unlösliche und toxische Aggregate aus (Prusiner et al. 1983). Weitere Unterschiede sind in Tab. 1 zusammengefasst.

\begin{tabular}{|c|c|c|}
\hline Eigenschaft & PrP $^{\mathbf{C}}$ & PrP $^{\text {Sc }}$ \\
\hline Sekundärstruktur & hauptsächlich $\alpha$-helikal & hauptsächlich $\beta$-helikal \\
\hline Halbwertszeit & $2-6 \mathrm{~h}$ & $\geq 24 \mathrm{~h}$ \\
\hline Infektiosität & nein & ja \\
\hline Löslichkeit & ja & nein \\
\hline Proteinase K-Resistenz & keine & (relative) Resistenz \\
\hline
\end{tabular}

Tabelle 1: Unterschiede zwischen $\operatorname{PrP}^{\mathrm{C}}$ und $\operatorname{PrP}^{\mathrm{Sc}}$ bezogen auf Struktur, Halbwertszeiten und Eigenschaften.

\subsubsection{Heterodimer- oder Umfaltungsmodell}

Das Umfaltungsmodell von Prusiner besagt, dass $\operatorname{PrP}^{\mathrm{C}}$ mit dem infektiösen $\mathrm{PrP}^{\mathrm{Sc}}$ interagiert unter der Bildung eines Heterodimers und es dabei unter Überwindung einer hohen Energiebarriere zur Konformationsänderung von $\operatorname{PrP}^{\mathrm{C}} \quad \mathrm{zu} \quad \operatorname{PrP}^{\mathrm{Sc}}$ kommt (Abb. 1). Katalysatoren in Form von Enzymen oder Chaperonen werden dabei nicht ausgeschlossen (Prusiner 1991). Die Umfaltung setzt sich exponentiell fort und kann durch bestimmte Genmutationen begünstigt werden (hereditäre Prionerkrankungen). 


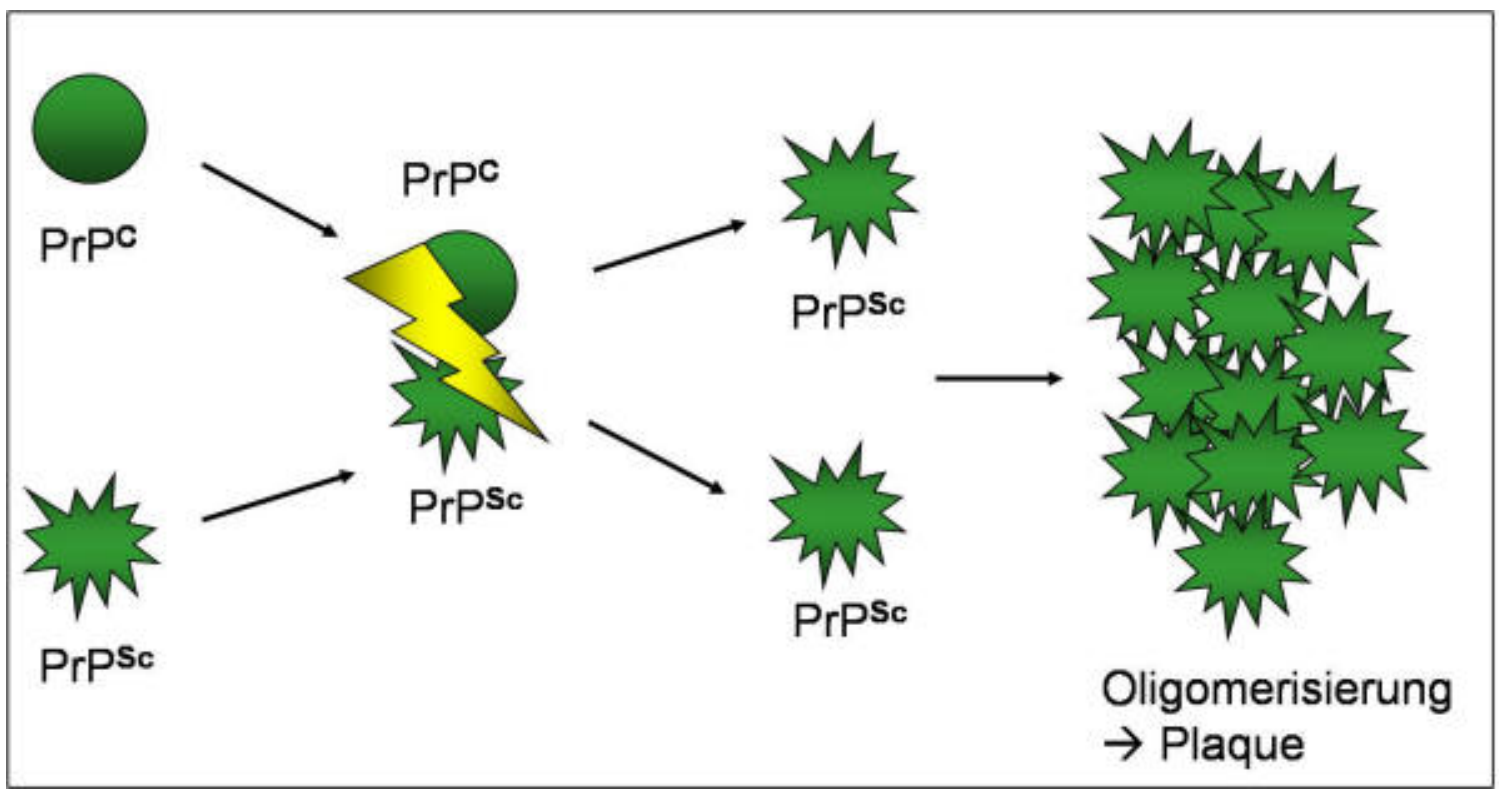

\section{Abbildung 1: Das Umfaltungsmodell von $\operatorname{PrP}^{\mathrm{C}} \mathrm{zu} \operatorname{PrP}^{\mathrm{Sc}}$}

Durch den Kontakt von $\operatorname{PrP}^{\mathrm{C}}$ mit $\operatorname{PrP}^{\mathrm{Sc}}$ kommt es nach Bildung des HeterodimerKomplexes zur Umwandlung in $\mathrm{PrP}^{\mathrm{Sc}}$, gefolgt von der Oligomerisierung und Plauqebildung (Becker 2005).

\subsubsection{Nukleations- oder Keimbildungsmodell}

Das zweite sogenannte Keimbildungsmodell nach Lanysbury geht von einem Gleichgewicht zwischen beiden PrP-Formen aus. Dieses liegt normalerweise auf der Seite von $\operatorname{PrP}^{\mathrm{C}} \cdot \operatorname{PrP}^{\mathrm{Sc}}$ ist nach dieser Vorstellung nur dann stabil, wenn es durch einen Faktor X zur Bildung von Multimeren kommt, welche in der Zelle nicht mehr abgebaut werden können (Jarrett und Lansbury 1993). Diese können sich erneut teilen und zu weiteren $\operatorname{PrP}^{\mathrm{Sc}}$ Multimeren führen (Abb. 2).

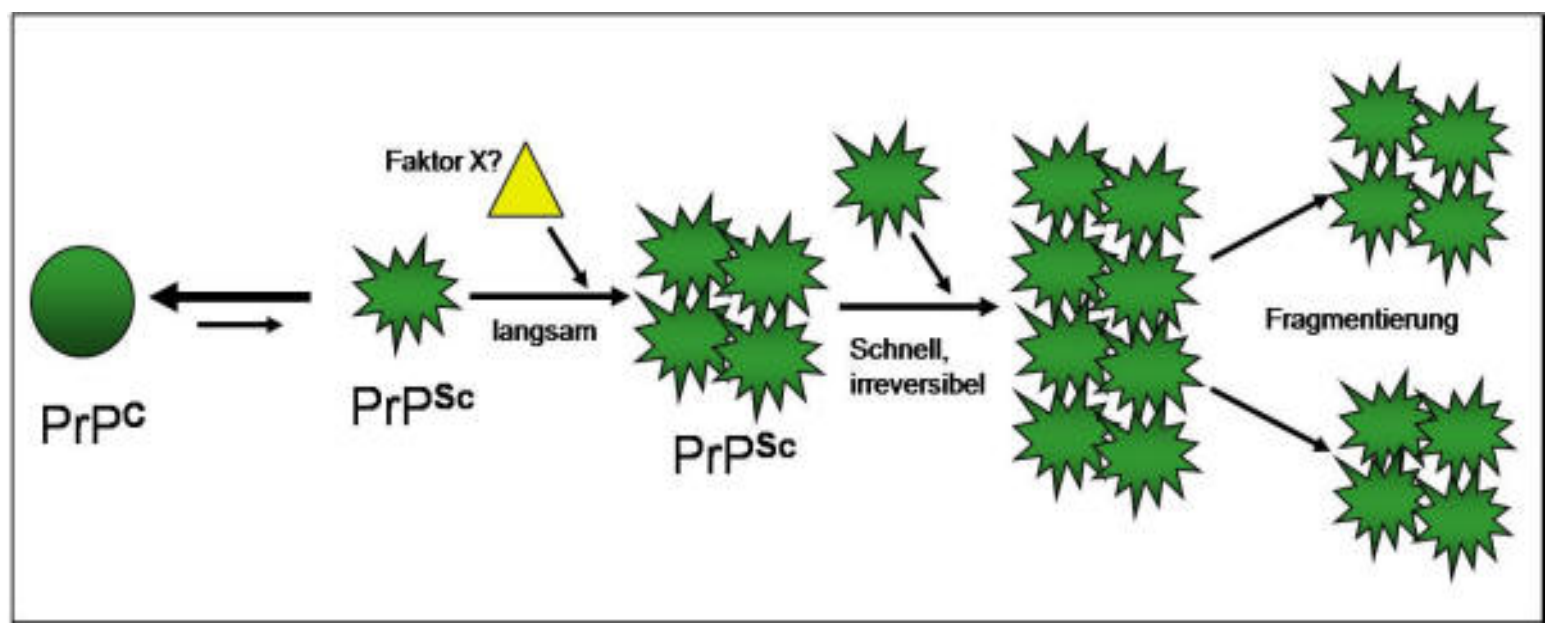




\section{Abbildung 2: Das Keimbildungsmodell für die Umwandlung von $\operatorname{PrP}^{\mathrm{C}} \mathrm{zu}^{\mathrm{PrP}} \mathrm{P}^{\mathrm{Sc}}$}

Zwischen $\operatorname{PrP}^{\mathrm{C}}$ und $\operatorname{PrP}^{\mathrm{Sc}}$ herrscht ein dynamisches Gleichgewicht, welches normalerweise auf der Seite von $\operatorname{PrP}^{\mathrm{C}}$ liegt. Kommt ein Faktor $\mathrm{X}$ hinzu, vermehrt sich $\operatorname{PrP}^{\mathrm{Sc}}$. Ist eine kritische Größe erreicht, wird $\mathrm{PrP}^{\mathrm{Sc}}$ irreversibel gebunden und es kommt zur Aggregation und Fragmentierung (Becker 2005).

\subsection{Das zelluläre Prion-Protein $\left(\operatorname{PrP}^{\mathrm{C}}\right)$}

\subsubsection{Struktur, Biosynthese und Prozessierung des zellulären Prion-Proteins}

$\operatorname{PrP}^{\mathrm{C}}$ ist ein hochkonserviertes, körpereigenes Glykoprotein (Oesch et al. 1985). Es besteht aus 253 Aminosäuren, ist über einen Glykosylphospatidylinositol-Anker (GPI-Anker) an die äußere Plasmamembran gebunden (Baldwin et al. 1990; Stahl et al. 1987) und an zwei Asparagin-Resten mit Oligosacchariden vom Mannosetyp N glykosyliert (Endo et al. 1989; Haraguchi et al. 1989). Im N-terminalen Bereich befindet sich eine Repeat-Region aus fünf sich wiederholenden Sequenzen (Oktarepeatregion). Diese besitzt eine Kupferbindungsdomäne (Brown et al. 1997a; Hornshaw et al. 1995). Im C-terminalen Bereich befinden sich zwei Cysteinreste, welche eine Disulfidbrücke bilden (Prusiner 1993). Das zelluläre PrionProtein besitzt drei $\alpha$-helikale und einen kurzen $\beta$-Faltblatt-Bereich (Riek et al. 1996). Es wird durch das PRNP kodiert (Basler et al. 1986; Borchelt et al. 1990). Beim Menschen befindet es sich auf dem kurzen Arm des Chromosom 20, bei Mäusen auf Chromosom 2 (Sparkes et al. 1986). Die Biosynthese von $\operatorname{PrP}^{\mathrm{C}}$ ist ähnlich derjenigen anderer Membran- und sekretorischer Proteine: Die Translation erfolgt im endoplasmatischen Retikulum. Es folgt eine posttranslationale Prozessierung im Golgiapparat. Dort wird die Disulfidbrücke zwischen zwei Cysteinen ausgebildet und die Asparaginreste werden glykosyliert. $\operatorname{PrP}^{\mathrm{C}}$ wird dann in sekretorischen Vesikeln an die Zelloberfläche transportiert, wo es mit Hilfe des GPI-Ankers an die Plasmamembran gebunden ist (Stahl et al., 1987). Besonders konzentriert befindet es sich in den so genannten Lipid-Raft-Domänen. Diese scheinen am Prion-ProteinMetabolismus beteiligt zu sein (Gorodinsky und Harris 1995; Harmey et al. 1995; Naslavsky et al. 1997; Taylor und Hooper 2006; Vey et al. 1996). Von dort aus wird $\operatorname{PrP}^{\mathrm{C}}$ vermutlich über Clathrin-vermittelte Endozytose oder Kaveolen internalisiert und lysosomal abgebaut bzw. zur Zelloberfläche zurück transportiert (Marella et al. 2002; Peters et al. 2003; Prado et al. 2004; Shyng et al. 1993; Sunyach et al. 2003). Kurz vor oder nach dem Transport an die Zelloberfläche unterliegt $\operatorname{PrP}^{\mathrm{C}}$ proteolytischen Spaltungen. Es wird vermutet, dass die dadurch inaktivierten Fragmente von $\operatorname{PrP}^{\mathrm{C}}$ eine Rolle bei der pro-apoptotischen Funktion von $\operatorname{PrP}^{\mathrm{C}}$ in 
neuronalen Zellen spielen (Paitel et al. 2002). Die physiologische Bedeutung dieses Prozesses ist jedoch noch ungeklärt.

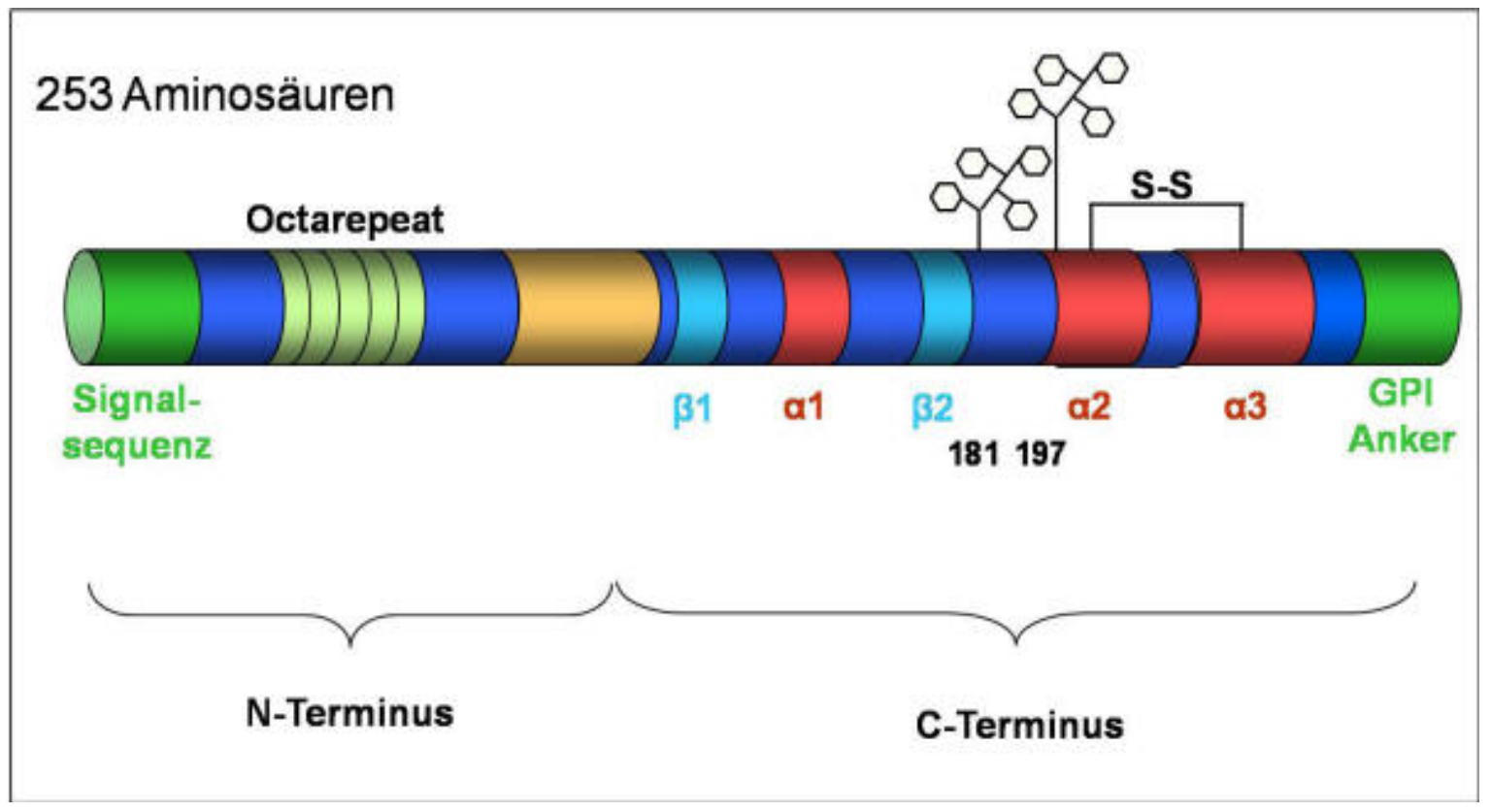

Abbildung 3: Die Struktur des Prion-Proteins (Becker 2005).

\subsubsection{Physiologische Funktion des $\operatorname{PrP}^{\mathrm{C}}$}

Seine physiologische Funktion ist bis heute nicht vollständig geklärt. $\operatorname{PrP}^{\mathrm{C}}$ ist ein kupferbindendes Glykoprotein, welches über den GPI-Anker an die Zelloberfläche gebunden wird. Dieser Anker wird hauptsächlich in Neuronen exprimiert (Brown et al. 1997a; McLennan et al. 2001; Sales et al. 1998), in geringeren Mengen auch in anderen Geweben wie dem Herzmuskel, dem lymphatischem Gewebe, der Haut und dem Plexus myenterikus im Gastrointestinaltrakt (Bendheim et al. 1992; Brown et al. 2000; Pammer et al. 1998; Shmakov et al. 2000). Durch die Kupferbindung an $\operatorname{PrP}^{C}$ wird eine Konformationsänderung der Oktarepeatregion induziert (Qin et al. 2000). Die genaue Funktion dieser Konformationsänderung ist noch nicht verstanden. Es wird vermutet, dass die Kupferbindung die Endozytose von $\operatorname{PrP}^{\mathrm{C}}$ stimuliert und somit als Transporter für Kupfer dient (Pauly und Harris 1998). Beweise, die diese These bestätigen, gibt es aber noch nicht. Weiterhin wird vermutet, dass die Kupferbindung letztlich als ein Signal für die antioxidative Schutzfunktion des $\operatorname{PrP}^{\mathrm{C}}$ dient (Vassallo und Herms 2003).

Viele Studien legen nahe, dass $\operatorname{PrP}^{\mathrm{C}}$ ein multifunktionales Protein ist, dass in verschiedene Prozesse involviert ist. Hierzu zählt neben der Kupferbindung die Regulation des Zelltodes, die Protektion gegenüber oxidativem Stress, Zelladhäsion, die Beteiligung an Signalwegen 
beim zellulären Überleben oder bei der Embryogenese (Bounhar et al. 2001; Cashman et al. 1990; Kuwahara et al. 1999; Manson et al. 1992; Mouillet-Richard et al. 2000; Ramljak et al. 2008; Reilly 2000; Zomosa-Signoret et al. 2008). Es wird diskutiert, welche Rolle die Nterminale Sequenz des Prion-Proteins spielt. Auf Grund der Ähnlichkeit zwischen der Bcl-2Domäne und dem offenem Leseraster (ORF) in der N-terminalen-Domäne von $\operatorname{PrP}^{\mathrm{C}}$ wird eine Funktion beim Zelltod vermutet. Die Bcl-2-Familie, zu welcher auch Bax gehört, wirkt proapoptotisch. Bax spielt eine wichtige Rolle in Neuronen des Zentralnervensystems (Yuan und Yankner 2000). Zudem konnte nachgewiesen werden, dass das zerebrale $\operatorname{PrP}^{\mathrm{C}}$ als Antwort nach einer (fokalen) zerebralen Ischämie hochreguliert wird. Ebenso zeigten sich deutlich größere Infarktvolumina bei Prion-Protein-Knockout-Mäusen (Prnp ${ }^{0 / 0}$ ) im Vergleich zu Wildtyp-Mäusen (McLennan et al. 2004; Mitteregger et al. 2007; Weise et al. 2006). Interessant ist auch ein möglicher Zusammenhang zwischen $\operatorname{PrP}^{\mathrm{C}}$ und der AlzheimerErkrankung. Die dabei involvierte $\beta$-Sekretase führt normalerweise zu einer Spaltung des Amyloid-Vorläufer-Proteins (amyloid precursor protein, APP) zu Amyloid $\beta\left(\mathrm{A} \beta\right.$ ). $\operatorname{PrP}^{\mathrm{C}}$ führt über die Hemmung der $\beta$-Sekretase zu einem Verminderung von APP. Anhand der Gehirne von Wildtyp-Mäusen im Vergleich zu Prion-Protein-Knockout-Mäusen konnte dies bestätigt werden. Es zeigten sich deutlich höhere Konzentrationen von $A \beta_{1-40}$ und $A \beta_{1-42}$ in den PrionProtein-Knockout-Zellen (Parkin et al. 2007).

\subsubsection{Die Rolle des $\operatorname{PrP}^{\mathrm{C}}$ bei der Neuroprotektion}

Im Gegensatz zu den toxischen Eigenschaften der pathologischen PrP-Konformation wird beim $\operatorname{PrP}^{\mathrm{C}}$ von einer protektiven Funktion ausgegangen. Erste Hinweise über die Schutzfunktion von $\mathrm{PrP}^{\mathrm{C}}$ bei oxidativem Stress wurden anhand von Experimenten mit primären Neuronen gezeigt (Kuwahara et al. 1999). Zudem konnte durch ischämische Insulte bei Mäusen und Ratten bereits die neuroprotektive Aktivität von $\operatorname{PrP}^{\mathrm{C}}$ demonstriert werden, indem es zu signifikant kleineren Infarktvolumina nach einem ischämischen Insult führte. (McLennan et al. 2004; Mitteregger et al. 2007; Shyu et al. 2005; Spudich et al. 2005; Weise et al. 2006). Diese Ergebnisse konnten in verschiedenen Zellstudien bestätigt werden, was die Vermutung, dass $\operatorname{PrP}^{\mathrm{C}}$ Signalkaskaden bei Stresssituationen protektiv beeinflusst, unterstützt (Westergard et al. 2007). So ist zum Beispiel bei Überexpression von $\operatorname{PrP}^{\mathrm{C}}$ ein Schutz der Zellen gegenüber verschiedenen apoptotischen Stimuli zu beobachten. Dazu gehört eine BaxÜberexpression (Bounhar et al. 2001; Roucou et al. 2005), oxidativer Stress (Brown et al. 1997b; Brown et al. 2002) und Serum-Entzug (Diarra-Mehrpour et al. 2004; Kuwahara et al. 1999). Eine neuroprotektive Funktion des $\operatorname{PrP}^{\mathrm{C}}$ wird auch auf Grund der Interaktion von $\operatorname{PrP}^{\mathrm{C}}$ 
mit dem Stress-induziertem Protein 1 (STI1) angenommen. Dadurch besteht ein Schutz vor der durch Anisomycin-induzierten Apoptose (Chiarini et al. 2002). Es wird postuliert, dass auf Grund der hohen Expressionsrate von STI1 und $\operatorname{PrP}^{\mathrm{C}}$ im Hippocampus, die Interaktion dieser beiden Proteine zur Neuroprotektion führt (Lopes et al. 2005). Eine weitere neuroprotektive Funktion des $\operatorname{PrP}^{\mathrm{C}}$ wird der N-terminalen Oktarepeatregion zusammen mit der Signalkasakade der Phophatidylinositol 3-Kinase (PI3K)/Akt zugeschrieben. In einer in vivo Studie wurde gezeigt, dass Mäuse, denen die Oktarepeatregion fehlte, nach einem ischämischen Insult ein dreifach größeres Infarktareal aufwiesen als Wildtyp-Mäuse (Mitteregger et al. 2007).

In weiteren Studien von Weise et. al wurden geringere Läsionen in Gehirnen bei $\operatorname{PrP}{ }^{\mathrm{C}}$ exprimierenden Mäusen nach vorangegangener zerebral induzierter Ischämie nachgewiesen (Abb. 4). In einem Experiment wurden nach induzierter transienter Ischämie und anschließender Reperfusion die Läsionsvolumina in den Gehirnen von Prnp ${ }^{0 / 0}$-Mäusen (keine $\mathrm{PrP}^{\mathrm{C}}$-Expression) und WT-Mäusen mittels TTC-Färbung detektiert. Es zeigten sich deutlich kleine Infarktvolumina in Anwesenheit von $\operatorname{PrP}^{\mathrm{C}}$ (Weise et al. 2006). Über welchen genauen Mechanismus $\operatorname{PrP}^{\mathrm{C}}$ protektiv unter Sauerstoffmangelbedingungen auf das Zellüberleben wirkt, bleibt weiterhin Bestandteil aktueller Studien. Es konnte nachgewiesen werden, dass $\operatorname{Pr} \mathrm{P}^{\mathrm{C}}$ Einfluss auf die Regulation von LDH hat (Ramljak et al. 2008). Welche Funktion Laktat im Energiestoffwechsel von Neuronen hat, wird im Verlauf dieser Arbeit noch diskutiert. 


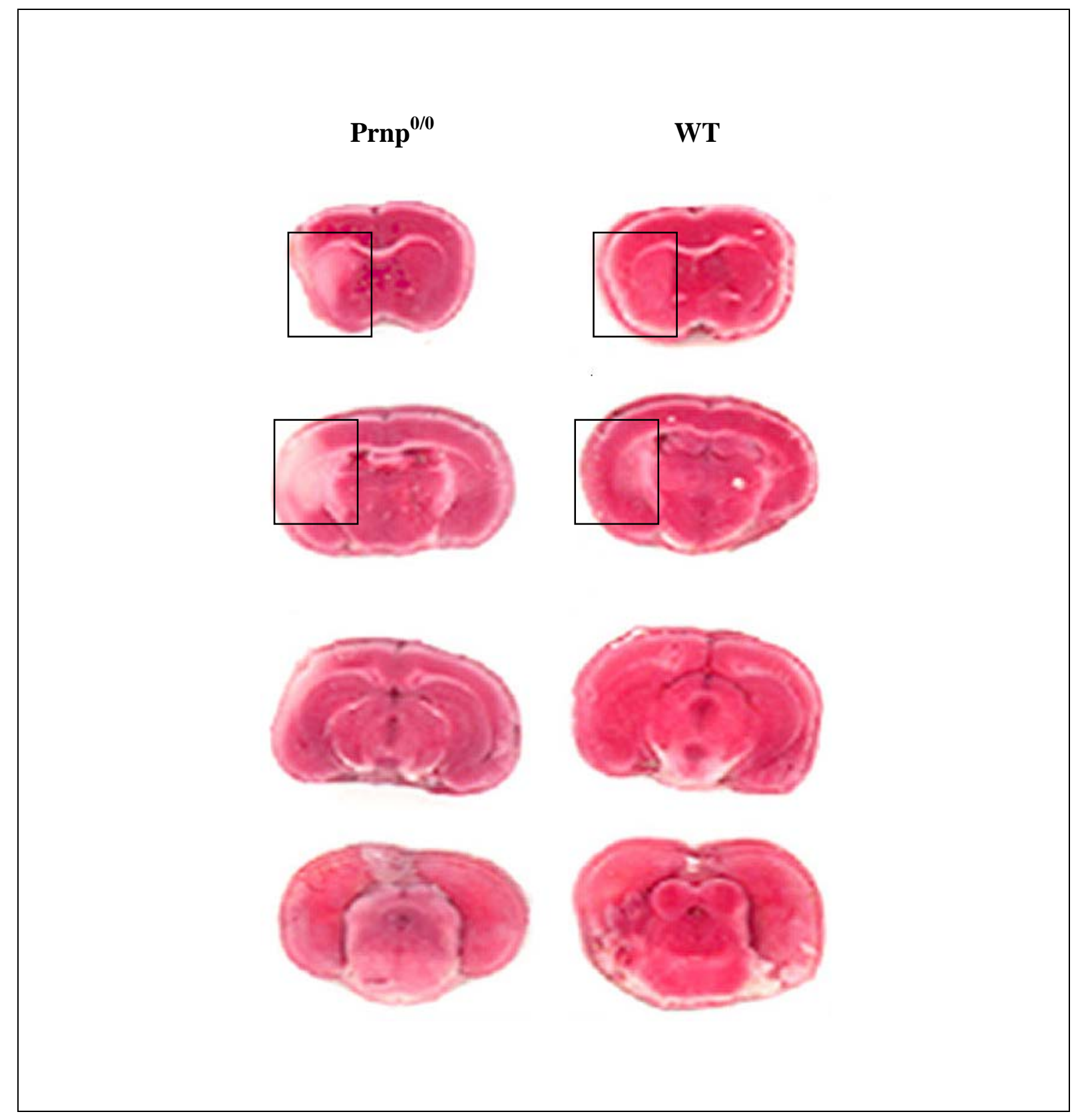

Abbildung 4: Verschiedene Schnitte durch die zerebrale Infarktregion von $\operatorname{PrP}^{0 / 0}$ - und WT-Mäusen nach Hypoxie, angefärbt durch 2,3,5-Triphenyl-Tetrasoliumchlorid (Weise et al. 2006, S. 3 )

Das Fehlen der 2,3,5-Triphenyl-Tertasoliumchlorid-Färbung in den linken Hemisphären der Prnp ${ }^{0 / 0}$ - und WT- Mäuse signalisiert die Infarktregionen. Diese sind in den Prnp ${ }^{0 / 0}$-Mäusen deutlich größer ausgeprägt als in den WT-Mäusen. 


\subsubsection{Potentielle Interaktionspartner}

Um die Funktion und mögliche Signalwege des $\operatorname{PrP}^{\mathrm{C}}$ weiter zu verstehen, ist es wichtig, die Interaktionspartner des Prion-Proteins zu identifizieren. Einige potentielle sind zum Beispiel Grb2, Pint1 und Synapsin 1b (Spielhaupter und Schatzl 2001), Tubulin (Nieznanski et al. 2005), der Kaliumkanal TREK-1 (Azzalin et al. 2006), das pro-apoptotische Protein NRAGE (Neutrophin-Rezeptor-Interaktion) (Bragason und Palsdottir 2005), Bcl-2 (Kurschner und Morgan 1995), das anti-apoptotische Protein STI-1 (Stress-Inducible-Protein 1) (Zanata et al. 2002), das Chaperon Hsp 60 (heat shock protein $60 \mathrm{kDa}$ ) (Edenhofer et al. 1996), Laminin (Graner et al. 2000a; Graner et al. 2000b), der Lamininrezeptor (Gauczynski et al. 2001), Caveolin-1 (Mouillet-Richard et al. 2000) und das Zelladhäsionsmolekül N-CAM (SchmittUlms et al. 2001). Die physiologische Relevanz einiger Interaktionspartner bleibt jedoch unklar, da viele von ihnen im Zytosol lokalisiert sind und sich das Prion-Protein hauptsächlich auf der Zelloberfläche befindet (Westergard et al. 2007). Die meisten Proteine, die in den programmierten Zelltod involviert sind, werden unter bestimmten Wachstumsfaktoren exprimiert. Diese apoptotischen Aktivitäten werden unter anderem durch die Bcl-2-Familie gesteuert (Borner 2003; Cory et al. 2003). Ein komplexes Netzwerk von Interaktionen zwischen Proteinen der Bcl-2-Familie interagiert mit Signalen von zellulärem Stress oder Normalzustand, so dass eine Entscheidung für oder gegen die Apoptose getroffen werden kann. Die Mitglieder der Bcl-2-Familie besitzen ein oder mehrere konservierte Regionen, sogenannte Bcl-2 homologe Domänen, über die sie sowohl pro- als auch antiapoptotisch wirken können (Chittenden et al. 1995; Muchmore et al. 1996; Yin et al. 1994). Dies hat zur Folge, dass bei Mutationen im Bcl-2-Gen Tumoren entstehen können. Beschrieben wurde dies bereits bei B-Zell-Lymphomen (Bakhshi et al. 1985; Cleary et al. 1985; Tsujimoto und Croce 1986). Bax, welches ein proapoptotisches Mitglied der Bcl-2-Familie ist, (Apte et al. 1995; Oltvai et al. 1993; Shi et al. 1999; Spampanato et al. 2012; Zhou et al. 1998), spielt eine große Rolle in Neuronen des zentralen Nervensystems. $\operatorname{PrP}^{\mathrm{C}}$ ist in der Lage, Neurone vor der von Bax induzierten Apoptose zu schützen (Bounhar et al. 2001; Van Delft und Huang 2006; Yuan und Yankner 2000). Da Bcl-2 als Interaktionspartner des $\operatorname{PrP}^{\mathrm{C}}$ identifiziert wurde, ist von einer Rolle des $\operatorname{PrP}^{\mathrm{C}}$ bei der Apoptose auszugehen (Kurschner und Morgan 1995; Westergard et al. 2007).

\subsubsection{Die Rolle von Calcium bei der Apoptose und die Interaktion mit PrP}

Calcium spielt eine wichtige Rolle bei der Apoptose. Anstiege der intrazellulären Calciumkonzentration konnten als Ursache für Ischämie-bedingte Apoptose identifiziert 
werden (Pisani et al. 2004), so dass die Vermeidung dieses Anstieges und die Freisetzung von Calcium eine wichtige Rolle bei der Ischämie spielt. Bei verminderter ATP-Abgabe durch die Glykolyse wird vermehrt Calcium intrazellulär freigesetzt und damit der zerstörenden Effekt der Ischämie forciert. Bereits in vitro konnte gezeigt werden, dass $\operatorname{PrP}^{\mathrm{C}}$ die Calciumfreisetzung aus dem endoplasmatischem Retikulum (ER) limitiert sowie die Aufnahme in die Mitochondrien reduziert (Brini et al. 2005). Es konnte demonstriert werden, dass die Hemmung der Glykolyse in kultivierten Astrozyten zu einer enormen Reduktion der ATP-Produktion führt, gefolgt von dramatischen Anstiegen der Calciumfreisetzung aus intrazellulären Speichern. Dies lässt vermuten, dass das glykolytisch gewonnene ATP wichtig für die intrazellulären Calciumspeicher ist (Kahlert und Reiser 2000).

\subsection{Oxidativer Stress, Hypoxie und Ischämie}

Sauerstoff wird benötigt, um auf zellulärer Ebene Energie zu gewinnen. Ist das Sauerstoffangebot kleiner als der Sauerstoffbedarf, so spricht man von Hypoxie. Sie führt zur Minderversorgung von Zellen und Geweben. Bei einer Minderversorgung durch Mangel an sauerstoffreichem Blut spricht man von einer Ischämie. Auch diese führt über den Mangel an Sauerstoff schließlich zur Apoptose oder Nekrosen von Zellen (Banasiak et al. 2000; Zipfel et al. 2000). Sauerstoff und seine reaktionsfähigen Radikale haben in aeroben biologischen Systemen die Eigenschaft, biologische Verbindungen oxidativ zu verändern und damit funktionell zu beeinträchtigen. Reaktive Sauerstoffspezies wie Wasserstoffperoxid $\left(\mathrm{H}_{2} \mathrm{O}_{2}\right)$ oder Superoxidradikale $\left(\mathrm{O}_{2}^{-}\right)$entstehen während normaler zellulärer Aktivität in der Atmungskette (Freeman und Crapo 1982) sowie bei der Zerstörung von Viren und Bakterien (Colton und Gilbert 1987). Damit die Konzentration der Radikale in einer Zelle nicht zu groß wird, besitzen Zellen Antioxidantien und antioxidative Enzyme (Superoxiddismutase, Glutathion-Peroxidase und Katalase). Diese fangen die freien Radikalen ab und machen sie unschädlich. Als oxidativen Stress bezeichnet man eine Störung im Gleichgewicht zwischen Oxidantien und Antioxidantien [Ascorbat (Vitamin C), $\alpha$-Tocopherol (Vitamin E) und $\beta$ Carotin]. Es kommt zu oxidativen Zellschäden, z.B. an der DNA. Dies kann zu Störungen der Transkription und Replikation sowie Mutationen führen. Auch die Funktion von Proteinen kann so beeinflusst werden (Butterfield und Kanski 2001). Bei Krebs und neurodegenerativen Erkrankungen (z. B. Alzheimer) kommen vermehrt oxidativer Stress und freie Radikale vor (Christen 2000; Markesbery 1999). 


\subsubsection{Apoptose}

Apoptose ist ein physiologischer Prozess, welcher eine entscheidende Rolle bei der Homöostase von Geweben, Immunsystem und Entwicklung spielt (Danial und Korsmeyer 2004; Fadeel und Orrenius 2005; Opferman und Korsmeyer 2003). Eine defekte Apoptoseregulation wird in Zusammenhang gebracht mit einer Vielzahl von Krebs- und neurodegenerativen Erkrankungen. Sie ist außerdem wichtig als physiologische Antwort auf Stress, Unfälle oder Infektionen. Es ist bekannt, dass Mitochondrien eine wichtige Rolle in der Regulation der Apoptose spielen, genauso wie das endoplasmatische Retikulum als Calciumspeicher (Annis et al. 2004; Breckenridge et al. 2003; Germain und Shore 2003; Orrenius et al. 2003). Die Rolle des $\operatorname{PrP}^{\mathrm{C}}$ bei der Apoptose ist noch nicht vollständig geklärt. Eine Übersicht der Funktionen und deren Einfluss auf die Apoptose ist in Tab. 2 dargestellt.

\begin{tabular}{|c|c|}
\hline Funktion & mögliche apoptotische Wirkung \\
\hline programmierter Zelltod (p53) & pro-apoptotisch \\
\hline Kupferbindung & unklar, eher anti-apoptotisch \\
\hline Bcl-2, Bax & sowohl pro- als auch anti-apoptotisch \\
\hline Antioxidans & anti-apoptotisch \\
\hline Mediator für Neuritenwachstum und & anti-apoptotisch \\
\hline synaptische Funktionen & unklar, eher anti-apoptotisch \\
\hline Immunzellaktivität & unklar \\
\hline Zelladhäsion & unklar \\
\hline Embryogenese & \\
\hline
\end{tabular}

Tabelle 2: Mögliche Funktionen von $\operatorname{PrP}^{\mathrm{C}}$ und deren Einfluss auf die Apoptose.

\subsection{Laktat-Dehydrogenase-Enzym}

Enzyme sind spezifische Biokatalysatoren, die einzelne Stoffwechselreaktionen beschleunigen, indem sie die notwendige Aktivierungsenergie absenken. Sie selbst gehen dabei unverändert aus der Reaktion hervor. Sämtliche physiologische Reaktionen sind davon 
abhängig, dass sie mit Hilfe von Enzymen schneller ablaufen, als dies spontan möglich wäre. Das Enzym Laktat-Dehydrogenase (LDH) spielt eine wesentliche Rolle im anaeroben Stoffwechsel. Es katalysiert folgende Reaktion:

$$
\text { Laktat }+\mathrm{NAD}^{+} \stackrel{\mathrm{LDH}}{\longleftrightarrow} \quad \text { Pyruvat }+\mathrm{NADH} / \mathrm{H}^{+}
$$

Laktat wird dabei zu Pyruvat oxidiert unter gleichzeitiger Reduktion von $\mathrm{NAD}^{+}$zu NADH/H $\mathrm{H}^{+}$ Auch die Rückreaktion wird von LDH katalysiert. Während einer Ischämie kommt es zum Wegfall von Metaboliten für die Versorgung. Dies führt über eine Kaskade von zellulären Ereignissen zur Apoptose- oder Nekrose-Mechanismen (Banasiak et al. 2000; Zipfel et al. 2000). Unter normalen physiologischen Bedingungen werden $\mathrm{NAD}^{+}$Moleküle im Zitratzyklus regeneriert. Unter Sauerstoffmangelbedingungen kann dieser Zyklus nicht ablaufen und $\mathrm{NAD}^{+}$wird von LDH reduziert (siehe oben) um Energie zu gewinnen. Daneben ist LDH ein unspezifischer Marker für Zellschäden und Nekrosen. Es ist erhöht bei einer Vielzahl von Infektionen, Lymphomen, Hämolysen und anderen Vorgängen (Boothpur und Brennan 2008). Physiologisch beträgt die Serumaktivität der LDH bis zu 240 U/l. Bei einem Anstieg darüber hinaus kann von einem Zerfall von Zellen ausgegangen werden, wodurch die LDH in den Blutstrom freigesetzt wurde. LDH kommt ubiquitär vor. Die höchste Affinitäten finden sich in der Niere, der Herz- und Skelettmuskulatur sowie in der Leber. Man unterteilt sie in fünf Isoenzyme (LDH 1-5), die sich jeweils aus vier Untereinheiten zusammensetzen (Cahn et al. 1962; Plagemann et al. 1960). Es wird dabei zwischen zwei Typen von Untereinheiten unterschieden: der H- und der M-Form. Es ergeben sich fünf Varianten, die in bestimmten Organen vorherrschen (Tab. 3). 


\begin{tabular}{|c|c|c|}
\hline Isoenzym & Untereinheit & (hauptsächliches) Vorkommen \\
\hline LDH-1 & $4 \mathrm{H}$ & Lymphsystem \\
\hline LDH-2 & $3 \mathrm{H} 1 \mathrm{M}$ & Lunge \\
\hline LDH-3 & $2 \mathrm{H} 2 \mathrm{M}$ & verschiedene Organe \\
\hline LDH-4 & $1 \mathrm{H} 3 \mathrm{M}$ & Leber, quergestreifte Muskulatur \\
\hline LDH-5 & $4 \mathrm{M}$ & \\
\hline
\end{tabular}

Tabelle 3: Varianten der LDH und deren Vorkommen.

\subsubsection{LDH-A- und LDH-B-Isoformen}

Über die Isoformen LDH-A und LDH-B wurde bereits in der Vergangenheit geforscht. Es konnte gezeigt werden, dass LDH-A vor allem in Geweben vorkommt, die viel Glykolyse betreiben. Dort führt das Enzym in Phasen von verminderter Sauerstoffkonzentration (anaeroben Bedingungen) zu der Bildung von Laktat aus Pyruvat. Im Gegensatz dazu, ist die Isoform LDH-B vor allem zur Bildung von Pyruvat aus Laktat fähig bei aeroben Bedingungen. Es konnte nachgewiesen werden, dass LDH-A von $\operatorname{PrP}^{\mathrm{C}}$ reguliert wird (Ramljak et al. 2008).

\subsubsection{LDH und das zelluläre Prion-Protein}

Verschiedene Studien haben in den letzten Jahren den Einfluss des $\operatorname{PrP}^{\mathrm{C}}$ auf die Regulation des physiologischen Energiestoffwechsels untersucht (Kleene et al. 2007; Pellerin und Magistretti 1994; Shyu et al. 2005a). Dabei konnte gezeigt werden, dass ein vermindertes Sauerstoffangebot $\mathrm{zu}$ einer Erhöhung der Expression von $\operatorname{PrP}^{\mathrm{C}}$ sowie der LaktatDehydrogenase führt (McLennan et al. 2004; Mitteregger et al. 2007; Weise et al. 2004). Unter hypoxischen/ischämischen Bedingungen benötigen Neurone Laktat, um ihren Energiemetabolismus aufrechtzuerhalten (Schurr et al. 1997) und um dadurch zu überleben. Daher kommt der Regulation des Energiestoffwechsels durch $\operatorname{PrP}^{\mathrm{C}}$ eine Schlüsselrolle zu. Allerdings sind die genauen physiologischen Mechanismen nicht bekannt. 


\subsubsection{Der Monocarboxylase-Transporter 1 (MCT1)}

Der MCT1 fungiert als Laktattransporter, indem er den bidirektionalen Laktatfluss in Astrozyten vermittelt. Er interagiert zudem mit Basigin (Wilson et al. 2005) und wird hauptsächlich von Astrozyten exprimiert (Kirk et al. 2000; Pellerin et al. 2005). Es konnte gezeigt werden, dass der MCT1 Glutamat-abhängig arbeitet und durch das Prion-Protein reguliert wird (Kleene et al. 2007). Glutamat wird von Neuronen als exzitatorischer Transmitter freigesetzt (Pellerin et al. 2005; Pellerin und Magistretti 1994). Dieser Laktattransport ist wichtig, um Neurone mit Laktat als Energiequelle zu versorgen, besonders während Phasen von hoher neuronaler Aktivität. Es schützt Neurone unter Hypoxie- oder Ischämie-Bedingungen (Chih et al. 2001; Dienel und Hertz 2001; Schurr et al. 1997). Die extrazellulären Laktatlevel steigen doppelt bis dreifach an ( >20 mM) unter Neuronenaktivität oder ischämischen Bedingungen, besonders unter Glutamatzugaben (Kleene et al. 2007).

\subsection{Ziele der Arbeit}

Dem zellulären Prion-Protein werden verschieden Funktionen zugeschrieben, die jedoch noch nicht vollständig verstanden sind. Hierzu gehören unter anderem die Beteiligung an der Regulation des Zelltodes, die Protektion gegenüber oxidativem Stress, Zelladhäsion oder bei Signalwegen. Daneben gibt es auch Studien, die dem $\operatorname{PrP}^{\mathrm{C}}$ eine apoptotische Funktion zuschreiben.

Ziel dieser Arbeit war es, einen möglichen molekularen Mechanismus der neuroprotektiven Funktion des zellulären Prion-Proteins zu erforschen. Aus der Literatur existieren bereits Hinweise darauf, dass $\operatorname{PrP}^{\mathrm{C}}$ eine Rolle beim Energiestoffwechsel der Zelle spielt.

Als erstes sollten verschiedene $\operatorname{PrP}^{\mathrm{C}}$-exprimierende Zellmodelle etabliert werden: In zwei verschiedenen Zelllinien, HEK-293- (mit endogener $\operatorname{PrP}^{\mathrm{C}}$-Expression) sowie Prnp ${ }^{0 / 0}$-Zellen ( $\operatorname{PrP}^{\mathrm{C}}$-Knockout) sollte eine $\operatorname{PrP}^{\mathrm{C}}$-Überexpression mittels transienter Transfektion induziert werden. Da Zelllinien im Allgemeinen anfällig für Artefakte sind, sollten zusätzlich primäre kortikale Neurone aus $\operatorname{PrP}^{\mathrm{C}}$-Knockout- und WT-Mäusen präpariert werden.

Die Neuroprotektion durch $\operatorname{PrP}^{\mathrm{C}}$ erfolgt insbesondere unter oxidativen Stressbedingungen wie bei der Hypoxie. Deshalb sollte zusätzlich ein Hypoxiemodell, bei dem verschiedene Arten neuronaler Zellen oxidativem Stress ausgesetzt werden, etabliert werden. Insbesondere galt es, die optimale Dauer der Stressinduktion sowie die anschließende Reoxygenierung an die jeweiligen Zelltypen zu adaptieren.

Das Enzym LDH nimmt eine Schlüsselrolle im Energiestoffwechsel von Zellen ein. Eine vorausgehende Proteomik-Studie lieferte bereits Hinweise für eine mögliche Regulation von 
LDH durch $\operatorname{PrP}^{\mathrm{C}}$. Dieser Hypothese sollte in dieser Arbeit nachgegangen werden, indem die LDH-Expression in den oben beschriebenen Zelltypen jeweils vor und nach Hypoxie in Abhängigkeit von $\operatorname{PrP}^{\mathrm{C}}$ untersucht werden sollte. 


\section{Material und Methoden}

Alle in dieser Arbeit durchgeführten Versuche wurden als Triplikate oder zumindest als Duplikate durchgeführt.

\subsection{Material und Geräte}

\begin{tabular}{|c|c|c|}
\hline Gerät & Modell & Hersteller \\
\hline Agarose Gel Kammer & Mini Sub II ${ }^{\mathrm{TM}}$ DNA & Bio-Rad (München, D) \\
\hline Autoklav & & Schütt \\
\hline $\begin{array}{l}\text { beheizbarer Magnet- } \\
\text { Rührer }\end{array}$ & MAG® RCT & IKA-Labortechnik (Staufen, D) \\
\hline Gelkammer & Mini Protean II ${ }^{\mathrm{TM}}$ & Bio-Rad (München, D) \\
\hline Heizapparat & Thermomixer Comfort & Eppendorf (Hamburg, D) \\
\hline Heizofen & $\begin{array}{l}\text { Hybridization } \\
\text { oven/shaker }\end{array}$ & $\begin{array}{l}\text { Amersham Life Science (Freiburg, } \\
\text { D) }\end{array}$ \\
\hline Horizontaler Schüttler & HS 501 digital & IKA-Labortechnik (Staufen, D) \\
\hline Hypoxie Kammer & Inkubator C42 & Labotect GmbH (Göttingen, D) \\
\hline Inkubator & Cellstar & Nunc (Wiesbaden, D) \\
\hline Kühlschrank $\left(4^{\circ} \mathrm{C}\right)$ & & Liebherr (Biberbach a. d. Riss, D) \\
\hline Laborwaage & Te1502S & Sartorius (Göttingen, D) \\
\hline Lichtmikroskop & $\mathrm{BH} 2$ & Olympus (Hamburg, D) \\
\hline Mikrowelle & ER-6320 PW & $\begin{array}{l}\text { Brother International (Bad Vilbel, } \\
\text { D) }\end{array}$ \\
\hline Photometer & Bio Photometer & Eppendorf (Hamburg, D) \\
\hline Scanner & ScanMarker 4 & $\begin{array}{l}\text { Microtek, International, Inc. } \\
\text { (Taiwan, China) }\end{array}$ \\
\hline
\end{tabular}




\begin{tabular}{|l|l|l|}
\hline Semi-Dry Transfer Cell & Trans-Blot SD & Bio-Rad (München, D) \\
\hline Stromanschluss & Power Pac 3000 & Bio-Rad (München, D) \\
\hline Tiefkühlschrank (-80C) & & Sanyo (München, D) \\
\hline Ultraschallwasserbad & Transsonic 310/H & Elma ${ }^{\circledR}$ (Pforzheim, D) \\
\hline Vortexer & REAX 200 & Heidolph (Schwabach, D) \\
\hline Wasserbad & Köttermann (Wangen, D) \\
\hline Western Blot-Maschine & HTI & BioLane ${ }^{\text {TM } \text { (Luckenwalde, D) }}$ \\
\hline Zellbank & 5415 D & $\begin{array}{l}\text { Kendro Laboratory Products } \\
\text { GmbH (Langenselbold, D) }\end{array}$ \\
\hline Zentrifuge & $510 \mathrm{R}$ & Eppendorf (Hamburg, D) \\
& & Eppendorf (Hamburg, D) \\
\hline
\end{tabular}

\subsubsection{Verbrauchs- und spezielles Material}

\begin{tabular}{|l|l|}
\hline Eppendorf Cups & Eppendorf (Hamburg, D) \\
\hline Falkon-Röhrchen & Sarstedt (Newton, USA) \\
\hline Knopfsonde & Rettberg (Göttingen, D) \\
\hline Petrischale & Falcon (Heidelberg, D) \\
\hline Pipetten & Eppendorf (Hamburg, D) \\
\hline Spritzen & Braun (Melsungen, D) \\
\hline Pinzetten & Rettberg (Göttingen, D) \\
\hline Röhrchen & Sarstedt (Newton, USA) \\
\hline Scheren & Rettberg (Göttingen, D) \\
\hline
\end{tabular}




\begin{tabular}{|l|l|}
\hline Skalpell & Rettberg (Göttingen, D) \\
\hline Tissue Culture 6-Well-Plates & Sarstedt (Nümbrecht, D) \\
\hline Tissue Culture Flask $\left(75 \mathrm{~cm}^{2}\right)$ & Sarstedt (Nümbrecht, D) \\
\hline Zell Schaber & Sarstedt (Nümbrecht, D) \\
\hline
\end{tabular}

\subsubsection{Chemikalien und Reagenzien}

\begin{tabular}{|l|l|}
\hline Acrylamid/Bisacrylamidlösung & Roth (Karlsruhe, D) \\
\hline APS & BioRad (München, D) \\
\hline Aqua Dest & Ampuwa (Bad Homburg, D) \\
\hline BSA & Sigma-Aldrich (München, D) \\
\hline EDTA & Fluka (Neu-Ulm, D) \\
\hline Glycin & Roth (Karlsruhe, D) \\
\hline Magermilchpulver & Roth (Karlsruhe, D) \\
\hline Methanol & Geyer (Renningen, D) \\
\hline Natriumhlorid & Roth (Karlsruhe, D) \\
\hline PBS & Biochrom (Berlin, D) \\
\hline PFA & Serva Elektrophoresis (Heidelberg, D) \\
\hline Probenpuffer & Roth (Karlsruhe, D) \\
\hline Proteinstandard & BioRad (München, D) \\
\hline TEti Load & \\
\hline & Roth (Karlsruhe, D) \\
\hline & \\
\hline & \\
\hline
\end{tabular}




\begin{tabular}{|l|l|}
\hline Tris/HCl & Roth (Karlsruhe, D) \\
\hline Triton X-100 & Fluka (Neu-Ulm, D) \\
\hline Tween & BioRad (München, D) \\
\hline
\end{tabular}

\subsection{Puffer und Lösungen}

\begin{tabular}{|c|c|}
\hline Bezeichnung & Zusammensetzung \\
\hline $\begin{array}{l}\text { Blockierungspuffer für } \text { Western } \\
\text { (Blotto) }\end{array}$ & $\begin{array}{l}\text { - } \quad \text { 5\% Milchpulver } \\
\text { - } \quad \text { PBS-Tween }\end{array}$ \\
\hline ECL-Lösung 1 & $\begin{array}{ll}\text { - } & 5 \mathrm{mM} \text { Luminol } \\
\text { - } & 0.4 \mathrm{mM} \text { p-Coumarsäure } \\
\text { - } & 0.1 \mathrm{M} \text { Tris-HCl } \mathrm{pH}=8,5\end{array}$ \\
\hline ECL-Lösung 2 & $\begin{array}{ll} & 18 \% \mathrm{H}_{2} \mathrm{O}_{2} \\
- & 0.1 \mathrm{M} \text { Tris pH 8,5 }\end{array}$ \\
\hline Elektrophoresepuffer (SDS-Laufpuffer) & $\begin{array}{ll}\text { - } & 25 \mathrm{mM} \text { Tris } \mathrm{pH}=8.3 \\
\text { - } & 192 \mathrm{mM} \text { Glycin } \\
\text { - } & 0.1 \% \text { SDS }\end{array}$ \\
\hline Lysepuffer I & $\begin{array}{ll}- & 0,5 \% \text { SDS } \\
- & 1 \mathrm{mM} \text { DTT } \\
\text { - } & 50 \mathrm{mM} \text { Tris-HCL pH } 8.0\end{array}$ \\
\hline Lysepuffer II & $\begin{array}{ll}- & 7 \mathrm{M} \text { Urea } \\
\text { - } & 2 \mathrm{M} \text { Thiourea } \\
\text { - } & 4 \% \text { CHAPS } \\
\text { - } & 2 \% \text { Ampholytes } \\
\text { - } & 1 \% \text { DTT }\end{array}$ \\
\hline OKANO & $\begin{array}{ll}\text { - } & 3 \mathrm{mM} \text { Tris } \mathrm{pH} 8,2 \mathrm{mM} \\
\text { - } & \mathrm{NaCl} \\
\text { - } & 0,05 \% \text { Triton X } 100\end{array}$ \\
\hline
\end{tabular}




\begin{tabular}{|c|c|}
\hline & $\begin{array}{ll} & 0,1 \mathrm{mM} \text { EDTA } \\
- & 0,002 \% \mathrm{SDS} \\
- & 0,1 \% \mathrm{BSA}\end{array}$ \\
\hline PBS & $\begin{array}{l}\text { - } 9.55 \text { g PBS-Pulver } \\
\text { - } \quad 11_{\mathrm{dd}} \mathrm{H}_{2} \mathrm{O}\end{array}$ \\
\hline PBS-Tween & $\begin{array}{ll}- & \text { PBS } \\
- & 0.1 \% \text { Tween-20 }\end{array}$ \\
\hline Transferpuffer für Western Blot & $\begin{array}{ll}\text { - } & 192 \mathrm{mM} \text { Glycin } \\
\text { - } & 20 \% \text { Methanol } \\
\text { - } & 25 \text { mM Tris- } \mathrm{HCl} \mathrm{pH}=8,3\end{array}$ \\
\hline Trypsin/EDTA Lösung & $\begin{array}{ll}- & 0,05 \% \text { Trypsin/0,02\%EDTA } \\
- & \text { PBS }\end{array}$ \\
\hline
\end{tabular}

\subsection{Zelllinien und Kulturmedien}

Alle Zellversuche wurden unter sterilen Bedingungen in der Zellkultur der Neuropathologie durchgeführt. Die Zellen wurden bei $37^{\circ} \mathrm{C}, 5 \% \mathrm{CO}_{2}$ und bei $95 \%$ Luftfeuchtigkeit inkubiert. Die Kultivierung fand in geeignetem Medium statt. In Abhängigkeit von der Zelldichte wurden die Zellen alle 3-4 Tage zwischen 1:5 und 1:10 verdünnt (ab einer Dichte von 70\%).

\subsubsection{Human-embryonic-kidney-293-Zellen (HEK-293-Zellen)}

HEK-293-Zellen wurden bezogen von Stratagene, La Jolla, USA. Die Kultivierung fand in folgendem Kulturmedium statt: Dulbecco's modified Eagle's medium (DMEM) (SigmaAldrich Chemie, Steinheim, Deutschland), 10\% fetal bovine serum (FBS) (Biochrom AG, Berlin, Deutschland) und 2\% Penicillin/Streptomycin (Biochrom AG, Berlin, Deutschland). Zum Splitten wurde zunächst das komplette Medium abgenommen und anschließend wurden die Zellen mit sterilem PBS (Biochrom, Berlin, Deutschland) gewaschen. Nach der Abnahme wurden $3 \mathrm{ml}$ einer erwärmten $\left(37^{\circ} \mathrm{C}\right)$ 0,05\% Trypsin/0,02\% EDTA-Lösung zum Lösen der Zellen vom Flaschenboden dazugegeben. Nach 2 min Inkubation bei $37{ }^{\circ} \mathrm{C}$ wurde die Trypsinaktivität durch Zugabe von $7 \mathrm{ml}$ frischen erwärmten Medium (im Wasserbad bei 37 ${ }^{\circ} \mathrm{C}$ für $15 \mathrm{~min}$ ) gestoppt. Anschließend wurde das komplette Zelllysat in ein $15 \mathrm{ml}$ Falkontube überführt und für 5 min bei $1,000 \times \mathrm{G}$ bei $20{ }^{\circ} \mathrm{C}$ zentrifugiert. Der Überstand wurde 
verworfen und die Zellen in $5 \mathrm{ml}$ frischem erwärmten Kulturmedium resuspendiert. Die gewünschte Zellmenge wurde in eine neue Kulturflasche gegeben und mit $13 \mathrm{ml}$ frischem Medium versorgt. Nach 2 Tagen wurde ein Mediumwechsel durchgeführt. Dazu wurde das alte Medium abpipettiert und $13 \mathrm{ml}$ neues, erwärmtes Medium vorsichtig auf die Zellen gegeben.

\subsubsection{Präparation und Pflege der primären kortikalen Zellen von Prnp ${ }^{\text {0/0}}$-Knock-Out- Mäusen und Wildtyp-Mäusen}

Alle Experimente wurden nach den Richtlinien des Gesundheitsamtes für den Schutz und den Gebrauch von Labortieren durchgeführt und genehmigt durch lokale Behörden. WT- und Prnp $^{0 / 0}$ - Mäuse wurden von dem 129/Sv und C57BL/6 genetische Hintergrund abgeleitet.

Die Präparation der Zellen fand wie folgt statt: Trächtige WT- und Prnp ${ }^{0 / 0}$ - Mäuse wurden am 14. Tag mittels 2-bromo-2-chloro-1,1,1-trifluoroethan (Sigma Aldrichm Taufkirchen, Deutschland) betäubt und durch Genickbruch getötet. Im Anschluss wurden die Gehirne von den 14 Tage alten Embryonen entfernt und von den Meningen befreit. Das Gehirn-Gewebe wurde durch mechanische und mehrfache 10-minütige Behandlung durch Trypsin/EDTA (Biochrom, Berlin, Deutschland) bei $37^{\circ} \mathrm{C}$ aufgetrennt. Die Neurone wurden zentrifugiert bei 13,000 x G bei $4{ }^{\circ} \mathrm{C}$ und auf poly-D-Lysin (10 $\left.\mu \mathrm{M}\right)$-behandelten Kultur-Wells bei einer Dichte von $1 \times 10^{6}$ Zellen pro Well $\left(9,6 \mathrm{~cm}^{2}\right)$ ausgesät. Zunächst wuchsen die Zellen in DMEM mit 10\% FBS, 20 mM KCl, N-2 (1:100, Gibco/Invitrogen, Karlsruhe, Deutschland), B-27 (1:50, Gibco/Invitrogen) und $0.1 \%$ PS. Vier Tage nach der Präparation wurde das Kulturmedium durch frisches ersetzt. Diese bestand aus 60 \% DMEM, 30\% Coon's F 12 modified Medium (Biochrom AG, Berlin, Deutschland) 10\% FBS und 1\% PS. Das Splitten der Zellen erfolgte analog zu den HEK-293-Zellen.

\subsubsection{Auftauen der Zellen}

Die Zellen wurden für 5 min in einem $37{ }^{\circ} \mathrm{C}$ warmen Wasserbad aufgetaut und direkt im Anschluss zentrifugiert bei 4,000 x G für 5 min. Der Überstand inklusive Dimethylsulfoxid (DMSO) wurde abgenommen und verworfen. Das Zellpellet wurde mit frischem erwärmtem Medium resuspendiert und anschließend in Kulturflaschen gegeben.

\subsubsection{Bestimmung der Zellzahl}

Die Anzahl der Zellzahl wurde mit einer Zählkammer von Neubauer bestimmt. Zunächst wurden die Zellen 1:100 verdünnt. $100 \mu$ l Zellsuspension wurden dafür mit $900 \mu \mathrm{l}$ PBS 
gemischt. In einem zweiten Schritt wurden $100 \mu \mathrm{l}$ dieser Mischung mit $450 \mu \mathrm{l}$ PBS und 450 $\mu l$ Trypanblau gemischt. Die Neubauer-Zählkammer wurde nun mit der 1:100-TrypanblauZellsuspension gefüllt und unter dem Lichtmikroskop konnten die ungefärbten (lebenden) Zellen gezählt werden. Nach dem Auszählen der Zellen in allen vier Quadranten konnte die Zellzahl pro Milliliter berechnet werden. Dazu wurde zunächst der Mittelwert ( $Q_{\text {gesamt }}$ ) bestimmt, indem man die Gesamtzahl der Zellen der vier Quadranten $\left(\mathrm{Q}_{1-4}\right)$ durch vier teilte. Mit der nachfolgenden Formel konnte die Zellzahl der Zellsuspension berechnet werden:

Qgesamt $x$ Verdünnung (hier: $10^{2}$ ) x $10^{4}=$ Zellen $/ \mathrm{ml}$

$\left(10^{4}=\right.$ konstanter Faktor, der sich aus der Größe der Zellkammer ergibt)

\subsubsection{Kryokultur der Zellen}

Zur Langzeitlagerung wurden die Zellen bei $-80{ }^{\circ} \mathrm{C}$ eingefroren. Damit die Zellen dabei nicht zerstört wurden, wurde Dimethylsulfoxid (DMSO) verwendet. Die einzufrierenden Zellen wurden zentrifugiert und mit $1 \mathrm{ml}$ frischem, $37{ }^{\circ} \mathrm{C}$ warmen Medium vermischt. Es wurden 10\% FBS dazu gegeben, so dass eine 20\% Konzentration von FBS erreicht wurde (10\% sind im Medium enthalten). Anschließend wurde 10\% DMSO hinzugegeben. Die Suspension wurde mit Trockeneis heruntergekühlt und im Anschluss bei $-80{ }^{\circ} \mathrm{C}$ gelagert.

\subsubsection{Herstellung von Zelllysaten}

Zelllysate wurden wie folgt gewonnen. Zunächst wurde das Medium von den 6-Well-Platten entfernt und der Zellrasen zweimal vorsichtig mit erwärmten PBS gewaschen. Anschließend wurden die Zellen lysiert in 0,5\% SDS, 50 mM Tris-HCL pH 8.0 und 1 mM DTT (Lysepuffer I) und in Eppendorfgefäße pipettiert. Um die Denaturierung der Proteine zu verhindern, wurde ein Proteasehemmer (Roche, Deutschland) hinzugefügt. Die Proteinkonzentration wurde anschließend nach Bradford bestimmt.

\subsection{Transfektion der Zelllinien mit pCMS-PRNP-EGFP-Vektor}

Zunächst wurden die Zellen in 6-Well-Platten ausgesät, mit einer Zelldichte von einer Million pro Well. Nach 1 d (Prnp ${ }^{0 / 0}$-Zellen) bzw. 3-4 d (HEK-293-Zellen) wurden die Zellen mit dem pCMS-PRNP-EGFP-Vektor transfiziert. Zur Kontrolle wurde ein leerer Vektor ohne Prnp verwendet. $8 \mu \mathrm{l}$ der DNA bzw. des Kontroll-Vektors wurden mit $250 \mu$ l OPTI-MEM (GIBCO, 
Auckland, Neuseeland) in ein Eppendorfgefäß pipettiert. Parallel dazu wurden $8 \mu \mathrm{l}\left(\mathrm{Prnp}^{0 / 0}\right.$ Zellen) bzw. $4 \mu \mathrm{l}$ (HEK-293-Zellen) Lipofectamine mit $250 \mu$ l OPTI-MEM gemischt und für 5 min bei RT unter der Zellbank inkubiert. Dann wurde beides vorsichtig gemischt und für 20 min bei RT inkubiert. Während des Inkubierens wurde das Medium von den 6-Well-Platten abgenommen und mit je 2 ml PBS gespült. Im Anschluss wurden 2 ml Transfektionsmedium (98\% OPTI-MEM, 2\% FBS) ins Well pipettiert und die Zellen zurück in den Brutschrank gestellt. Nach dem Inkubieren konnten $500 \mu$ DNA auf jedes Well vorsichtig pipettiert werden. Die Zellen wurden anschließend zurück in den Brutschrank gegeben. Nach 6-8 Stunden wurde das Transfektionsmedium abgenommen und normales, vorgewärmtes Medium draufgegeben (1 ml pro Well). Nach 24 Stunden konnte unter UV-Licht die Transfektionsrate auf Grund des EGFP beurteilt werden. Die Zellen wurden nach der gewünschten Zeit mit PBS vom Wellboden mit Zellschabern abgelöst, sedimentiert (1000 x G) und eingefroren bei $-4{ }^{\circ} \mathrm{C}$ oder gleich zu Analysen verwand.

\subsection{Hypoxie}

Die Zellen wurden ab einer Zelldichte von $10^{6}$ pro Well für unterschiedliche Zeiten (30, 60 und $90 \mathrm{~min}$ ) in die Hypoxiekammer gestellt. Dort lagen folgende Bedingungen vor: $37{ }^{\circ} \mathrm{C}$, 5\% $\mathrm{CO}_{2}$, 95\% Luftfeuchtigkeit, $1 \% \mathrm{O}_{2}$. Im Anschluss fand eine Reoxygenierungsphase unter Standardbedingungen statt $\left(37^{\circ} \mathrm{C}, 5 \% \mathrm{CO}_{2}, 95 \%\right.$ Luftfeuchtigkeit). Es folgte die Präparation wie unter 2.3 beschrieben.

\subsection{Bakterienstämme und Kulturmedium}

Es wurde mit einem DH5 $\alpha$ Escherichia coli Stamm gearbeitet (Stratagene, La Jolla, USA).

\subsubsection{Transformation von Plasmiden in E. coli-Bakterien}

Ziel der Transformation war es, Plasmide mit Hilfe von E. coli-Bakterien zu vermehren. Dabei nahmen die Bakterien die Plasmide mittels Hitzschock und Elektroschock auf. $50 \mu \mathrm{l}$ der DH10B kompetenten E. coli-Bakterien wurden mit 0,5 $\mu \mathrm{g}$ Vektor (PCMS-PRNP-EGFP) vermischt. Elektrische Küvetten wurden für 5 min auf Eis gelegt. Die Zellen und die DNA (Vektor) wurden in die gekühlten Küvetten gegeben und für weitere 2 min auf Eis inkubiert. Es folgte ein elektrischer Schock, der zur Aufnahme der DNA in die Bakterien führte. $1 \mathrm{ml}$ vorgewärmtes LB Medium (1\% Trypton, 0,5\% Hefe Extrakt, $171 \mathrm{mM} \mathrm{NaCl)}$ wurde für 45 min bei $37^{\circ} \mathrm{C}$ im Wasserbad inkubiert und dabei geschüttelt. $10 \mu \mathrm{l}$ der Kultur wurden in den $1 \mathrm{ml}$ vorgewärmten LB Medium gelöst. $50 \mu$ l dieser Lösung wurden zum Wachsen auf LB- 
Ampicillin-Agar-Platten (LB-Medium mit 1,5\% Agar und Ampicillin $100 \mu \mathrm{g} / \mathrm{ml}$ ) (Sigma, Seelze, Deutschland) als Selektionsantibiotika ausgesät und für 16 Stunden bei $37{ }^{\circ} \mathrm{C}$ inkubiert. Nur Bakterien, die den Vektor mit der Ampicillinresistenz enthielten, überlebten. Nach 12 bis 16 Stunden waren transformierte Bakterien auf dem Nährboden zu sehen. Mit einer sterilen Öse konnte die gewünschte Anzahl von Bakterienkolonien in $100 \mathrm{ml}$ Ampicillin-haltiges LB-Medium (100 $\mu \mathrm{g} / \mathrm{ml})$ überführt werden. Die Bakterien wuchsen über Nacht bei $37^{\circ} \mathrm{C}$ zu einer Dichte von $\mathrm{OD}_{600}=0,5-0,8$ an und standen wegen des Ampicillins unter Selektionsdruck. Die Plasmide konnten mit Hilfe eines Plasmid Isolation Kit (Qiagen) aus den Bakterien isoliert bzw. die transformierten E.coli-Bakterien zur Langzeitlagerung eingefroren werden. Dazu wurden $850 \mu$ l der Bakterienkultur mit $150 \mu$ l Glycerin in ein geeignetes Gefäß pipettiert und bei $-80{ }^{\circ} \mathrm{C}$ eingefroren.

\subsubsection{Plasmide}

Die verwendeten Plasmide dieser Arbeit sind in der Tabelle 4 aufgelistet, eine schematische Darstellung des pCMS-PRNP-EGFP-Genoms ist in Abb. 5 zu sehen.

\begin{tabular}{|l|l|l|}
\hline Name & relevante Eigenschaften & Herkunft \\
\hline pCMS-EGFP & Expressions Vektor; CMV IE & $\begin{array}{l}\text { BD Biosciences, Palo Alto, } \\
\text { USA }\end{array}$ \\
\hline pCMS-PRNP-EGFP & $\begin{array}{l}\text { Promotor; SV 40 Promotor; } \\
\text { Amp }^{r}\end{array}$ & $\begin{array}{l}\text { Klinik für Neurologie, } \\
\text { Universitätsmedizin } \\
\text { Göttingen, D }\end{array}$ \\
\hline
\end{tabular}

Tabelle 4: Plasmide 


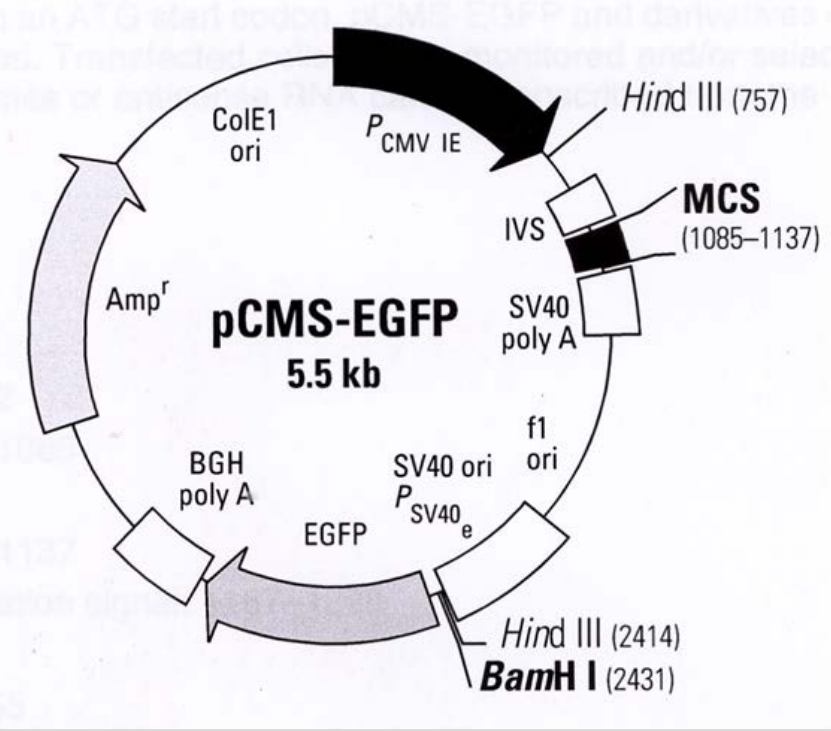

Abbildung 5: Schematische Darstellung des pCMS-EGFP-Plasmids (Ramljak 2007, S. 34)

\subsubsection{Plasmid-DNA-Extraktion (Minipräparation)}

Für die Minipräparation wurde das High Pure Plasmid Isolation Kit (Roche Applied Science (Mannheim, Deutschland) verwendet. Zunächst wurde $50 \mathrm{ml}$ LB-Medium (+ $100 \mu \mathrm{g} / \mathrm{ml}$ Ampicillin) bei $37^{\circ} \mathrm{C}$ im Wasserbad erwärmt und 50-100 $\mu$ l der transformierten Bakterien (nach kurzem Antauen aus dem $-80{ }^{\circ} \mathrm{C}-$ Kühlschrank) in das Medium gegeben. Die Bakterien wuchsen über Nacht (16 Stunden) bei $37^{\circ} \mathrm{C}$. Von dieser Zellsuspension wurden $20 \mathrm{ml}$ für 510 min bei 6000 x G zentrifugiert. Der Überstand wurde verworfen und die Zellen mit einer optischen Dichte zwischen 1,5 und 5,0 ( $\mathrm{A}_{600}$ units pro Milliliter) nach folgendem Schema behandelt. Zunächst wurden die Zellen in $250 \mu \mathrm{l}$ RNase Puffer (P1) resuspendiert. Durch Zugabe von P2 Lyse-Puffer startete die Lysereaktion für 5 min. Die Lysereaktion wurde durch Hinzufügen von $350 \mu \mathrm{l}$ des vorher auf Eis gelegten P3 Binding-Puffers neutralisiert und die Suspension für 5 min auf Eis inkubiert. Die DNA, Proteine und Zelldepritus präzipitierten in weißen Flocken aus. Es wurde 10 min bei 13,000 x G in einer Tischzentrifuge zentrifugiert und der Überstand mit der Plasmid-DNA in ein Filter Tube überführt und erneut für 1 min bei max. Geschwindigkeit zentrifugiert. Durch Zugabe von $700 \mu \mathrm{l}$ P4 Wasch-Puffer und zweimaligem zentrifugieren (je 1 min bei maximaler Geschwindigkeit) wurde die DNA gereinigt. Sie befand sich nun in dem Filter. Der Filter wurde in ein neues steriles 1,5 ml 
Eppendorfgefäß gegeben und durch $100 \mu \mathrm{l}$ P5 Elutions-Puffer, erneutes maximales Zentrifugieren für 1 min wurde die DNA aus dem Filter gewaschen und befand sich nun in dem Eppendorfgefäß. Der Plasmid konnte bei $-4{ }^{\circ} \mathrm{C}$ eingefroren oder direkt für weitere Versuche verwendet werden.

\subsubsection{Plasmid-DNA-Extraktion (Midipräparation)}

Für die Midipräparation wurde das Plasmid Midi- und Maxi- Kit (Qiagen, Hilden, Deutschland) verwendet. Im Vergleich zu der Minipräparation ließen sich hierbei größere Mengen an DNA extrahieren. Nachdem die Bakterien über Nacht gewachsen waren, wurde wie in der Anleitung beschrieben vorgegangen. Die Bakterien wurden bei $4{ }^{\circ} \mathrm{C}$ für 15 min bei 6000 x G zentrifugiert. Das Pellet wurde anschließend in 4 ml Puffer 1 resuspendiert, mit 4 ml Puffer 2 gemischt und für 5 min bei RT inkubiert. Die Bakterien waren nun lysiert. Für die Präzipitation wurde auf Eis gekühlter Puffer 3 dazugegeben und für 15 min auf Eis inkubiert. Im Anschluss wurde alles bei 20000 x G für 30 min bei $4{ }^{\circ} \mathrm{C}$ zentrifugiert, so dass der Überstand die DNA enthielt und diese dann erneut bei 20000 x $\mathrm{G}$ für 15 min bei $4{ }^{\circ} \mathrm{C}$ zentrifugiert wurde. Der DNA-haltige Überstand wurde nun durch Qiagen-tip 100 Filter filtriert. Um die DNA zu lösen, wurden $5 \mathrm{ml}$ Puffer QF filtriert und die DNA anschließend mit 3,5 ml Isopropanol gelöst und sofort zentrifugiert bei $4{ }^{\circ} \mathrm{C}$ für $15 \mathrm{~min}$ bei $15000 \mathrm{x}$ G. Der Überstand wurde vorsichtig verworfen und das Pellet mit $2 \mathrm{ml} \mathrm{70 \%} \mathrm{Ethanol} \mathrm{gewaschen} \mathrm{und}$ bei 15000 x G für 10 min zentrifugiert. Der Überstand wurde verworfen und das Pellet für 510 min an der Luft getrocknet. Anschließend konnte die DNA eingefroren oder sofort verwendet werden.

\subsubsection{Plasmidnachweis}

Der Plasmidnachweis erfolgte durch die DNA-Agarose-Gelelektrophorese. Dazu wurden 0,8 g Agarose mit $40 \mathrm{ml}$ TAE-Puffer durch Erhitzen in der Mikrowelle zu 2\%igem Agarosegel hergestellt. Nach Abkühlung auf RT wurden 1,4 $\mu \mathrm{l}$ Ethidiumbromid in die Agarose gegeben, alles in eine Agarose-Gelkammer gegossen und die Kämme für die Gelkammern eingesetzt. Nachdem das Gel auspolymerisiert war, wurden $20 \mu \mathrm{l}$ der Probe in die Gelkammern pipettiert (18 $\mu$ l DNA $+2 \mu$ l Loading-Buffer). Die Gele liefen in TAE-Puffer bei $80 \mathrm{~V}$ für $30 \mathrm{~min}$. Die DNA-Banden wurden durch UV-Licht von $302 \mathrm{~nm}$ in Gel Documentation $2000^{T M} \mathrm{UV}$ Transiluminator (Bio-Rad, München, Deutschland) sichtbar gemacht. Durch einen mitlaufenden DNA-Standard wurden die DNA-Fragmente identifiziert. Die Konzentration wurde mit einem Fotometer (Bio Fotometer, Eppendorf, Hamburg, Deutschland) bestimmt. 


\subsection{Bestimmung der Proteinkonzentration nach Bradford}

Die Proteinkonzentration der Zelllysate wurde mit der Methode nach Bradford (1976) bestimmt. Das Verfahren beruht auf einer Verschiebung des Absorptionsmaximums des Farbstoffes Coomassie Brilliant Blue G-250 bei Bindung an Protein von $\lambda=465 \mathrm{~nm} \mathrm{zu} \lambda=$ $595 \mathrm{~nm}$ in saurer Lösung, die fotometrisch gemessen werden kann. Die Reaktionslösung wurde hergestellt, indem das Protein-Assay-Reagenz (Bio-Rad Laboratories, München, Deutschland) mit ${ }_{\mathrm{dd}} \mathrm{H}_{2} \mathrm{O}$ im Verhältnis 1:4 verdünnt und anschließend filtriert wurde. Als Proteinstandard wurde Rinderserumalbumin (BSA) (Roth, Karlsruhe, Deutschland) verwendet und eine Verdünnungsreihe mit ${ }_{d d} \mathrm{H}_{2} \mathrm{O}$ und Proteinkonzentrationen von 50-1000 $\mu \mathrm{g} / \mu \mathrm{l}$ hergestellt. Die Zelllysate wurden 1:20 verdünnt und $20 \mu \mathrm{l}$ davon mit $980 \mu \mathrm{l}$ der Bradfordreagens gemischt. Nach einer Inkubationszeit von 5 min wurde die Absorption bei 595 nm mit dem Fotometer (Bio Fotometer, Eppendorf, Hamburg, Deutschland) gemessen. Die Berechnung der Proteinkonzentrationen wurde mit Microsoft Office 2007 Excel Software durchgeführt.

\subsection{Deglykosylierung}

Zur Entfernung der Zuckerseitenketten wurde ein Deglycosylation Kit (Calbiochem, Darmstadt, Deutschland) benutzt. Dabei wurde das Enzym N-Glykosidase F verwendet. Das Zelllysat mit $20 \mu \mathrm{g}$ Gesamtprotein wurde in $30 \mu \mathrm{l}$ deionisiertem Wasser gelöst. $10 \mu \mathrm{l}$ XX Reaktionspuffer (250 mM Sodium Phosphat Puffer, $\mathrm{pH}$ 7) und 2,5 $\mu$ l Denaturation Solution (2\% SDS, 1 M $\beta$-Mercaptoethanol) wurden hinzugefügt und vorsichtig gemischt. Alles wurde für 5 min bei $100{ }^{\circ} \mathrm{C}$ erhitzt. Nach Abkühlung auf RT wurden 2,5 $\mu$ l TRITON ${ }^{\circledR}$ X-100 dazugegeben. Nun wurde $1 \mu \mathrm{l}$ N-Glykosidase F hinzugefügt und die Probe für 3 Stunden bei $37^{\circ} \mathrm{C}$ inkubiert. Es konnte dann die gewünschte Analyse durchgeführt werden.

\subsection{Western Blot}

Der gebräuchliche Begriff Western Blot geht auf den Namen des Erfinders der Blottingtechnik namens Southern zurück. In Anlehnung an seinen Namen wurde der Transfer von RNA-Fragmenten als Northern-, der Transfer von DNA-Fragmenten als Southern- und der Proteintransfer als Western-Blotting bezeichnet. Demnach bezeichnet der Begriff Western Blot das Proteinblotting mit anschließender Immundetektion. 


\subsubsection{Sodiumdodecylsulfat-Polyacrylamid-Gelelektrophorese (SDS-PAGE)}

Bei der SDS-PAGE werden die Proteine in einem elektrischen Feld in einem 2-Phasen und quervernetzten 12\%igen Polyacrylamidgel (0.375 mM Tris-HCL pH 8.8, 12\% Acrylamid, 0.1\% APS, 0.04\% TEMED) nach ihrem Molekulargewicht aufgetrennt. Die Eigenladung der Proteine wurde durch das SDS überdeckt, sodass die Proteine nicht nach ihrer Ladung und nur nach dem molekular Gewicht aufgetrennt wurden. Die Quervernetzung kam durch die Zugabe von APS und TEMED zustande. Die für den Western Blot verwendete Apparatur bestand aus zwei durch Spacer getrennte Glasplatten, die in eine Gelapparatur eingespannt wurden. Beim Gießen eines Gels musste das APS immer frisch angesetzt werden bzw. durfte nicht älter als eine Woche sein. APS und TEMED wurden beim Gießen eines Gels immer als letztes dazugegeben. Der Abstand der beiden Glasplatten betrug 1,5 mm. In den Zwischenraum wurde zunächst das Trenngel auf ca. 3/4 der Gellänge gegossen, mit Wasser überschichtet und für 20 min auspolymerisiert. Danach wurde das Sammelgel darüber gegeben, die Kämme für die Probentaschen eingesetzt und ebenfalls 20 min auspolymerisiert. Im Anschluss wurde das SDS-Gel in eine mit Laufpuffer gefüllte Mini-Twin-Gelelektrophoresekammer von Biometra eingesetzt und der Kamm vorsichtig entfernt. Nun wurden die Geltaschen mit Laufpuffer gespült, um überflüssige Gelreste zu entfernen und mit den zu untersuchenden Proben beladen. Die Proteinproben wurden vorab mit dem Puffer Roti ${ }^{\circledR L o a d ~(R o t h, ~ K a r l s r u h e, ~ D e u t s c h l a n d) ~}$ gemischt und denaturiert. Damit sich die Sekundär - und Tertiärstrukturen der Proteine lösten, wurden die Proben für 2 min bei $95{ }^{\circ} \mathrm{C}$ im Thermomixer erhitzt und nach 5 min Abkühlen in die Geltaschen pipettiert. Für die Western Blot-Analyse wurden von den jeweiligen Zelllysaten $20 \mu \mathrm{g}$ Gesamtprotein pro Geltasche aufgetragen. Um den Proben das Einwandern in das Sammelgel zu erleichtern, wurde zunächst eine Stromspannung von 80-100 Volt angelegt. Mit einer Spannung von 120 Volt lief die Elektrophorese für ca. zwei Stunden, bis das Bromphenolblau des Roti ${ }^{\circledR L} L o a d$ den Boden des Gels erreicht hatte. Es folgte der eigentliche Western Blot, bei dem die Proteine auf Polyvinyliden-Difluorid-Membranen (PVDF-Membranen) (AppliChem, Darmstadt, Deutschland) übertragen wurden. Dazu wurde die Membran in Ethanol für eine Minute eingelegt, gefolgt von einer Minute in Wasser und schließlich in dem Transferpuffer äquilibriert. Der Blot lief dann für 70 min bei konstanten 12 Volt. Anschließend wurde die Membran bei RT für eine Stunde im Blockierungspuffer (5\% Trockenmilch in PBS) geblockt und dann über Nacht mit dem ersten Antikörper gelöst in Blockierungspuffer bei $4{ }^{\circ} \mathrm{C}$ inkubiert. Danach wurde die Membran mit Waschlösung (PBSTween 0,01\%) für $5 \mathrm{~min}$, mit Blockierungspuffer für $10 \mathrm{~min}$ und erneut mit PBS-Tween zweimal für 10 min gewaschen, bevor die Inkubation mit dem zweiten Antikörper für eine 
Stunde bei RT in Blockierungspuffer auf dem horizontalen Schüttler erfolgte. Die zweiten Antikörper sind mit dem Enzym Meerrettichperoxidase (Horseradish Peroxidase, (HRP)) konjugiert, so dass nach einminütiger Inkubation der Membran in ECL-Entwicklungslösung auf ECL-Hyperfilm (Amersham Bioscience, Buckinhamshire, UK) eine Lichtreaktion nachgewiesen werden konnte. Die Filme wurden eingescannt und anschließend densitometrisch analysiert mittels Scion Image (Microtek, International, Inc.) und PD QUEST V 7.11 Software (Bio-Rad) oder Lab Imiging Software (Kapelan Bio-Imaging GmbH, Leipzig, Deutschland). Jede Analyse wurde mit drei Western Blots durchgeführt von drei verschiedenen Proteinextraktionen.

\subsubsection{Antikörper}

Die folgenden Antikörper wurden in der angegebenen Verdünnung für die Western BlotAnalysen verwendet (Tab. 5 und 6).

\begin{tabular}{|c|c|c|c|}
\hline Primäre Antikörper & Spezifikation & Verdünnung & Firma \\
\hline $\begin{array}{l}\text { anti-PrP }{ }^{\mathrm{C}} \text {-Antikörper } \\
12 \mathrm{~F} 10\end{array}$ & $\begin{array}{l}\text { Maus, } \\
\text { monoklonal }\end{array}$ & $1: 300$ & SPI-Bio, Massy, Frankreich \\
\hline $\begin{array}{l}\text { anti-PrP }{ }^{C} \text {-Antikörper } \\
\text { SAF } 32\end{array}$ & $\begin{array}{l}\text { Maus, } \\
\text { monoklonal }\end{array}$ & $1: 500$ & SPI-Bio, Massy, Frankreich \\
\hline anti- $\beta$-Actin-Antikörper & $\begin{array}{l}\text { Maus, } \\
\text { monoklonal }\end{array}$ & $1: 5000$ & Abcam, Cambridge, UK \\
\hline $\begin{array}{l}\text { anti-Laktat- } \\
\text { Dehydrogenase- } \\
\text { Antikörper }\end{array}$ & $\begin{array}{l}\text { Ziege, } \\
\text { polyklonal }\end{array}$ & $1: 500$ & Abcam, Cambridge, UK \\
\hline
\end{tabular}

Tabelle 5: Auflistung der primären Antikörper 


\begin{tabular}{|l|l|l|l|}
\hline Sekundäre Antikörper & Spezifikation & Verdünnung & Firma \\
\hline anti-Maus-IgG-Antikörper & Affe & $1: 5000$ & $\begin{array}{l}\text { Santa Cruz Biotechnology, } \\
\text { Santa Cruz, USA }\end{array}$ \\
\hline anti-Ziege-IgG-Antikörper & Affe & $1: 5000$ & $\begin{array}{l}\text { Santa Cruz Biotechnology, } \\
\text { Santa Cruz, USA }\end{array}$ \\
\hline
\end{tabular}

Tabelle 6: Auflistung der sekundären Antikörper

\subsection{LDH-Aktivitätsbestimmung}

Hypoxie oder toxische Substanzen schädigen Zellen unspezifisch und bewirken einen Verlust der Integrität der Zellmembran. Dies führt zur Freisetzung des Enzyms LDH. Um die Aktivität der $\mathrm{LDH}$ zu bestimmen, wurde mittels Absorption die NADH/H ${ }^{+} \mathrm{Zu}$ - bzw. Abnahme bestimmt. Dies wurde mit Hilfe des Lactate-Dehydrogenase-Assay-Kit (BioVision, Kalifornien, USA) gemacht. Durch Gabe eines Substratmixes zu einer Zellprobe konnte durch die Zunahme der $\mathrm{NADH} / \mathrm{H}^{+}$-Konzentration die $\mathrm{LDH}$-Aktivität errechnet werden. Das $\mathrm{NADH} / \mathrm{H}^{+}$bildet dabei einen Farbstoff, der fotometrisch im Anschluss bestimmt werden konnte. Es wurde wie in der Anleitung beschrieben verfahren: Zunächst wurden die Zellen $\left(10^{6}\right)$ im Assay-Puffer auf Eis homogenisiert. Anschließend bei 1000 x G und $4{ }^{\circ} \mathrm{C}$ für 15 min zentrifugiert, der Überstand abgenommen und auf Eis gestellt. In einer 96-Well-Platte wurden gleiche Mengen der Zelllysate pipetiert und zu einem Endvolumen von $50 \mu$ l mit AssayPuffer aufgefüllt. Um die Reaktion zu starten, wurde $50 \mu$ l eines Reaktionsmixes (2 $\mu$ l Substratmix und $48 \mu$ l Assay-Puffer) hinzugefügt und im Anschluss die optische Dichte bei $450 \mathrm{~nm}$ gemessen. Nach einer Inkubationszeit von $30 \mathrm{~min}$ bei $37^{\circ} \mathrm{C}$ wurde ein zweites Mal gemessen. Im Anschluss konnte die Zunahme der $\mathrm{NADH} / \mathrm{H}^{+}$-Konzentration berechnet und so auf die LDH-Aktivität geschlossen werden. Proportional dazu ist dann die LDH-Menge in dem jeweiligen Zelllysat. Um später die Werte der Zellproben zu analysieren, wurde eine $\mathrm{NADH} / \mathrm{H}^{+}$-Kurve generiert. Dazu wurden verschiedene Mengen $(0,2,4,6,8,10 \mu \mathrm{l})$ des 1.25 mM NADH Standard wie zuvor die Zellproben behandelt.

\subsection{Immunozytochemische Anfärbung}

Um den neuronalen Schaden der Zellen nach Hypoxie visuell vergleichen zu können, wurde der monoklonale neuronale Antikörper der Klasse $3 \beta$-Tubulin eingesetzt (Covance, Princeton, 
New Jersey). Als Kontrolle dienten Zellen, die nicht der Hypoxie ausgesetzt wurden. Zunächst wurden die Zellen fixiert in PBS mit 4 \% Paraformaldehyd für 20 min, dreimal in PBS gewaschen und permeabilisiert durch Inkubation für 10 min in PBS mit 2 \% BSA. Im Anschluss wurden die Zellen mit dem monoklonalen neuronalen Antikörper der Klasse $3 \beta$ Tubulin (1:500), PBS und 1 \% BSA für 2 Stunden inkubiert bei RT. Alle Arbeitsschritte wurden dabei im Dunkeln durchgeführt. Die Inkubation wurde durch dreimaliges Waschen in PBS gestoppt. Die Zellen wurden in Mowiol 4-88 (Roth, Karlsruhe, Deutschland) auf dem Objektträger gelagert, bevor die Färbung durch das Olympus BX51 Mikroskop (Olympus, Hamburg, Deutschland) bei 400-facher Vergrößerung beurteilt werden konnte. Die Bilder wurden gespeichert mittels F-Software (Olympus).

\subsection{Fluoreszenzmikroskopie}

Zur optischen Darstellung der Transfektion besitzt der PCMS-Prnp-EGFP-Vektor eine sogenannte EGFP-Region. Das EGFP steht dabei für das sogenannte Grün-FluoreszierendeProtein (GFP). Dieses GFP fluoresziert bei Anregung mit ultraviolettem Licht. Somit kann unter dem geeigneten Mikroskop die Transfektion beurteilt werden.

\subsubsection{Anfärbung der DNA mit 4',6-Diamidin-2-Phenylindol (DAPI)}

Der Fluoreszenzfarbstoff DAPI dient zur Anfärbung von nuklearer DNA und RNA in Zellen. Die anzufärbenden Zellen wurden auf runden Deckplättchen angezüchtet und bei ausreichender Dichte in 24-Well-Platten 5 min mit $500 \mu$ l PBS gewaschen. Zur Fixierung der Zellen folgte eine 20 minütige Inkubation in $4 \%$ Paraformaldehyd. Nach dreimaligem waschen mit PBS für jeweils 5 min wurden die Zellkerne mit PBS + 0,2 $\mu \mathrm{g} / \mathrm{ml}$ DAPI für 10 min angefärbt. Danach wurden die fixierten Zellen dreimal gewaschen. Die Darstellung des Fluoreszenzfarbstoffes DAPI konnte im Anschluss unter dem Fluoreszenzmikroskop bei ultraviolettem Licht (100-380 nm) dargestellt werden.

\subsubsection{Immunfluoreszenz}

Nachdem die Zellen wie unter 2.12.1. beschrieben behandelt wurden, folgte im Anschluss die Bindung des mit Fluoreszenzfarbstoff markierten Anti-PrP ${ }^{\mathrm{C}}$-Antikörper 12F10. Dazu wurde die Zellmembran mit Hilfe einer zehnminütigen Inkubation mit PBS + 0,2 \% Triton zunächst permeabel gemacht. Es folgte die Waschung mit $500 \mu \mathrm{l}$ PBS für $5 \mathrm{~min}$. Vor der Antikörperinkubation wurde eine Blocklösung (PBS + 2 \% BSA + $10 \%$ FBS) für eine Stunde auf die Zellen gegeben. Der Antikörper blieb dann über Nacht bei $4^{\circ} \mathrm{C}$ in spezifischer 
Verdünnung mit PBS + 2 \% BSA auf den Zellen. Im Anschluss wurde die Blocklösung entfernt und die Zellen vorsichtig gewaschen mit PBS. Nach Trocknung konnte die Beurteilung der Färbung unter dem Fluoreszenzmikroskop dargestellt werden.

\subsection{Immunpräzipitation}

Ziel der Immunpräzipitation ist der Nachweis von Interaktionspartnern. Dazu wurden Zelllysate gewonnen. Durch Zentrifugieren bei 5400 x G für 15 min bei $4{ }^{\circ} \mathrm{C}$ wurde der ZellDetritus entfernt. Für die Immunpräzipitation wurden Dynabeads® Protein G (Invitrogen, Carlsbad, Kalifornien, USA ) nach den Herstelleranweisungen verwendet. $4 \mu \mathrm{l}$ des monoklonalen LDH-A- oder SAF32-Antikörper (Verdünnung 1:50) und $315 \mu$ g des Proteins wurden unter Rotation für 1 Stunde bei $4{ }^{\circ} \mathrm{C}$ inkubiert. Anschließend wurden $50 \mu \mathrm{l}$ von 50\% verdünnten Dynabeads ${ }^{\circledR}$ auf jede Zellprobe gegeben und über Nacht bei $4{ }^{\circ} \mathrm{C}$ rotierend inkubiert. Drei Waschungen mit PBS folgten, bevor das Zielantigen ausgewaschen werden konnte. Die immunpräzipitierten Proteine wurden mittels SDS-PAGE und Western Blot im Anschluss analysiert. 


\section{Ergebnisse}

\subsection{Ermittlung der Transfektionseffizienz}

Zur Darstellung der Zellen wurden diese immunozytochemisch angefärbt. Die nukleare DNA wurde mittels 4',6-Diamidin-2-Phenylindol (DAPI) angefärbt (Abb. 6 A). Durch das Anfärben mit dem Prion-Protein-Antikörper $12 \mathrm{~F} 10$ wurde das $\operatorname{PrP}^{\mathrm{C}}$ in den Zellen detektiert. Die DNA wie auch die Expression des $\operatorname{PrP}^{\mathrm{C}}$ wurden unter dem Fluoreszenzmikroskop bei ultraviolettem Licht detektiert (Abb. 6 A, 6 B). Für die transiente Transfektion wurde das pCMS-PRNP-EGFP-Plasmid verwendet. Transient bedeutet, dass das Plasmid bei einer Zellteilung nicht repliziert wird. Die Hochregulation von $\operatorname{PrP}^{\mathrm{C}}$ ist daher nur kurzzeitig. Der pCMS-PRNP-EGFP-Vektor besitzt eine EGFP-Region. Diese führte zur Expression des grünfluoreszierenden Proteins (GFP), das bei Anregung mit ultraviolettem Licht grün fluoreszierte (Abb. 6 C). Durch den Vergleich der grün-fluoreszierenden Zellen mit den nichtfluoreszierenden Zellen konnten die Transfektionseffizienz ermittelt werden (Abb. 6 C). Diese lag bei ca. 60-70\%.

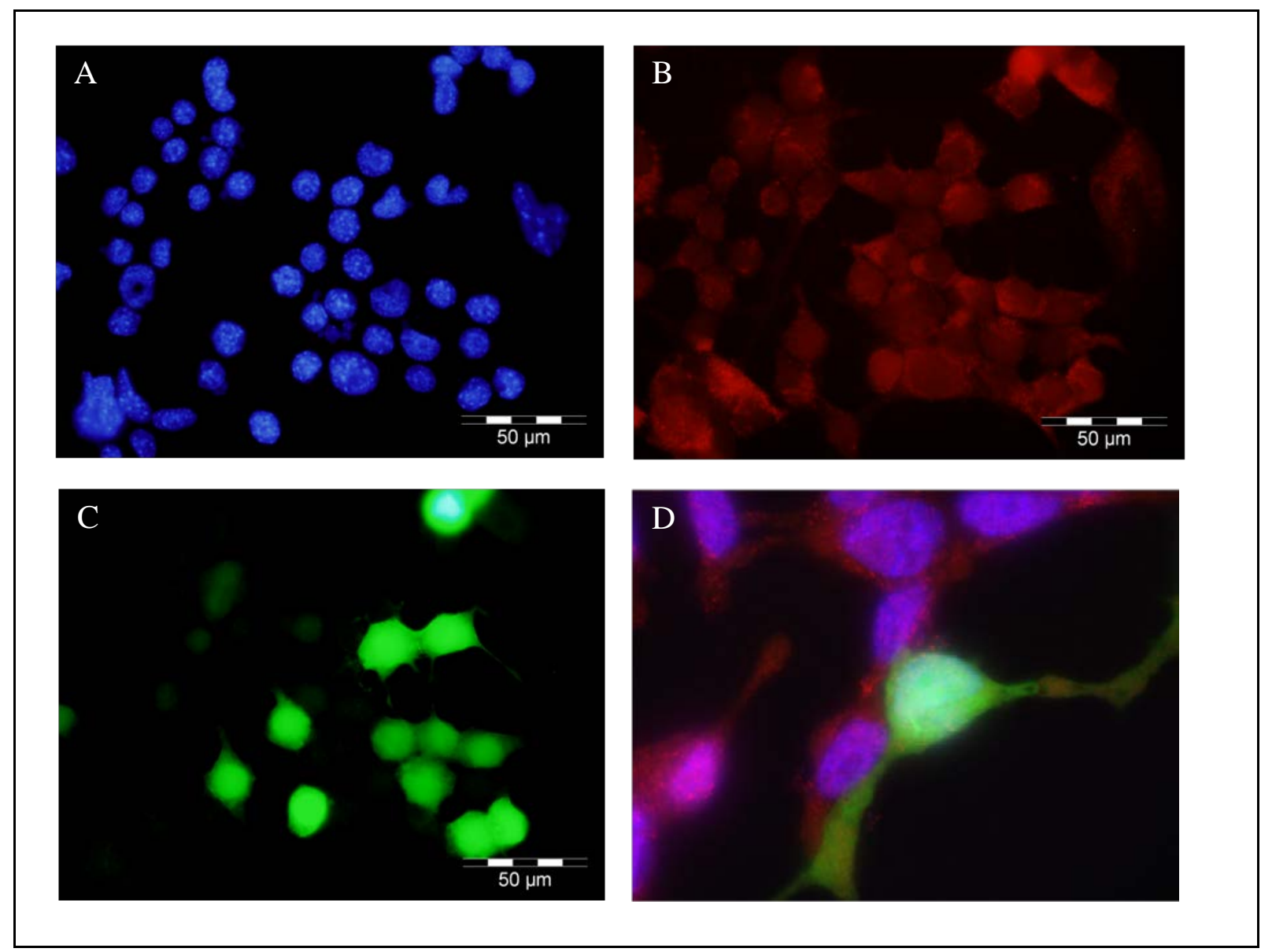




\section{Abbildung 6: Bestimmung der Transfektionseffizienz und immunozytochemische Anfärbung von PrP ${ }^{C}$ in HEK-293-Zellen}

(A) Die Detektion der blau-fluoreszierenden DNA in den Zellkernen erfolgte mittels DAPI. (B) $\operatorname{PrP}^{\mathrm{C}}$ mit Anti-PrP-Antikörper 12F10. Das $\operatorname{PrP}^{\mathrm{C}}$ wurde mit Hilfe des Zweitantikörper Alexa Fluor 546 angefärbt und ist an seiner rötlichen granulatartigen Färbung zu erkennen. (C) Darstellung des GFP nach Transfektion. Die transfizierten HEK-293-Zellen fluoreszieren grün. (D) DNA-, Prion-Protein- und GFP-Darstellung in 1000facher Vergrößerung übereinander gelagert.

\subsection{Deglykosylierung des $\operatorname{PrP}^{\mathrm{C}}$ bei HEK-293-Zellen durch N-Glykosidase $\mathbf{F}$}

Um zu zeigen, dass die in den nachfolgenden Versuchen verwendeten HEK-293-Zellen das zelluläre Prion-Protein exprimieren, erfolgte zunächst eine Inkubation mit N-Glykosidase F, die eine Deglykosylierung von $\operatorname{PrP}^{\mathrm{C}}$ zur Folge hatte. Diese diente dazu die spezifische Detektion von $\mathrm{PrP}^{\mathrm{C}}$ nachzuweisen, welches unter physiologischen Bedingungen in einer di-, einer mono- und in einer unglykosylierten Form vorliegt. Dabei weisen die verschiedenen Glykosylierungsformen unterschiedliche Molekulargewichte auf: die diglykosylierte Form besitzt ein Molekulargewicht von 36 kDa, die monoglykosylierte Form von 33 kDa und die unglykosylierte Form von 27 kDa (Abb. 7). Alle drei Isoformen konnten im HEK-293Zelllysat mittels Western Blot nachgewiesen werden (Abb. 7). Bei der Deglykosylierung wurden die gebundenen Zuckerketten enzymatisch durch N-Glykosidase F entfernt. Anhand der Abnahme des molekularen Gewichts konnte die Spezifität der $\operatorname{PrP}^{\mathrm{C}}$-Detektion gezeigt werden. Als Kontrolle wurde rekombinantes $\mathrm{PrP}^{\mathrm{C}}$ in unglykosylierter Form aufgetragen, das ein molekulares Gewicht von $26 \mathrm{kDa}$ aufweist. Zur Darstellung des $\operatorname{PrP}^{\mathrm{C}}$ wurde der monoklonale anti-PrP ${ }^{\mathrm{C}}$-Antikörper 12F10 (Verdünnung 1:300) verwendet. 


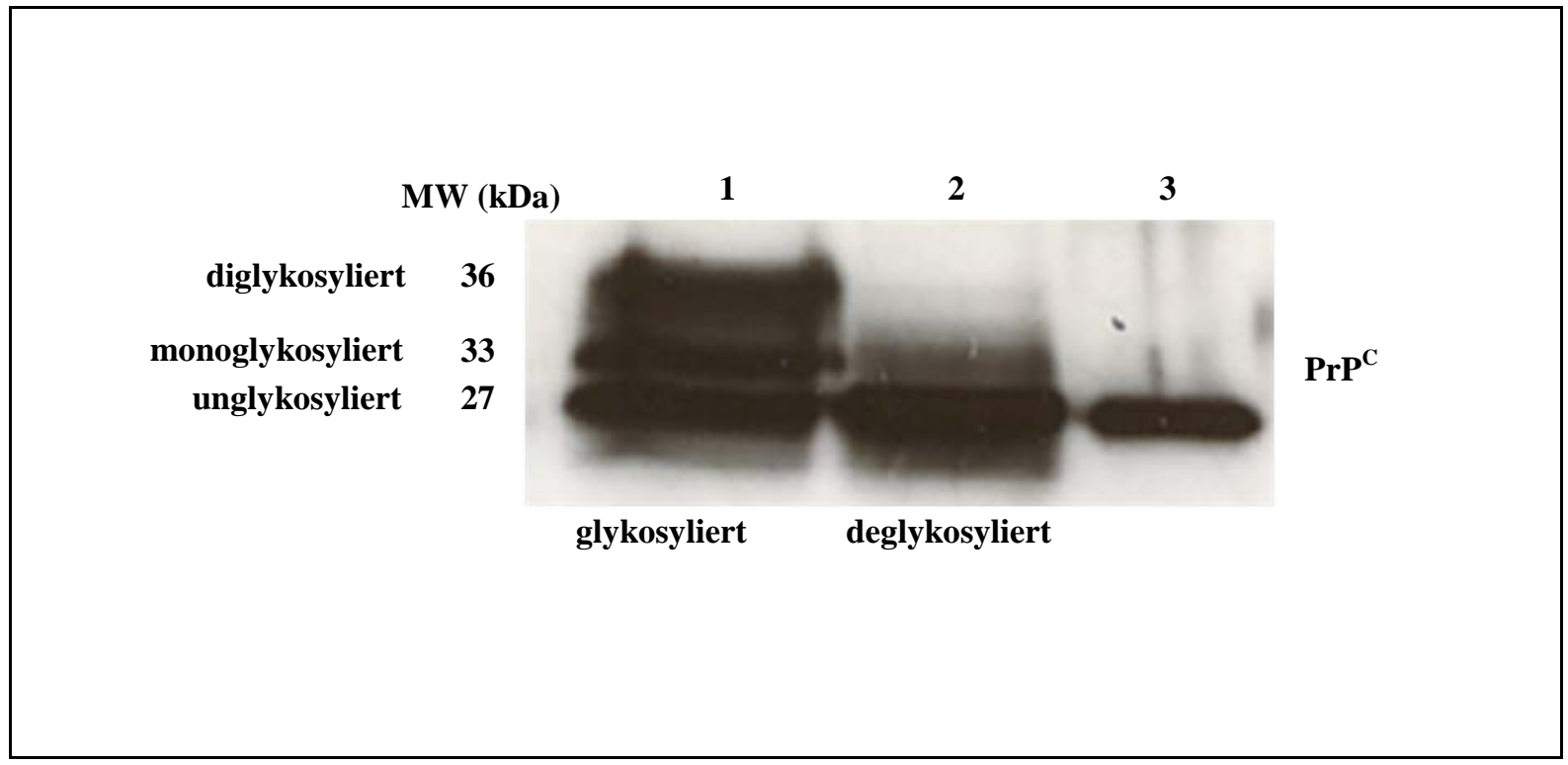

Abbildung 7: Expressionsmuster des $\operatorname{PrP}^{\mathrm{C}}$ in HEK-293-Zellen vor und nach Deglykosylierung

Spur 1 zeigt das glykosylierte $\operatorname{PrP}^{\mathrm{C}}$ in den drei Glykosylierungsformen. Spur 2 stellt das deglykosylierte $\mathrm{PrP}^{\mathrm{C}}$ mit nur einer Bande bei $27 \mathrm{kDa}$ nach erfolgter Deglykosylierung dar. Zum Vergleich ist in der dritten Spur eine Kontrolle bestehend aus unglykosyliertem, rekombinantem $\operatorname{PrP}^{\mathrm{C}}$ bei $26 \mathrm{kDa}$ zu sehen.

\section{3 Überexpression von $\operatorname{PrP}^{\mathrm{C}}$ durch transiente Transfektion}

Zur Etablierung eines $\mathrm{PrP}^{\mathrm{C}}$-überexprimierenden Zellmodells wurden HEK-293-Zellen und Prnp $^{0 / 0}$-Zellen mit dem pCMS-PRNP-EGFP-Plasmid transient transfiziert. Durch die Transfektion wurde eine Überexpression des $\operatorname{PrP}^{\mathrm{C}}$ induziert. Kontrollzellen wurden mit einem Leervektor, der kein PRNP enthielt, transfiziert. Durch die Kontrollzellen sollte ein möglicher Einfluss der Transfektion auf die Zellen ausgeschlossen werden.

\subsubsection{Transfektion von HEK-293-Zellen mit dem pCMS-PRNP-EGFP-Plasmid führt zu einer signifikanten Erhöhung der $\operatorname{PrP}^{\mathrm{C}}$-Expression}

HEK-293-Zellen wurden mit dem pCMS-PRNP-EGFP-Vektor transient transfiziert, um eine Überexpression des $\operatorname{PrP}^{\mathrm{C}}$ zu erreichen. Nachfolgend 24 und 48 Stunden wurde die $\operatorname{PrP}^{\mathrm{C}}$ Menge mittels Western Blot semiquantitativ im Vergleich zu den Kontrollzellen gemessen. Die densitometrische Quantifizierung der Banden im Western Blot erfolgte mit dem Programm Scion Image. In Abbildung 8 erkennt man zu beiden Zeitpunkten eine signifikante Hochregulation von $\mathrm{PrP}^{\mathrm{C}}$ in $\mathrm{PRNP}^{+/+}$-Zellen, verglichen mit den Kontrollzellen, die lediglich 
endogenes $\operatorname{PrP}^{\mathrm{C}}$ exprimierten (WT-PrP $\mathrm{P}^{\mathrm{C}}$ ) (Abb. 8 A, 8 B). Vergleicht man die beiden Zeitpunkte, war die $\mathrm{PrP}^{\mathrm{C}}$-Expression 48 Stunden nach Transfektionsende am höchsten (Abb. 8 B). Auf diesem Befund basierend wurden die nachfolgenden Transfektionsexperimente ausschließlich 48 Stunden nach der Transfektion durchgeführt. Die Proteinmengen wurden mittels Bradford angeglichen (20 $\mu \mathrm{g}$ Gesamtprotein pro Probe). Für die Darstellung von $\operatorname{PrP}^{\mathrm{C}}$ wurde der monoklonale anti-PrP ${ }^{\mathrm{C}}$-Antikörper 12F10 (Verdünnung 1:300) verwendet. Die $\beta$ Actin-Ladekontrolle zeigt gleiche Proteinmengen an.

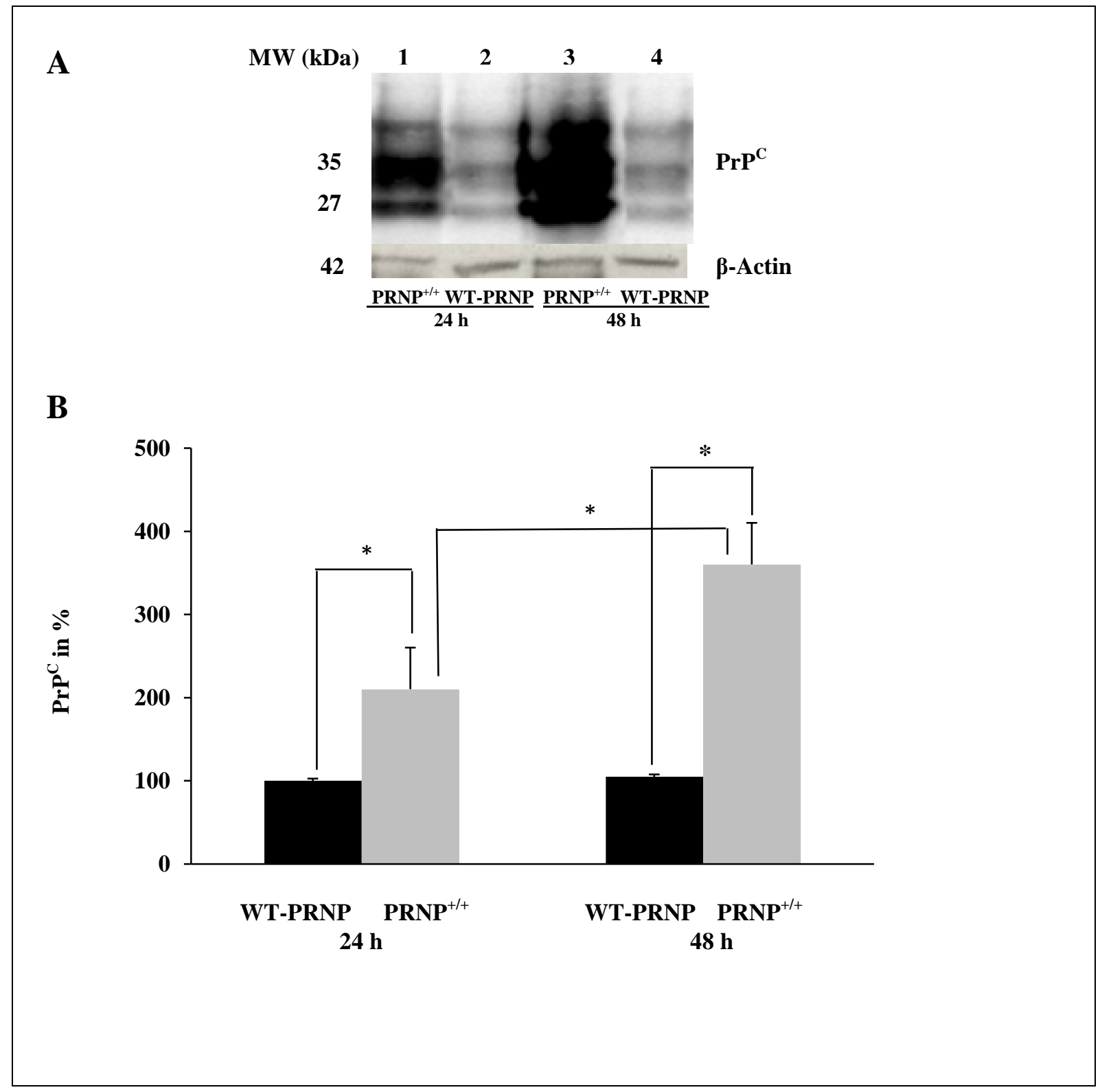




\section{Abbildung 8: Hochregulation der $\operatorname{PrP}^{\mathrm{C}}$-Expression in den $\mathrm{PRNP}^{+/+}$-transfizierten Zellen nach transienter Transfektion mittels PRNP $^{+/+}$-Vektor}

(A) Analyse von $\mathrm{PRNP}^{+/+}$- und $\mathrm{PRNP}^{-/-}$-transfizierten Zellen mittels WB. Nach Transfektion der HEK-293-Zellen mit PRNP zeigte sich eine Zunahme der $\operatorname{PrP}^{\mathrm{C}}$ Expression im Vergleich zu den Kontrollzellen, die mit dem Leervektor transfiziert wurden und nur das endogene $\operatorname{PrP}^{\mathrm{C}}$ (WT-PRNP) exprimierten. Zudem lag die $\operatorname{PrP}^{\mathrm{C}}$ Expression nach 48 Stunden deutlich über der Expression nach 24 Stunden. (B) Densitometrische Quantifizierung der Proteinbanden mittels Scion Image. Eine Hochregulation der Expression kann bereits nach 24 Stunden nachgewiesen werden. Nach 48 Stunden nahm die $\operatorname{PrP}^{\mathrm{C}}$-Expression um ca. 350 \% zu. In den WT-PRNPZellen ist dagegen keine Zunahme von $\mathrm{PrP}^{\mathrm{C}}$ zu beobachten (schwarze Balken). Die densitometrischen Messungen werden als Prozentwerte dargestellt. Die Kontrolle lag definitionsgemäß bei 100 \%. Jeder Balken repräsentiert dabei den Durchschnittswert der $\quad \operatorname{PrP}^{\mathrm{C}}$-Konzentration mit entsprechender Standardabweichung. Die densitometrische Auswertung wurde an drei unabhängig voneinander durchgeführten Western Blots verwendet. Grad der Signifikanz: *, p<0,05.

\subsubsection{Transfektion von Prnp ${ }^{0 / 0}$-Zellen mit dem pCMS-PRNP-EGFP-Vektor führt zu einer Induktion der PrP $^{\mathrm{C}}$-Expression}

Prnp $^{0 / 0}$-Zellen besitzen im Gegensatz zu den HEK-293-Zellen kein endogenes $\operatorname{PrP}^{\mathrm{C}}$. Ein möglicher Einfluss des endogen produzierten $\operatorname{PrP}^{\mathrm{C}}$ konnte daher in den nachfolgenden Versuchen mit Prnp ${ }^{0 / 0}$-Zellen ausgeschlossen werden.

Zur Induktion der $\mathrm{PrP}^{\mathrm{C}}$-Expression in Prnp $^{0 / 0}$-Zellen wurden diese mit dem pCMS-PRNPEGFP-Vektor transfiziert $\left(\operatorname{Prnp}^{+/+}\right)$. Die Detektion von $\operatorname{PrP}^{\mathrm{C}}$ erfolgte mit dem Antikörper 12F10 im WB. Dabei konnte eine deutliche Expression von $\operatorname{PrP}^{\mathrm{C}}$ nachgewiesen werden (Abb. 9 A, 9 B). Im Vergleich dazu ist in den mit dem Leervektor transfizierten Zellen ( $\left.\mathrm{PrP}^{-/}\right)$keine $\mathrm{PrP}^{\mathrm{C}}$-Expression zu beobachten. Die Ladekontrolle durch den anti- $\beta$-Actin-Antikörper zeigten ähnliche Proteinmengen an. Die densitometrische Auswertung der WB-Banden erfolgte erneut mittels Scion Image und ergab in drei unabhängigen Experimenten eine signifikante Induktion der $\operatorname{PrP}^{\mathrm{C}}$-Expression. Der Hintergrund wurde dabei als $100 \%$ definiert. 
A

MW (kDa)

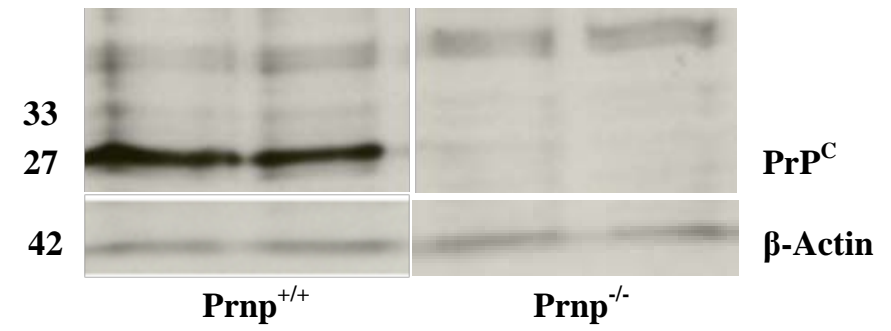

B

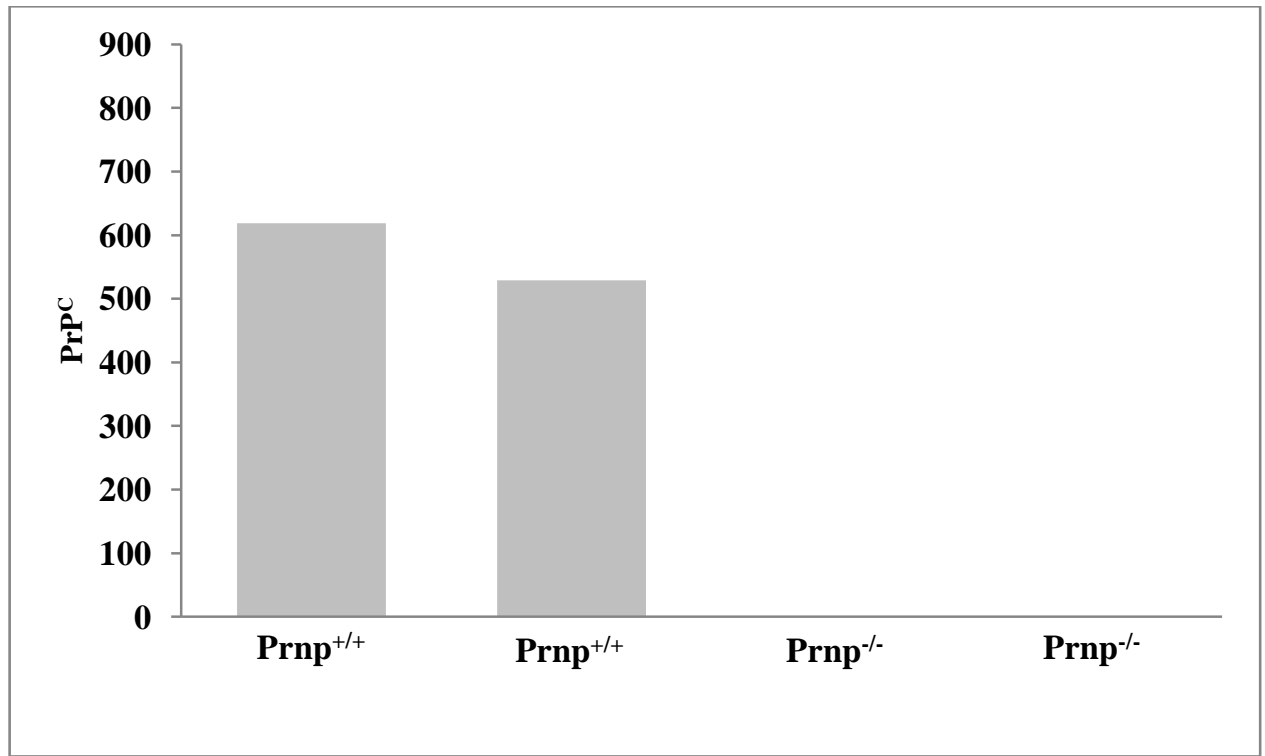

Abbildung 9: Induktion von $\operatorname{PrP}^{\mathrm{C}}$ mittels Transfektion mit pCMS-PRNP-EGFP- Vektor in $\operatorname{Prnp}^{0 / 0}$-Zellen

Die Abbildung zeigt Prnp ${ }^{-/-}$(ohne $\operatorname{PrP}^{\mathrm{C}}$-Expression) und $\operatorname{Prnp}^{+/+}$-Zellen (mit $\operatorname{PrP}^{\mathrm{C}}$ Expression) 24 Stunden nach Transfektion. Dabei erkennt man eine deutliche Hochregulation der $\operatorname{PrP}^{\mathrm{C}}$-Expression in den $\operatorname{Prnp}^{+/+}$-Zellen. Die $\operatorname{PrP}^{-/-}$-Zellen weisen keine $\operatorname{PrP}^{\mathrm{C}}$-Expression auf. Die $\beta$-Actin-Ladekontrolle zeigt ähnliche Proteinmengen an.

\subsection{Immunpräzipitation der beiden Proteine LDH-A und $\operatorname{PrP}^{\mathrm{C}}$}

Um eine mögliche Interaktion von $\operatorname{PrP}^{\mathrm{C}}$ und LDH in HEK-293-Zellen zu untersuchen, wurde eine Co-Immunpräzipitation durchgeführt. Bei diesem Versuch wurde ein bestimmtes Protein mitsamt seiner Interaktionspartner, dem sogenannten Co-Präzipitat, aus einem Proteingemisch 
(hier HEK-293-Zellen) präzipitiert. Die Immunpräzipitate (IP) wurden aus transfizierten HEK-293-Zellen mithilfe des $\operatorname{PrP}^{\mathrm{C}}$-Antikörpers SAF32 bzw. mithilfe eines LDH-AAntikörpers gewonnen. Die Analyse der IP erfolgte mittels Western Blot. Auf diese Weise konnte $\operatorname{PrP}^{\mathrm{C}}$ im LDH-Immunpräzipitat nachgewiesen werden (Abb. $10 \mathrm{~A}$, Spur 1). Zur Kontrolle wurde eine Probe mit dem HEK-Zelllysat (input) im Western Blot aufgetragen. Diese zeigte eine Proteinbande des $\operatorname{PrP}^{\mathrm{C}}$ von gleichem Molekulargewicht. Die negative BeadKontrolle (ohne 1. AK) zeigte keine Interaktion der verwendeten Dynabeads ${ }^{\circledR}$ mit den untersuchten Proteinen. Danach wurde das Immunpräzipitat von $\operatorname{PrP}^{\mathrm{C}}$ mit dem polyklonalen anti-LDH-A-Antikörper untersucht und es konnte eine deutliche LDH-A-Bande im Western Blot beobachtet werden. Als Kontrolle diente erneut HEK-Zelllysat (input). Dieses zeigte eine Bande für LDH-A, welches das gleiche Molekulargewicht aufwies wie das zuvor detektierte LDH-A im IP (Abb. 10 A, 10 B). In der negativen Kontrolle konnte erneut keine Interaktion der verwendeten Dynabeads® mit LDH nachgewiesen werden. Der gegenseitige Nachweis von LDH-A und $\operatorname{PrP}^{\mathrm{C}}$ im jeweiligen Immunpräzipitat weist auf eine direkte oder indirekte Interaktion der beiden Proteine hin.

A

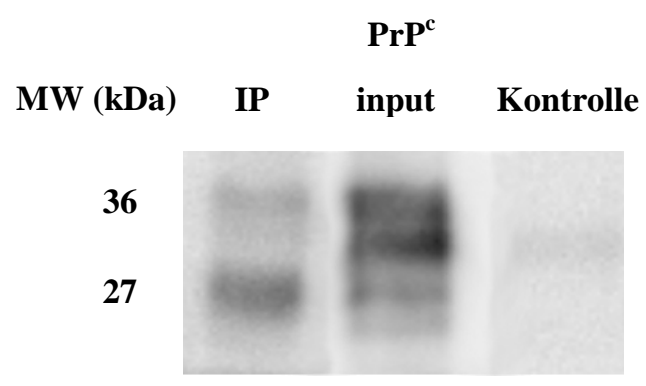

B

LDH-A

IP input Kontrolle MW (kDa)

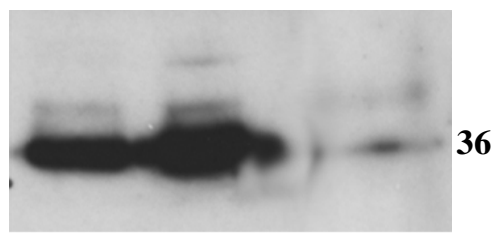

\section{Abbildung 10: Co-Immunpräzipitation von LDH-A und $\operatorname{PrP}^{\mathrm{C}}$ in HEK-293-Zellen}

Immunpräzipitate von LDH-A und $\operatorname{PrP}^{\mathrm{C}}$ wurden im Western Blot untersucht. (A) Detektion von $\operatorname{PrP}^{\mathrm{C}}$ im Immunpräzipitat von LDH durch den Anti-PrP ${ }^{\mathrm{C}}$-Antikörper SAF32, sowie (B) die Detektion von LDH im Immunpräzipitat von $\mathrm{PrP}^{\mathrm{C}}$ durch den polyklonalen Anti-LDH-A-Antikörper. Die negative Bead-Kontrolle zeigte keine Interaktion. 


\subsection{Bestimmung der LDH-Expression vor und nach Hypoxie in verschiedenen Zelllinien}

\subsubsection{Regulation der LDH-Expression durch $\operatorname{PrP}^{\mathrm{C}}$ in kortikalen Neuronen in Folge einer Hypoxie}

Die LDH-A-Expression sollte unter normalen und hypoxischen Bedingungen in Wildtyp- und Prnp $^{0 / 0}$-Zellen analysiert werden, um einen möglichen Einfluss von $\mathrm{PrP}^{\mathrm{C}}$ auf die LDHExpression zu untersuchen. Da Tumorzellen möglicherweise Artefakte liefern könnten, wurden zunächst primäre Nervenzellen untersucht.

Die primären kortikalen Nervenzellen aus den Wildtyp- und den Prnp ${ }^{0 / 0}$-Mäusegehirnen wurden präpariert und unter normalen und hypoxischen Bedingungen miteinander verglichen. Die Hypoxiezeiten unterschieden sich dabei von 30 bis 90 Minuten. Im Western Blot zeigten sich zwei LDH-Banden in den Zelllysaten der primären Zellen, die später als LDH-A und LDH-B identifiziert wurden. Abbildung 11 zeigt in einem Western Blot die LDH-Expression einmal unter normalen und zum anderen nach erfolgter Hypoxie und anschließender Reoxigenierungsphase von 12 Stunden. Die densitometrische Auswertung ergab keinen signifikanten Unterschied der LDH-Expression unter normalen Bedingungen (Kontrolle). Nach 30-minütiger Hypoxie konnte eine leicht erhöhte Expression des LDH (Abb. 11 A, 11 B) in den WT-Zellen beobachtet werden. Nach 60-minütiger Hypoxie kam es zu einem 1,8 fachen Anstieg der LDH-Expression (Abb. 11 A, 11 B). Nach 90-minütiger Hypoxie stieg die LDH-Expression nochmals weiter an. Die Prnp ${ }^{0 / 0}$-Zellen wiesen lediglich einen geringen Anstieg der LDH-Expression nach Hypoxie auf. 


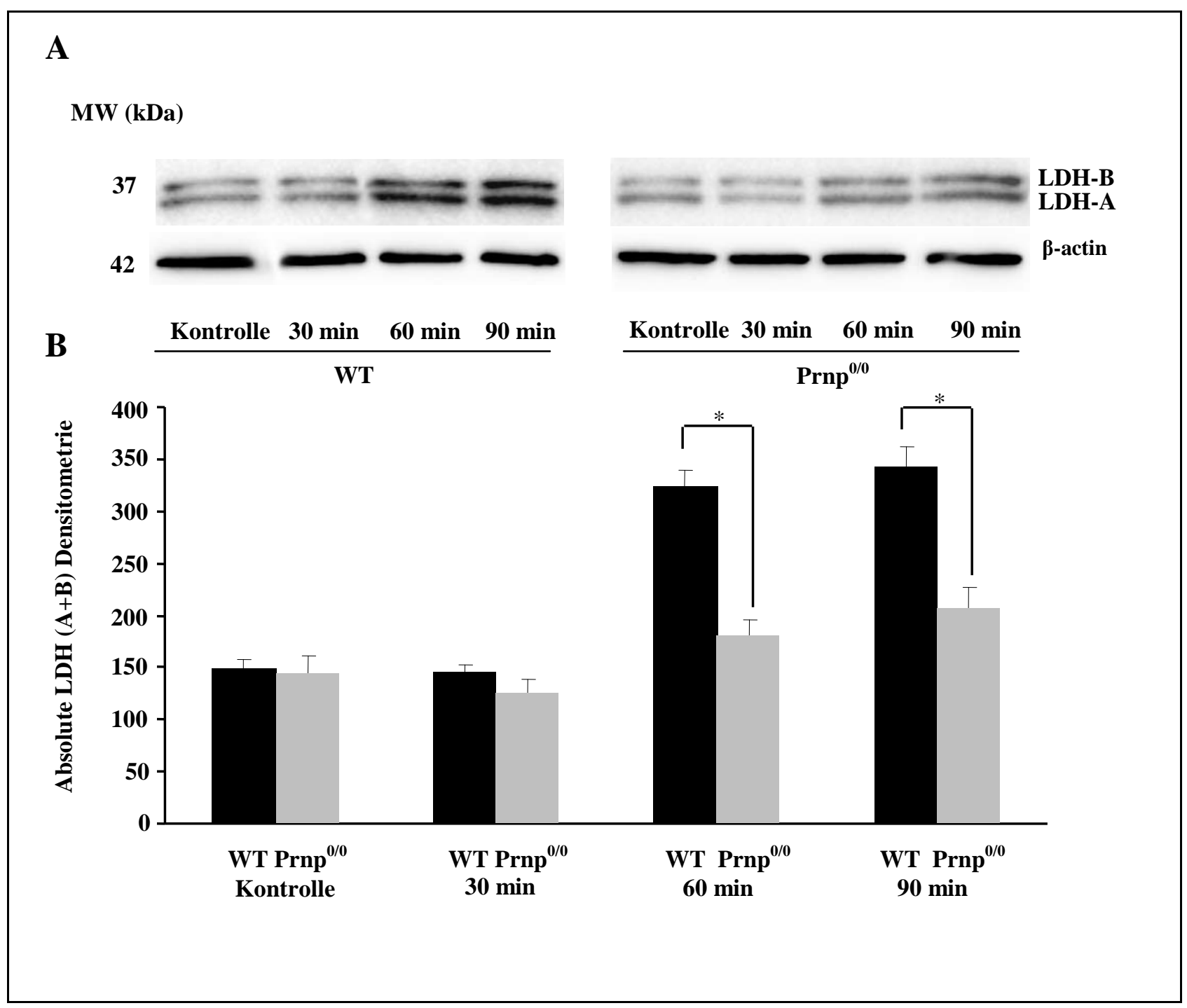

Abbildung 11: $\operatorname{PrP}^{\mathrm{C}}$ induziert eine Hochregulation der LDH-Expression in primären Neuronen nach Hypoxie

(A) Der Western Blot zeigt die Isoemzyme LDH-A (unten) und LDH-B (oben). Die Zellen wurden entweder normalen Sauerstoffbedingungen (Kontrolle) oder Hypoxiebedingungen mit einer Dauer von 30, 60 und 90 Minuten ausgesetzt. Die LDH-Expression wurde 12 Stunden nach Reoxygenierung im Brutschrank gemessen. (B) Die densitometrische Auswertung mittels Scan Image zeigten keinen signifikanten Unterschied zwischen den WT- (schwarze Balken) und den Prnp ${ }^{0 / 0}$-Zellen (graue Balken) unter normalen Bedingungen. Nach 30-minütiger Hypoxie konnte bereits ein geringer Anstieg der LDH-Expression in den WT-Zellen gemessen werden. Nach 60bzw. 90-minütiger Hypoxie konnte ein signifikanter Anstieg der LDH-Expression in den WT-Zellen beobachtet werden. Die gleiche Proteinmenge konnte durch die $\beta$ Actin-Ladekontrolle gezeigt werden. Dieser Western Blot ist repräsentativ für 
insgesamt drei Western Blots. Densitometrische Messungen wurden bei allen Western Blots durchgeführt. Es werden die absoluten Werte (x 103) angezeigt. Jeder Balken repräsentiert dabei den Durchschnittswert der LDH-Konzentration mit entsprechender Standartabweichung. Grad der Signifikanz: *, p<0,05. Verwendete Antikörper waren der Anti-PrP ${ }^{\mathrm{C}}$-Antikörper 12F10 (Verdünnung 1:1000) und der Anti-LDH-Antikörper (Verdünnung 1:500).

\subsubsection{Regulation von LDH nach Hypoxie in $\operatorname{PrP}^{\mathrm{C}}$ überexprimierenden HEK-293- Zellen}

Um den beobachteten Effekt an einem zweiten Zellmodell zu zeigen, wurden HEK-293Zellen transient für 48 Stunden transfiziert. HEK-293-Zellen wurden dann für 90 Minuten in eine Hypoxie-Kammer gestellt, in der der Sauerstoffanteil bei 1 \% lag. Danach wurden die Zellen für 6 Stunden im Brutschrank unter Normalbedingungen reoxygeniert. Im Anschluss erfolgte die LDH-A-Bestimmung mittels Western Blot (Abb. 12). Die densitometrischen Auswertungen der Western Blots zeigten eine 1,8 fache Zunahme der LDH-A-Expression nach 90-minütiger Hypoxie (und Reoxygenierung) in den $\mathrm{PRNP}^{+/+}$-HEK-293-Zellen. Im Vergleich zu den Kontrollzellen konnte ein signifikanter zweifacher $(\mathrm{p}<0.05)$ Anstieg der LDH-A-Expression in den PRNP $^{+/+}$-HEK-293-Zellen nach Hypoxie beobachtet werden. Kein wesentlicher Unterschied bezüglich der LDH-A-Expression existierte bei mit dem Leervektor transfizierten Zellen vor und nach Hypoxie (Abb. 12 A, 12 B). Interessanterweise zeigte sich eine Korrelation zwischen der LDH-A- und $\operatorname{PrP}^{\mathrm{C}}$-Expressionshöhe. Je höher die $\operatorname{PrP}^{\mathrm{C}}$ Expression war, desto höher war auch die LDH-A-Expression. Daneben konnte nach Hypoxie auch eine höhere $\mathrm{PrP}^{\mathrm{C}}$-Expression in den $\mathrm{PRNP}^{+/+}$-Zellen, im Vergleich zu den Kontrollzellen ohne Hypoxie nachgewiesen werden. Die $\beta$-Actin-Ladekontrolle zeigte ähnliche Proteinmengen an. 
A

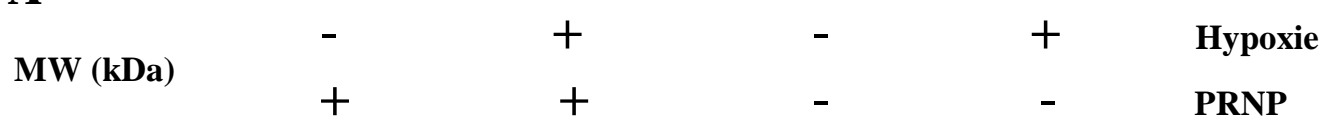

36

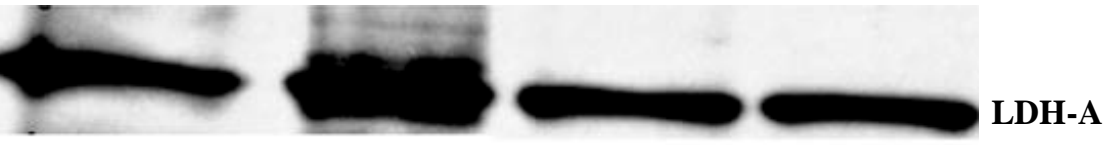

42

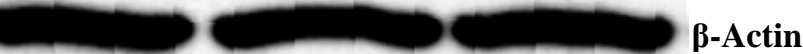

$3 5 \longdiv { 9 }$
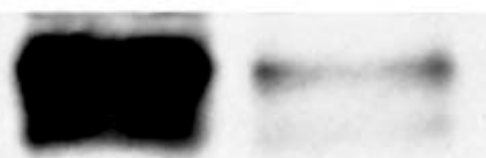

29

$\operatorname{PrP}^{\mathrm{c}}$

B

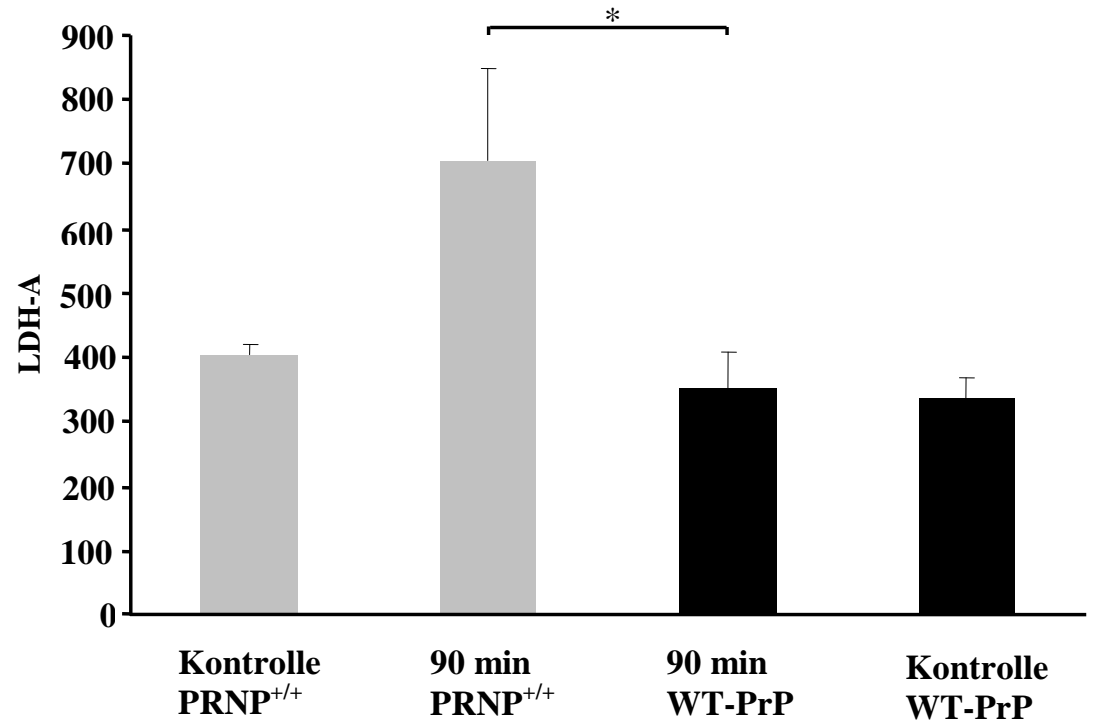

Abbildung 12: LDH-A-Expression in Kontroll- und $\operatorname{PrP}^{\mathrm{C}}$-überexprimierenden HEK293-Zellen unter normalen und hypoxischen Bedingungen

(A) Nach Hypoxie konnte eine höhere LDH-A-Expression in den $\mathrm{PrP}^{\mathrm{C}}$ überexprimierenden HEK-293-Zellen $\left(\mathrm{PRNP}^{+/}\right)$im Vergleich $\mathrm{zu}$ den mit dem Leervektor transfizierten HEK-293-Zellen (WT-PrP) nachgewiesen werden. Der Anstieg der LDH-A-Expression in den Kontrollzellen blieb dagegen vor und nach 
Hypoxie unverändert. Nach Hypoxie zeigte sich auch eine höhere $\operatorname{Pr}^{\mathrm{C}}$-Expression in den $\mathrm{PRNP}^{+/+}$-Zellen, im Vergleich zu den Kontrollzellen ohne Hypoxie. Durch den Anti- $\beta$-Actin-Antikörper konnten ähnliche Proteinmengen dargestellt werden. (B) Die densitometrische Quantifizierung wurde als absolute Werte der Bildpunkte (x 10 ${ }^{3}$ ) dargestellt. Jeder Balken repräsentiert dabei den Durchschnittswert der LDH-AKonzentration mit entsprechender Standartabweichung.

\subsubsection{Erhöhung der LDH-Expression in Abhängigkeit vom $\operatorname{PrP}^{\mathrm{C}}$-Level in $\operatorname{PRNP}^{+/+}$- transfizierten Prnp ${ }^{0 / 0}$-Zellen nach Hypoxie}

Um den Einfluss des $\operatorname{PrP}^{\mathrm{C}}$ auf die LDH-Expression in einem weiteren Zellmodell zu untersuchen, wurden Prnp ${ }^{0 / 0}$-Zellen mit PRNP-Plasmid transfiziert $\left(\mathrm{PRNP}^{+/+}\right)$und mit Leervektor $\left(\mathrm{PRNP}^{-/}\right.$) transfizierten Prnp ${ }^{0 / 0}$-Zellen verglichen. Es zeigten sich Unterschiede in der LDH-Expression nach 120-minütiger Hypoxie und 6-stündiger Reoxygenierung im Brutschank. Bei PRNP ${ }^{+/+}$-Zellen ist eine Zunahme der LDH-Expression nach Hypoxie zu sehen, wogegen $\mathrm{PRNP}^{-/}$-Zellen keine Zunahme der LDH-Expression weder vor noch nach Hypoxie zeigten (Abb. 13 A, 13 B). $\beta$-Actin diente erneut als Ladekontrolle für ähnliche Proteinmengen. 


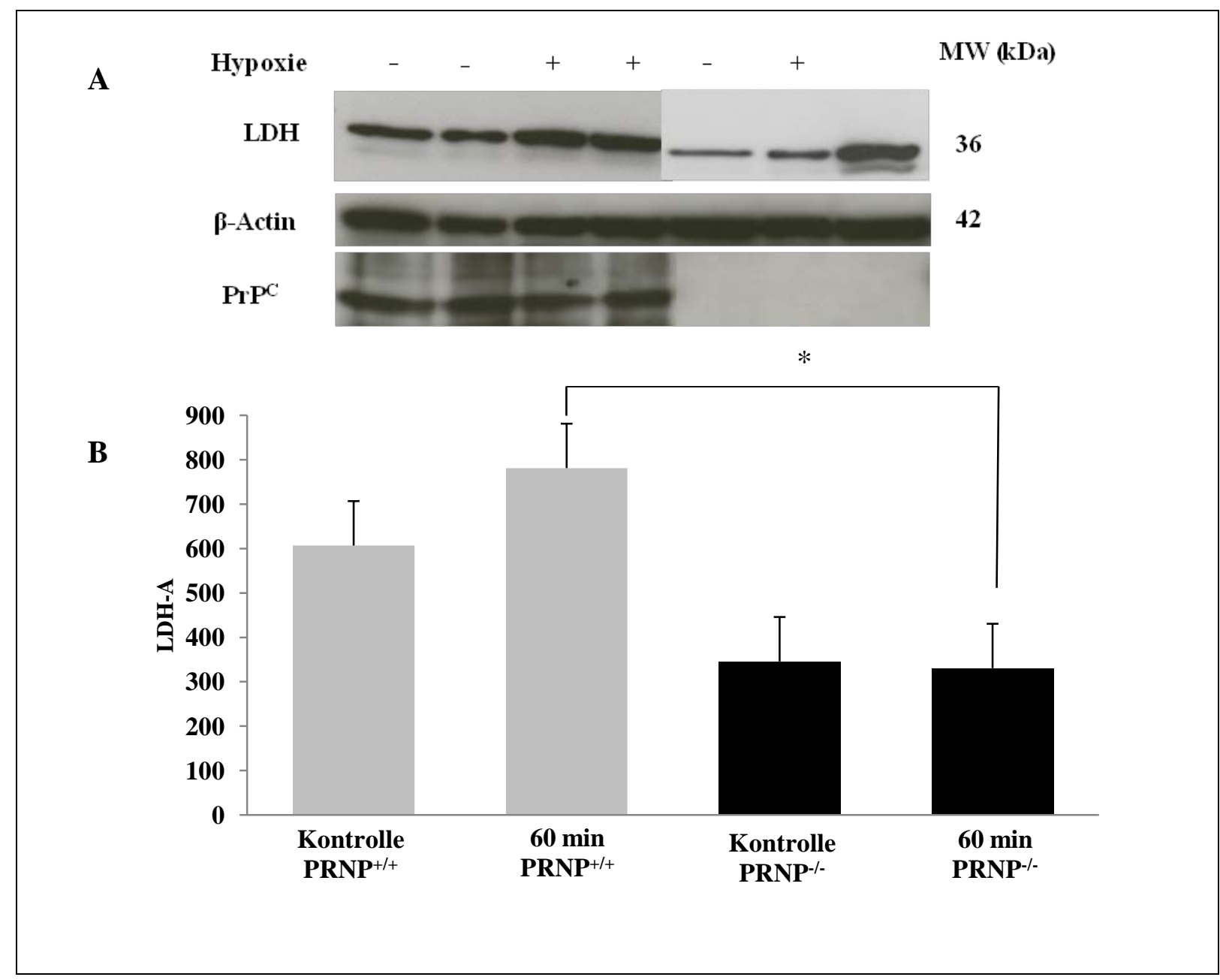

Abbildung 13: LDH-A-Expression vor und nach Hypoxie in $\mathrm{PRNP}^{+/+}$- und $\mathrm{PRNP}^{-/}$transfizierten Prnp ${ }^{0 / 0}-$ Zellen

Vergleich der LDH-A-Expression in $\mathrm{PRNP}^{+/+}$- mit PRNP ${ }^{-/-}$-Zellen. Vor Hypoxie war eine geringere LDH-A-Expression zu sehen. Nach 60-minütiger Hypoxie zeigte sich eine deutliche Zunahme der LDH-A-Expression in den RRNP $^{+/+}$- im Vergleich zu den PRNP $^{+/+}$-Zellen vor Hypoxie. Positivkontrolle des LDH-A bei 36 kDa. Die $\beta$-ActinLadekontrolle zeigte bei $42 \mathrm{kDa}$ ähnliche Proteinmengen an.

\subsubsection{Hypoxie führt zu einer größeren Schädigung des Tubulinzytoskelettes in Prnp ${ }^{0 / 0}$ Zellen im Vergleich zu WT-Zellen}

Durch eine Hypoxie kommt es zum Untergang von Zellen. Dieser Zelluntergang lässt sich optisch durch die zunehmende Schädigung des Tubulinzytoskeletts darstellen. Um die schädigende Wirkung einer Hypoxie in Abhängigkeit von $\operatorname{PrP}^{\mathrm{C}}$ auf Zellen zu untersuchen, wurde der Zustand des Tubulinzytoskelett der WT- und Prnp ${ }^{0 / 0}$-Zellen zu Vergleichszwecken 
unter normaler Oxygenierung und nach Hypoxie immunozytochemisch angefärbt und verglichen. Die Färbung des Tubulins erfolgte durch den monoklonale neuronalen Antikörper der Klasse 3- $\beta$-Tubulin nach 12-stündiger Reoxygenierung. Abbildung 14 zeigt die immunozytochemische Färbung des Tubulinzytoskelettes beider Zelltypen, WT-Zellen (Abb. 14, Bild I) und Prnp ${ }^{0 / 0}$-Zellen (Abb. 14, Bild II), unter normalen Bedingungen ohne Hypoxie. Nach 90-minütiger Hypoxie, war das Zytoskelett der Prnp ${ }^{0 / 0}$-Zellen (Abb. 14, Bild IV) deutlicher stärker geschädigt als es in den WT-Zellen (Abb. 14, Bild III) der Fall war. Dies weist auf einen verminderten neuronalen Schaden nach Hypoxie in den WT-Zellen hin, als Folge der möglichen neuroprotektiven Funktion des $\operatorname{PrP}^{\mathrm{C}}$.
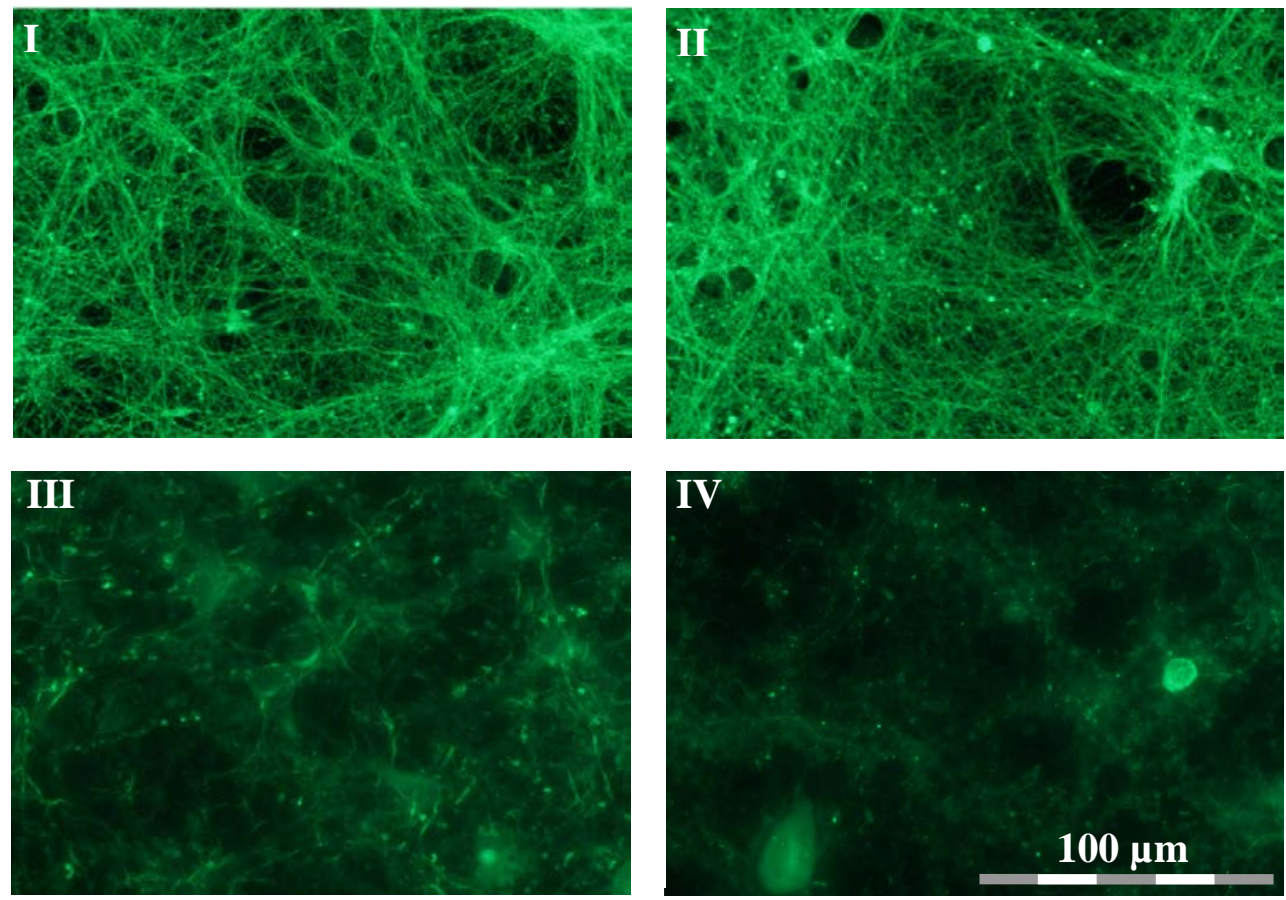

Abbildung 14: Immunozytochemische Darstellung des Tubulinzytoskeletts in primären kortikalen Neuronen von WT- und Prnp ${ }^{0 / 0}$-Zellen vor und nach Hypoxie

Primäre kortikale Neurone aus Wildtyp- (Bild I) und Prnp ${ }^{0 / 0}$-Mäusen (Bild II) zeigten eine gleiche Struktur des Tubulinzytoskelettes unter normalen Sauerstoffbedingungen. Die Struktur des Zytoskeletts wurde durch die $\beta$-Tubulin-Isotyp-III-Anfärbung gezeigt. Nachdem die Zellen einer 90-minütigen Hypoxie ausgesetzt wurden, zeigte sich 12 
Stunden nach Reoxygenierung ein geringerer Schaden im Zytoskelett der WT-Zellen (Bild III) im Vergleich zu den Prnp ${ }^{0 / 0}$-Zellen (Bild IV). Maßstab 100fach. 


\section{Diskussion}

Die physiologische Funktion des $\operatorname{PrP}^{\mathrm{C}}$ ist bis heute nicht vollständig verstanden und Teil vieler Studien. Eine mögliche neuroprotektive Funktion des $\operatorname{PrP}^{\mathrm{C}}$ wird immer wieder diskutiert. In der vorliegenden Arbeit wurde eine mögliche Interaktion von LDH mit $\operatorname{PrP}^{\mathrm{C}}$ untersucht sowie die $\operatorname{PrP}^{\mathrm{C}}$-abhängige LDH-Expression unter Hypoxiebedingungen. Das Ziel war es, eine mögliche neuroprotektive Funktion von $\operatorname{PrP}^{\mathrm{C}}$ unter Stressbedingungen zu untersuchen und besser $\mathrm{zu}$ verstehen. Es wurden dafür verschiedene Zelllinien mit unterschiedlicher $\operatorname{PrP}^{\mathrm{C}}$-Expression verglichen. Vorrausgegangene Studien konnten bereits eine neuroprotektive Funktion von $\operatorname{PrP}^{\mathrm{C}}$ unter Stressbedingungen zeigen (McLennan et al. 2004; Weise et al. 2004; Weise et al. 2006).

Auch außerhalb des zentralen Nervensystems spielt $\operatorname{PrP}^{C}$ eine wichtige Rolle. Es ist in verschiedenen peripheren Organsystemen gefunden worden, z.B. im Immunsystem und bei Entzündungsreaktionen. Dazu passend konnte in Studien belegt werden, dass in Prnp ${ }^{0 / 0}$ Mäusen eine geringere immunologische Antwort auf eine künstlich induzierte Entzündungsreaktion vorlag als in WT-Mäusen (De Almeida et al. 2005). Die $\operatorname{PrP}^{C_{-}}$ Konzentration im Plasma bei entzündetem und ischämischem Gewebe nimmt nach einem ischämischen Geschehen zu und scheint somit Einfluss auf hypoxische Zellschäden zu nehmen (Mitsios et al. 2007).

\subsection{Interaktion von LDH und $\operatorname{PrP}^{\mathrm{C}}$}

Die Interaktion von Proteinen spielt eine entscheidende Rolle in allen biologischen Prozessen, an denen Proteine beteiligt sind. Mittels der Co-Immunpräzipitationsmethode konnte eine Interaktion von $\mathrm{LDH}$ und $\mathrm{PrP}^{\mathrm{C}}$ in HEK-293-Zellen vermutet werden. Dabei ist theoretisch eine direkte oder eine indirekte Interaktion in HEK-293-Zellen möglich. Da in vorangegangenen Studien $\operatorname{PrP}^{\mathrm{C}}$ bereits als ein möglicher Interaktionspartner von $\mathrm{LDH}$ beschrieben wurde (Rutishauser et al. 2009; Watts et al. 2009), ist eine direkte Interaktion von $\mathrm{PrP}^{\mathrm{C}}$ und LDH auch in HEK-293-Zellen sehr wahrscheinlich. Die physiologische Bedeutung dieser Interaktion ist allerdings noch nicht ausreichend verstanden und wird im Laufe dieser Arbeit weiter thematisiert.

Eine wichtige Rolle dieser Interaktion für die Neuroprotektion ist wahrscheinlich das Laktat (als Produkt der LDH), welches eine neuroprotektive Wirkung unter hypoxischen und 
ischämischen Bedingungen zu haben scheint (Berthet et al. 2009; Schurr et al. 1988; Schurr et al. 1997; Schurr et al. 2001).

\subsection{1 $\operatorname{PrP}^{\mathrm{C}}$-vermittelte Hochregulation der LDH-Expression unter zellulären Stressbedingungen}

In dieser Arbeit konnte gezeigt werden, dass $\operatorname{PrP}^{\mathrm{C}}$ eine Hochregulation der LDH-Expression unter Hypoxie in den Zelllinien HEK-293 und Prnp ${ }^{0 / 0}$, sowie in kortikalen Neuronen (Maus) induziert. Dazu wurde in den genannten Zelltypen oxidativer Stress mittels Hypoxie induziert. Als Folge der Hypoxie kam es in allen Zelltypen neben einer Hochregulation der $\operatorname{PrP}^{\mathrm{C}}$ Expression auch zu einer $\operatorname{PrP}^{\mathrm{C}}$-vermittelten Hochregulation von LDH. In den Kontrollzellen, die kein $\left(\operatorname{Prnp}^{0 / 0}\right)$ oder nur endogenes $\operatorname{PrP}^{\mathrm{C}}$ (HEK-293) exprimierten und einer Hypoxie ausgesetzt wurden, blieb ein Anstieg der LDH-Expression aus. Ebenso konnte unter Normalbedingungen kein wesentlicher $\mathrm{PrP}^{\mathrm{C}}$-induzierter Unterschied bezüglich der $\mathrm{LDH}$ Expression in allen untersuchten Zelltypen beobachtet werden. Diese Daten unterstützen die bereits von verschiedenen Forschergruppen akzeptierte Annahme, dass $\operatorname{PrP}^{\mathrm{C}}$ lediglich unter zellulären Stressbedingungen eine wichtige physiologische Funktion hat (Walz et al. 1999; McLennan et al. 2004; Weise et al. 2004). Unter Normalbedingungen konnten auch in transgenen Prnp-Knockout-Mäusen keine wesentlichen Unterschiede bezüglich der Überlebenszeit oder der Anatomie gefunden werden (Bueler et al. 1992), weshalb die physiologische Funktion von $\operatorname{PrP}^{\mathrm{C}}$ lange unklar war.

Der in dieser Arbeit erstmals erhobene Befund, dass $\operatorname{PrP}^{\mathrm{C}}$ direkt in den metabolischen Stoffwechsel von Zellen involviert ist, indem es die Expression von LDH, einem Enzym, das für die anaerobe Umwandlung von Pyruvat in Laktat verantwortlich ist, reguliert, erklärt einen möglichen zellulären Mechanismus. Hinweise für eine wichtige Rolle von $\operatorname{PrP}^{\mathrm{C}}$ beim Zellstoffwechsel existierten bereits aus vorangehenden Proteomik-Studien (Zafar et al. 2011; Zafar et al. 2014). Es konnten neue Interaktionspartner von $\operatorname{PrP}^{\mathrm{C}}$ identifiziert werden: Zum einen Rab7a, Teil der GTPasen, die am intrazellulären Vesikeltransport beteilgt sind (Zafar et al. 2011) und die Pyruvatkinase M2 (Zafar et al. 2014), welche eine wichtige Rolle im Energiestoffwechsel der Zellen spielt.

Ein Anhaltspunkt, dass insbesondere das Enzym LDH eine sehr wichtige physiologische Funktion ausübt und nicht nur ein Marker für Apoptose ist, konnte in unreifen, neonatalen Gehirnen, die die Fähigkeit besitzen, längere Phasen des Sauerstoffmangels zu überstehen, gefunden werden. Unter Sauerstoffmangelbedingungen wurde beobachtet, dass die Zellen 
LDH-A deutlich hochregulieren, um vermehrt Laktat produzieren zu können (Maker et al. 1972). Später konnte gezeigt werden, dass diese erhöhte Aktivität der LDH-A bei verminderter Sauerstoffzufuhr durch den Hypoxie induzierten Faktor 1 (HIF-1) vermittelt wird (Semenza et al. 1996). Welche Auswirkungen diese LDH-Erhöhung in den Nervenzellen hat, wird gegenwärtig diskutiert. Da vor allem LDH-A zu einer vermehrten Produktion von Laktat führt, ist zu diskutieren, welche Rolle das Laktat in der durch das Prion-Protein vermittelten Kaskade spielt.

\subsubsection{Laktat als Energiesubstrat}

Aktuelle Studien diskutieren, dass Neurone neben Glukose auch Laktat als Substrat zur Energiegewinnung bei oxidativem Stress oder Ischämie nutzen. Es gibt immer mehr Hinweise auf einen sogenannten Astrozyten-Neuronen-Laktat-Shuttle (ANLS) (Erlichman et al. 2008; Pellerin und Magistretti 1994). Dabei geht man davon aus, dass bei hohem Energiebedarf Astrozyten Laktat generieren und dieses durch Monocarboxylase-Transporter (MCT) in den Extrazellulärraum geben. Das Laktat wird dann in den Mitochondrien von Neuronen in der Umgebung zu Pyruvat oxidiert. Energie wird gewonnen. Laktat wäre somit ein geeignetes Substrat zur Energiegewinnung in Neuronen.

Durch diese Energiegewinnung ist es den Zellen möglich länger zu überleben. Im Umkehrschluss würde dies bedeuten, dass es zu einem geringeren Zelluntergang kommt. Dies konnte in dieser Arbeit durch die immunzytochemische Anfärbung des Tubulinzytoskeletts indirekt belegt werden. Dies wies nach einer Hypoxie bei vermehrter $\operatorname{PrP}^{\mathrm{C}}$-Expression (in Wildtyp-Zellen) einen geringeren Schaden auf als bei fehlender $\operatorname{PrP}^{\mathrm{C}}$-Expression (in $\operatorname{Prnp}^{0 / 0}$ Zellen). Dieser geringere Schaden am Zytoskelett könnte dabei über die vermehrte LDHExpression und in Folge dessen, der erhöhten Laktat-Bereitstellung in der Zelle erklärt werden.

Passend dazu wurde in neusten Studien beschrieben, dass Prnp ${ }^{0 / 0}$-Mäuse im Vergleich zu WT-Mäusen Veränderungen der Proteine des Zytoskeletts aufweisen (Schmitz et al. 2014). $\operatorname{PrP}^{\mathrm{C}}$ konnte somit als Einflussprotein auf das Zytoskelett identifiziert werden. Dies würde die in dieser Arbeit beobachteten geringeren Schäden am Tubulinzytoskelett bei Wildtyp-Zellen (mit PrP ${ }^{\mathrm{C}}$-Expression) im Vergleich zu Prnp ${ }^{0 / 0}$-Zellen (ohne $\operatorname{PrP}^{\mathrm{C}}$-Expression) erklären. Das vermehrte Laktat in den WT-Zellen führt dabei über die höhere LDH-Konzentration zu einem längeren Überleben der Zellen bzw. einem geringeren neuronalen Schaden nach Hypoxie.

Daneben wurde postuliert, dass es ein Zusammenspiel zwischen $\operatorname{PrP}^{\mathrm{C}}$, dem GlutamatRezeptor 2, $\alpha 2 / ß 2-A d e n s o s i n$ Triphosphad (ATPase), Basigin und MCT1 Transporter gibt, 
welches in die Regulation des Transportes von Laktat in Astrozyten involviert ist (Kleene et al. 2007). Die Autoren veröffentlichten, dass dieses Zusammenspiel die Kommunikation zwischen Astrozyten und Neurone unter Stress-Situationen wie Hypoxie beeinflusst. Interessanterweise war das Protein Basigin, welches direkt die Laktataufnahme über die Interkation mit dem MCT1-Transporter fördert, signifikant vermindert in Neuronen von Prnp $^{0 / 0}$-Mäusen im Vergleich zu WT-Mäusen (Stella et al. 2012). Dies führt zu der Annahme,

dass die Laktat-Aufnahme in den Prnp $^{0 / 0}$-Mäusen im Vergleich zu den WT-Mäusen vermindert ist.

Stellt man die Ergebnisse aus dieser Arbeit mit denen von anderen vorausgegangenen Autoren in einen Kontext zusammen, so kann man mit großer Wahrscheinlichkeit annehmen, dass die $\operatorname{PrP}^{\mathrm{C}}$-assoziierte Hochregulation des intrazelluären $\mathrm{LDH}(\mathrm{A}+\mathrm{B})$ unter Hypoxiebedingungen zu einer erhöhten Laktat-Produktion führt. Dieses Laktat könnte dann via MCT1-Transporter zu den Neuronen gelangen, was wiederum in einer erhöhten Energiegewinnung resultiert.

All diese Ergebnisse könnten auch die durch Weise et. al postulierten Ergebnisse der verminderten Gehirnläsionen nach Hypoxie in WT-Mäusen erklären (Weise et al. 2006).

Durch weitere Studien sollte ausgeschlossen werden, dass die beobachtete $\operatorname{PrP}^{\mathrm{C}}$-assoziierte Hochregulation von LDH unter Hypoxiebedingungen nicht nur ein kompensatorisches Phänomen ist und nicht ursächlich mit den verminderten Läsionen in den WT-Mäusen zusammenhängt. Studien über mögliche selektive Hemmer der LDH und des Laktattransportes sind sinnvoll. Ebenso ist der genaue molekulare Mechanismus der LDHRegulation durch $\mathrm{PrP}^{\mathrm{C}}$ noch nicht ausreichend verstanden.

Als nächstes stellt sich nun die Frage, ob diese in vitro beobachteten Mechanismen auf Mäuse übertragbar, also auch in vivo nachzuweisen sind.

\section{2 $\operatorname{PrP}^{\mathrm{C}}$ wirkt neuroprotektiv bei einer Ischämie in Mäusen}

Das Zytoskelett von Zellen wird durch Gerüst-Proteine aufgebaut, bestehend aus Aktinfilamenten, Intermediärfilamenten und Mikrotubuli (Lazarides 1980). Diese drei Klassen von Proteinen dienen der mechanischen Stabilität von Zellen. In dieser Arbeit konnte der Einfluss der Hypoxie auf das Zytoskelett durch Anfärbung von Tubulin, welches der Hauptbestandteil der Mikrotubuli ist (Nogales 2000), dargestellt werden. Somit konnte ein möglicher Schutz vor Zelluntergang durch $\mathrm{PrP}^{\mathrm{C}}$ auf einem weiteren Wege untersucht werden. Es zeigte sich, dass bei primären aus $\operatorname{Prnp}^{0 / 0}$-Mäusen isolierte Prnp ${ }^{0 / 0}$-Zellen das Zytoskelett nach 90-minütiger Hypoxie deutlich stärker zerstört wurde, als es in den WT-Zellen der Fall 
war. Dies lässt einen verminderten Schaden nach Hypoxie in den WT-Zellen vermuten als in den Prnp ${ }^{0 / 0}$-Zellen. Bestätigen würde sich dies durch die in vivo-Versuche an Mäusen, die diesen vorangingen. Diese legten nahe, dass $\operatorname{PrP}^{\mathrm{C}}$ einen neuroprotektiven Effekt bei hypoxischer, ischämischer, traumatischer und epilepsiebedingter Hirnschädigung hat. Läsionen im Gehirn unterschieden sich dabei in Abhängigkeit vom $\operatorname{PrP}^{\mathrm{C}}$. Weise et al. beobachteten größere Unterschiede der Läsionsvolumina zwischen Prnp ${ }^{0 / 0}$-Mäusen (keine $\mathrm{PrP}^{\mathrm{C}}$-Expression) und WT-Mäusen (endogene $\mathrm{PrP}^{\mathrm{C}}$-Expression) nach transienter Ischämie und anschließender Reperfusion (Weise et al. 2006). Es lässt sich vermuten, dass die signifikant kleineren Infarktvolumen bei WT-Mäusen im Vergleich zu Prnp ${ }^{0 / 0}$-Mäusen aus den höherer ATP-Produktionen in den Neuronen der WT-Mäusen erklärt werden über eine erhöhte LDH-Expression. Auch durch weitere in vitro-Versuche konnte eine protektive Funktion des $\operatorname{PrP}^{\mathrm{C}}$ nachgewiesen werden (Kuwahara et al. 1999; Walz et al. 1999; Walz et al. 2002; Sakudo et al. 2003; Hoshino et al. 2003; McLennan et al. 2004; Nishimura et al. 2004; Kim et al. 2004; Spudich et al. 2005; Weise et al. 2004; Weise et al. 2006). Dabei wurde wiederholt ein vermehrtes Überleben in den $\operatorname{PrP}^{\mathrm{C}}$-exprimierenden Zellen nachgewiesen: unter Serum-Entzug, Hypoxie oder nach Schädel-Hirn-Traumen. $\operatorname{PrP}^{\mathrm{C}}$ führt zu einem geringeren Zelluntergang und schützt vor Apoptose. Nimmt man all die bereits gewonnenen Erkenntnisse zusammen, macht es die weitere Untersuchung der neuroprotektiven Funktion des $\operatorname{PrP}^{\mathrm{C}}$ um so interessanter.

\subsection{Relevanz von LDH in der Humanmedizin}

In neueren Studien konnte gezeigt werden, dass $\mathrm{PrP}^{\mathrm{C}}$ mit dem glykolytischen Enzym Aldolase $\mathrm{C}$ interagiert (Strom et al. 2006). Es lässt die Vermutung zu, dass $\operatorname{PrP}^{\mathrm{C}}$ regulierend in die Glykolyse eingreifen kann. Zudem wurde nachgewiesen, dass eine Hypoglykämie die Expression von $\operatorname{PrP}^{\mathrm{C}}$ in vitro erhöht (Shyu et al. 2005), während Phasen der Hyperglykämie zu einer Suppression der $\operatorname{PrP}^{\mathrm{C}}$-Expression in Beta-Zellen des Pankreas führten (Strom et al. 2007). Dies lässt vermuten, dass $\operatorname{PrP}^{C}$ eine wichtige Rolle in der Glukose-Homöostase spielt. Diese Theorie wird unterstützt durch die Tatsache, dass man im Liquor von an CreutzfeldtJakob erkrankten Patienten signifikant höhere LDH-Werte messen konnte als im Liquor von anderen Demenzen (Abb. 16) (Schmidt et al. 2004). Interessanterweise wird LDH seit langem als Marker für Zelluntergang gemessen. Dabei scheint es gerade für ein längeres Zellüberleben eine wichtige Funktion zu haben.

Es wurde nachgewiesen, dass fast $40 \%$ der durch die Creutzfeldt-Jakob-Krankheit beeinflussten Proteine in den Glukose Metabolismus involviert sind (Gawinecka et al. 2010.). 
Neuste Studien konnten zeigen, dass die Laktat-Konzentrationen in Gehirnen von CreutzfeldtJakob-Patienten erhöht sind (Fujita et al. 2011). Hierzu passend konnten bereits früher erhöhte Laktat-Spiegel bei der Huntington-Erkrankung gemessen werden (Harms et al. 1997) und Oxamat, als Hemmstoff der LDH, führte zur vermehrten Neurodegeneration im Korpus Striatum der Basalganglien (Fox et al. 2007). Es wirft die Frage auf, ob LDH und das Produkt Laktat eine weit größere Rolle in dem Prozess der Neurodegeneration spielen als bisher bekannt.

Neben neuen diagnostischen Möglichkeiten bietet dies eine Grundlage für die Erforschung der Frage, über welche genauen Mechanismen $\operatorname{PrP}^{C}$ zu einer erhöhten LDH-Expressionen führen könnte und ob es durch das vermehrte Laktat-Angebot zum Zellüberleben von Neuronen kommt.

Diese Arbeit bietet einen Ansatz für weitere Studien und Untersuchungen um schlussendlich einen Weg zu finden, Neurone bei bestimmten Erkrankungen wie der Alzheimerdemenz oder nach ischämischen Insulten zu schützen und die Folgen für den Menschen zu reduzieren.

Abschließend und zusammenfassend lassen sich die Ergebnisse und die sich daraus ergebenden Möglichkeiten in folgender Grafik darstellen: 
Interaktion von $\mathrm{LDH}$ und $\operatorname{PrP}^{\mathrm{C}}$ nachgewiesen

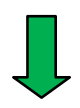

Hypoxie führt zu einer Hochregulation von LDH in...

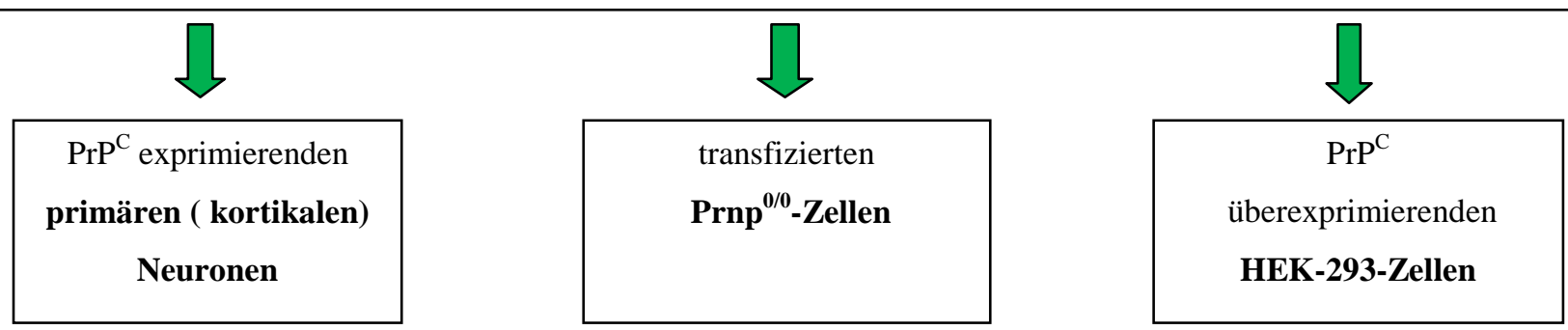

Führt eine LDH-Erhöhung durch $\operatorname{PrP}^{C}$ zur Neuroprotektion?

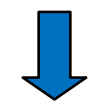

\section{Geringere Schäden des}

Tubulinzytoskelettes nach Hypoxie in

Anwesenheit von $\operatorname{PrP}^{\mathrm{C}}$ nachgewiesen.

Nutzen für die (Human-) Medizin?

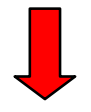

$\operatorname{PrP}^{\mathrm{C}}$ als Schutz vor Zelluntergang?

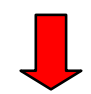

Potentieller Marker?
Neue

Therapieansätze?

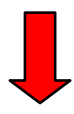

Möglicher Einfluss von $\operatorname{PrP}^{\mathrm{C}}$ auf die Glukose-Homöostase.

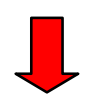

Weitere

Forschungs-

Möglichkeiten? 


\section{Zusammenfassung}

Die genaue physiologische Funktion des zellulären Prion-Proteins $\left(\operatorname{PrP}^{\mathrm{C}}\right)$ ist noch immer nicht vollständig verstanden. Eine mögliche Funktion des $\operatorname{PrP}^{\mathrm{C}}$ auf das neuronale Überleben nach einem hypoxischen oder ischämischen Insult wird diskutiert. In einem Vorversuch zeigten sich nach zerebraler Ischämie deutlich größere Infarktvolumina in den Gehirnen von PrionKnock-Out-Mäusen im Vergleich zu denen der Wild-Typ-Mäuse. Das Identifizieren der molekularen Mechanismen der $\operatorname{PrP}^{\mathrm{C}}$-vermittelten Neuroprotektion ist daher von großem Interesse und machte die Etablierung eines Zell-Modells erforderlich.

Neuere Studien konnten einen Einfluss des zellulären Prion-Proteins auf die Glykolyse nachweisen. Unter Sauerstoffmangelbedingungen kommt es zu einer vermehrten Bildung von Laktat durch das Enzym Laktat-Dehydrogenase (LDH). Neurone benötigen unter hypoxischen oder ischämischen Bedingungen dieses Laktat als Energiesubstrat. Je mehr Laktat den Neuronen zur Verfügung steht, umso höher ist das neuronale Überleben.

In dieser Arbeit konnte die Beteiligung der Laktat-Dehydrogenase an der durch das zelluläre Prion-Protein vermittelten Neuroprotektion nach Hypoxie nachgewiesen werden. Das Ziel dieser Arbeit bestand darin, mögliche Unterschiede der LDH-Expression in WT-Zellen, Prnp ${ }^{0 / 0}$-Zellen und HEK-293-Zellen unter normalen und hypoxischen Bedingungen in vitro zu untersuchen. Die Expression der LDH war unter hypoxischen Bedingungen in den WT-Zellen im Vergleich zu den $\operatorname{Prnp}^{0 / 0}$-Zellen deutlich höher. Dies konnte auch in $\operatorname{PrP}^{\mathrm{C}}$ überexprimierenden HEK-293-Zellen nach Hypoxie gezeigt werden. Ebenso konnte nachgewiesen werden, dass Hypoxie zu einem größeren Schaden des Tubulinzytoskelettes in $\mathrm{Prnp}^{0 / 0}$-Zellen führt als in WT-Zellen, was eine neuroprotektive Wirkung von $\operatorname{PrP}^{\mathrm{C}}$ vermuten lässt.

Eine direkte oder indirekte Interaktion von LDH-A und $\operatorname{PrP}^{\mathrm{C}}$ konnte durch eine CoImmunpräzipitation in HEK-293-Zellen nachgewiesen werden. Die genauen Mechanismen über die $\mathrm{PrP}^{\mathrm{C}}$ möglicherweise zu einer vermehrten Laktat-Produktion führt, sind noch nicht eindeutig identifiziert und müssen noch näher untersucht werden.

Zusammengefasst kann gesagt werden, dass die erhobenen Daten die Vermutung verstärken, dass das Enzym LDH und sein Produkt Laktat in die durch das zelluläre Prion-Protein vermittelte Neuroprotektion nach Hypoxie involviert sind. Es ist das erste Mal, dass gezeigt wurde, durch welchen Mechanismus $\operatorname{PrP}^{\mathrm{C}}$ zur Neuroprotektion beiträgt. 


\section{Literaturverzeichnis}

Annis MG, Yethon JA, Leber B, Andrews DW (2004): There is more to life and death than mitochondria: Bcl-2 proteins at the endoplasmic reticulum. Biochim Biophys Acta $\underline{1644}, 115-123$

Apte SS, Mattei MG, Olsen BR (1995): Mapping of the human BAX gene to chromosome 19q13.3-q13.4 and isolation of a novel alternatively spliced transcript, BAX delta. Genomics 26, 592-594

Azzalin A, Ferrara V, Arias A, Cerri S, Avella D, Pisu MB, Nano R, Bernocchi G, Ferretti L, Comincini $S$ (2006): Interaction between the cellular prion $\left(\operatorname{PrP}^{\mathrm{C}}\right)$ and the $2 \mathrm{P}$ domain $\mathrm{K}+$ channel TREK-1 protein. Biochem Biophys Res Commun $\underline{346}$, 108-115

Bakhshi A, Jensen JP, Goldman P, Wright JJ, McBride OW, Epstein AL, Korsmeyer SJ (1985): Cloning the chromosomal breakpoint of $t(14 ; 18)$ human lymphomas: clustering around $\mathrm{JH}$ on chromosome 14 and near a transcriptional unit on 18. Cell $\underline{41}$, 899-906

Baldwin MA, Stahl N, Reinders LG, Gibson BW, Prusiner SB, Burlingame AL (1990): Permethylation and tandem mass spectrometry of oligosaccharides having free hexosamine: analysis of the glycoinositol phospholipid anchor glycan from the scrapie prion protein. Anal Biochem 191, 174-182

Baldwin MA, Cohen FE, Prusiner SB (1995): Prion protein isoforms, a convergence of biological and structural investigations. J Biol Chem 270, 19197-19200

Banasiak KJ, Xia Y, Haddad GG (2000): Mechanisms underlying hypoxia-induced neuronal apoptosis. Prog Neurobiol 62, 215-249

Basler K, Oesch B, Scott M, Westaway D, Walchli M, Groth DF, McKinley MP, Prusiner SB, Weissmann C (1986): Scrapie and cellular PrP isoforms are encoded by the same chromosomal gene. Cell $\underline{46}, 417-428$

Becker T (2005): BSE, Creutzfeldt-Jakob \& Co. http://daten.didaktikchemie.unibayreuth.de/umat/bse/prion.htm (Stand: 20.09.2010; abgerufen am 16.11.2013, 19:15 Uhr)

Bellinger-Kawahara C, Diener TO, McKinley MP, Groth DF, Smith DR, Prusiner SB (1987): Purified scrapie prions resist inactivation by procedures that hydrolyze, modify, or shear nucleic acids. Virology $\underline{160,271-274}$ 
Bendheim PE, Brown HR, Rudelli RD, Scala LJ, Goller NL, Wen GY, Kascsak RJ, Cashman NR, Bolton DC (1992): Nearly ubiquitous tissue distribution of the scrapie agent precursor protein. Neurology $\underline{42,149-156}$

Berthet C, Lei H, Thevenet J, Gruetter R, Magistretti PJ, Hirt L (2009): Neuroprotective role of lactate after cerebral ischemia. J Cereb Blood Flow Metab 29, 1780-1789

Bolton DC, McKinley MP, Prusiner SB (1982): Identification of a protein that purifies with the scrapie prion. Science 218, 1309-1311

Boothpur R, Brennan DC (2008): Didactic lessons from the serum lactate dehydrogenase posttransplant: a clinical vignette. Am J Transplant $\underline{\text { 8, 862-865 }}$

Borchelt DR, Scott M, Taraboulos A, Stahl N, Prusiner SB (1990): Scrapie and cellular prion proteins differ in their kinetics of synthesis and topology in cultured cells. J Cell Biol 110, 743-752

Borner C (2003): The Bcl-2 protein family: sensors and checkpoints for life-or-death decisions. Mol Immunol 39, 615-647

Bounhar Y, Zhang Y, Goodyer CG, LeBlanc A (2001): Prion protein protects human neurons against Bax-mediated apoptosis. J Biol Chem 276, 39145-39149

Bragason BT, Palsdottir A (2005): Interaction of PrP with NRAGE, a protein involved in neuronal apoptosis. Mol Cell Neurosci 29, 232-244

Breckenridge DG, Germain M, Mathai JP, Nguyen M, Shore GC (2003): Regulation of apoptosis by endoplasmic reticulum pathways. Oncogene 22, 8608-8618

Brini M, Miuzzo M, Pierobon N, Negro A, Sorgato MC (2005): The prion protein and its paralogue Doppel affect calcium signaling in Chinese hamster ovary cells. Mol Biol Cell 16, 2799-2808

Brown DR, Qin K, Herms JW, Madlung A, Manson J, Strome R, Fraser PE, Kruck T, von Bohlen A, Schulz-Schaeffer WJ, Giese A, Westaway D, Kretzschmar H (1997a): The cellular prion protein binds copper in vivo. Nature $\underline{390,684-687}$

Brown DR, Schulz-Schaeffer WJ, Schmidt B, Kretzschmar HA (1997b): Prion proteindeficient cells show altered response to oxidative stress due to decreased SOD-1 activity. Exp Neurol 146, 104-112 
Brown DR, Nicholas RS, Canevari L (2002): Lack of prion protein expression results in a neuronal phenotype sensitive to stress. J Neurosci Res $\underline{67,211-224}$

Brown KL, Ritchie DL, McBride PA, Bruce ME (2000): Detection of PrP in extraneural tissues. Microsc Res Tech $\underline{50,40-45}$

Bueler HR, Fischer M, Lang Y, Bluethmann H, Lipp HP, DeArmond SJ, Prusiner SB, Aguet M, Weissmann C (1992): Normal development and behaviour of mice lacking the neuronal cell-surface PrP protein. Nature 356, 577-582

Butterfield DA, Kanski J (2001): Brain protein oxidation in age-related neurodegenerative disorders that are associated with aggregated proteins. Mech Ageing Dev $\underline{122,}$, 945962

Cahn RD, Zwilling E, Kaplan NO, Levine L (1962): Nature and Development of Lactic Dehydrogenases: The two major types of this enzyme form molecular hybrids which change in makeup during development. Science 136, 962-969

Cashman NR, Loertscher R, Nalbantoglu J, Shaw I, Kascsak RJ, Bolton DC, Bendheim PE (1990): Cellular isoform of the scrapie agent protein participates in lymphocyte activation. Cell $\underline{61}, 185-192$

Chiarini LB, de Freitas FG, Leal-Ferreira ML, Tolkovsky A, Linden R (2002): Cytoplasmic cJun N-terminal immunoreactivity: a hallmark of retinal apoptosis. Cell Mol Neurobiol 22, 711-726

Chih CP, Lipton P, Roberts EL Jr (2001): Do active cerebral neurons really use lactate rather than glucose? Trends Neurosci 24, 573-578

Chittenden T, Flemington C, Houghton AB, Ebb RG, Gallo GJ, Elangovan B, Chinnadurai G, Lutz RJ (1995): A conserved domain in Bak, distinct from BH1 and BH2, mediates cell death and protein binding functions. Embo J 14, 5589-5596

Christen Y (2000): Oxidative stress and Alzheimer disease. Am J Clin Nutr 71, 621S-629S

Cleary ML, Trela MJ, Weiss LM, Warnke R, Sklar J (1985): Most null large cell lymphomas are B lineage neoplasms. Lab Invest $\underline{53,521-525}$

Collinge J (2001): Prion diseases of humans and animals: their causes and molecular basis. Annu Rev Neurosci 24, 519-550 
Colton CA, Gilbert DL (1987): Production of superoxide anions by a CNS macrophage, the microglia. FEBS Lett 223, 284-288

Cory S, Huang DC, Adams JM (2003): The Bcl-2 family: roles in cell survival and oncogenesis. Oncogene 22, 8590-8607

Danial NN, Korsmeyer SJ (2004): Cell death: critical control points. Cell 116, 205-219

De Almeida CJ, Chiarini LB, da Silva JP, Martins MA, Linden R (2005): The cellular prion protein modulates phagocytosis and inflammatory response. J Leukoc Biol $\underline{77,238-}$ 246

Diarra-Mehrpour MS, Arrabal A, Jalil, Pinson X, Gaudin C, Pietu G, Pitaval A, Ripoche H, Eloit M, Dormont D, Chouaib S (2004): Prion protein prevents human breast carcinoma cell line from tumor necrosis factor alpha-induced cell death. Cancer Res $\underline{64,719-727}$

Dienel GA, Hertz L (2001): Glucose and lactate metabolism during brain activation. J Neurosci Res 66, 824-838

Edenhofer F, Rieger R, Famulok M, Wendler W, Weiss S, Winnacker EL (1996): Prion protein PrPc interacts with molecular chaperones of the Hsp60 family. J Virol $\underline{70}$, $4724-4728$

Endo T, Groth D, Prusiner SB, Kobata A (1989): Diversity of oligosaccharide structures linked to asparagines of the scrapie prion protein. Biochemistry $\underline{28,8380-8388}$

Erlichman JS, Hewitt A, Damon TL, Hart M, Kurascz J, Li A, Leiter JC (2008): Inhibition of monocarboxylate transporter 2 in the retrotrapezoid nucleus in rats: a test of the astrocyte-neuron lactate-shuttle hypothesis. J Neurosci 28, 4888-4896

Fadeel B, Orrenius S (2005): Apoptosis: a basic biological phenomenon with wide-ranging implications in human disease. J Intern Med 258, 479-517

Fox JH, Kama JA, Lieberman G, Chopra R, Dorsey K, Chopra V, Volitakis I, Cherny RA, Bush AI, Hersch S (2007): Mechanisms of copper ion mediated Huntington's disease progression. PLoS One 2, 334

Freeman BA, Crapo JD (1982): Biology of disease: free radicals and tissue injury. Lab Invest $\underline{47}, 412-426$ 
Fujita K, Harada M, Yuasa T, Sasaki M, Izumi Y, Kaji R (2011): Temporal evolution of sporadic Creutzfeldt-Jakob disease monitored by 3-Tesla MR spectroscopy. J Neurol 258, 1368-1370

Gajdusek DC, Gibbs CJ Jr, Asher DM, Brown P, Diwan A, Hoffman P, Nemo G, Rohwer R, White L (1977): Precautions in medical care of, and in handling materials from, patients with transmissible virus dementia (Creutzfeldt-Jakob disease). N Engl J Med 297, 1253-1258

Gauczynski S, Peyrin JM, Haik S, Leucht C, Hundt C, Rieger R, Krasemann S, Deslys JP, Dormont D, Lasmezasund CI, Weiss S (2001): The 37-kDa/67-kDa laminin receptor acts as the cell-surface receptor for the cellular prion protein. Embo J 20(21), 58635875

Gawinecka J, Dieks J, Asif AR, Carimalo J, Heinemann U, Streich JH, Dihazi H, SchulzSchaeffer W, Zerr I (2010): Codon 129 polymorphism specific cerebrospinal fluid proteome pattern in sporadic Creutzfeldt-Jakob disease and the implication of glycolytic enzymes in prion-induced pathology. J Proteome Res 9, 5646-5657

Germain M, Shore GC (2003): Cellular distribution of Bcl-2 family proteins. Sci STKE 2003, 10

Gorodinsky A, Harris DA (1995): Glycolipid-anchored proteins in neuroblastoma cells form detergent-resistant complexes without caveolin. J Cell Biol 129, 619-627

Graner E, Mercadante AF, Zanata SM, Forlenza OV, Cabral AL, Veiga SS, Juliano MA, Roesler R, Walz R, Minetti A, Izquierdo I, Martins VR, Brentani RR (2000a): Cellular prion protein binds laminin and mediates neuritogenesis. Brain Res Mol Brain Res $\underline{76}$, 85-92

Graner E, Mercadante AF, Zanata SM, Martins VR, Jay DG, Brentani RR (2000b): Laminininduced PC-12 cell differentiation is inhibited following laser inactivation of cellular prion protein. FEBS Lett $\underline{482,}$ 257-260

Griffith JS (1967): Self-replication and scrapie. Nature 215, 1043-1044

Haraguchi T, Fisher S, Olofsson S, Endo T, Groth D, Tarentino A, Borchelt DR, Teplow D, Hood L, Burlingame A (1989): Asparagine-linked glycosylation of the scrapie and cellular prion proteins. Arch Biochem Biophys 274, 1-13

Harmey JH, Doyle D, Brown V, Rogers MS (1995): The cellular isoform of the prion protein, $\mathrm{PrPc}$, is associated with caveolae in mouse neuroblastoma (N2a) cells. Biochem Biophys Res Commun 210, 753-759 
Harms L, Meierkord H, Timm G, Pfeiffer L, Ludolph AC (1997): Decreased N-acetylaspartate/choline ratio and increased lactate in the frontal lobe of patients with Huntington's disease: a proton magnetic resonance spectroscopy study. J Neurol Neurosurg Psychiatry 62, 27-30

Hornshaw MP, McDermott JR, Candy JM, Lakey JH (1995): Copper binding to the Nterminal tandem repeat region of mammalian and avian prion protein: structural studies using synthetic peptides. Biochem Biophys Res Commun 214, 993-999

Hoshino S, Inoue K, Yokoyama T, Kobayashi S, Asakura T, Teramoto A, Itohara S (2003): Prions prevent brain damage after experimental brain injury: a preliminary report. Acta Neurochir Suppl 86, 297-299

Jarrett JT, Lansbury PT Jr (1993): Seeding "one-dimensional crystallization" of amyloid: a pathogenic mechanism in Alzheimer's disease and scrapie? Cell 73, 1055-1058

Kahlert S, Reiser G (2000): Requirement of glycolytic and mitochondrial energy supply for loading of $\mathrm{Ca}(2+)$ stores and $\mathrm{InsP}(3)$-mediated $\mathrm{Ca}(2+)$ signaling in rat hippocampus astrocytes. J Neurosci Res $\underline{61,409-420}$

Kim BH, Lee HG, Choi JK, Kim JI, Choi EK, Carp RI, Kim YS (2004): The cellular prion protein (PrPC) prevents apoptotic neuronal cell death and mitochondrial dysfunction induced by serum deprivation. Brain Res Mol Brain Res 124, 40-50

Kirk P, Wilson MC, Heddle C, Brown MH, Barclay AN, Halestrap AP (2000): CD147 is tightly associated with lactate transporters MCT1 and MCT4 and facilitates their cell surface expression. Embo J 19, 3896-3904

Kleene R, Loers G, Langer J, Frobert Y, Buck F, Schachner M (2007): Prion protein regulates glutamate-dependent lactate transport of astrocytes. J Neurosci 27, 12331-12340

Kurschner C, Morgan JI (1995): The cellular prion protein (PrP) selectively binds to Bcl-2 in the yeast two-hybrid system. Brain Res Mol Brain Res 30, 165-168

Kuwahara C, Takeuchi AM, Nishimura T, Haraguchi K, Kubosaki A, Matsumoto Y, Saeki K, Matsumoto Y, Yokoyama T, Itohara S, Onodera T (1999): Prions prevent neuronal cell-line death. Nature 400, 225-226

Lazarides E (1980): Intermediate filaments as mechanical integrators of cellular space. Nature 283, 249-256 
Lopes MH, Hajj GN, Muras AG, Mancini GL, Castro RM, Ribeiro KC, Brentani RR, Linden R, Martins VR (2005): Interaction of cellular prion and stress-inducible protein 1 promotes neuritogenesis and neuroprotection by distinct signaling pathways. J Neurosci 25, 11330-11339

Maker HS, Lehrer GM, Weissbarth S, Bornstein MB (1972): Changes in LDH isoenzymes of brain developing in situ and in vitro. Brain Res $\underline{44}$, 189-196

Manson J, West JD, Thomson V, McBride P, Kaufman MH, Hope J (1992): The prion protein gene: a role in mouse embryogenesis? Development $\underline{115,117-122}$

Marella M, Lehmann S, Grassi J, Chabry J (2002): Filipin prevents pathological prion protein accumulation by reducing endocytosis and inducing cellular PrP release. $\mathrm{J}$ Biol Chem 277, 25457-25464

Markesbery WR (1999): The role of oxidative stress in Alzheimer disease. Arch Neurol 56, 1449-1452

McKinley MP, Bolton DC, Prusiner SB (1983). A protease-resistant protein is a structural component of the scrapie prion. Cell $\underline{35}, 57-62$

McLennan NF, Rennison KA, Bell JE, Ironside JW (2001): In situ hybridization analysis of PrP mRNA in human CNS tissues. Neuropathol Appl Neurobiol 27, 373-383

McLennan NF, Brennan PM, McNeill A, Davies I, Fotheringham A, Rennison KA, Ritchie D, Brannan F, Head MW, Ironside JW, Williams A, Bell JE (2004): Prion protein accumulation and neuroprotection in hypoxic brain damage. Am J Pathol 165, 227235

Meyer N, Rosenbaum V, Schmidt B, Gilles K, Mirenda C, Groth D, Prusiner SB, Riesner D (1991): Search for a putative scrapie genome in purified prion fractions reveals a paucity of nucleic acids. J Gen Virol 72, 37-49

Mitsios N, Saka M, Krupinski J, Pennucci R, Sanfeliu C, Miguel M, Turu, Gaffney J, Kumar, P, Kumar S, Sullivan M, Slevin M (2007): Cellular prion protein is increased in the plasma and peri-infarcted brain tissue after acute stroke. J Neurosci Res $\underline{85}$, 602-611

Mitteregger G, Vosko M, Krebs B, Xiang W, Kohlmannsperger V, Nolting S, Hamann GF, Kretzschmar HA (2007): The role of the octarepeat region in neuroprotective function of the cellular prion protein. Brain Pathol 17, 174-183 
Mouillet-Richard S, Ermonval M, Chebassier C, Laplanche JL, Lehmann S, Launay JM, Kellermann O (2000): Signal transduction through prion protein. Science 289, 19251928

Muchmore SW, Sattler M, Liang H, Meadows RP, Harlan JE, Yoon HS, Nettesheim D, Chang BS, Thompson CB, Wong SL, Ng SL, Fesik SW (1996): X-ray and NMR structure of human Bcl-xL, an inhibitor of programmed cell death. Nature $\underline{381,335-}$ 341

Naslavsky N, Stein R, Yanai A, Friedlander G, Taraboulos A (1997): Characterization of detergent-insoluble complexes containing the cellular prion protein and its scrapie isoform. J Biol Chem 272, 6324-6331

Nieznanski K, Nieznanska H, Skowronek KJ, Osiecka KM, Stepkowski D (2005): Direct interaction between prion protein and tubulin. Biochem Biophys Res Commun 334, 403-411

Nishimura T, Sakudo A, Nakamura I, Lee DC, Taniuchi Y, Saeki K, Matsumoto Y, Ogawa M, Sakaguchi S, Itohara S, Onodera T (2004): Cellular prion protein regulates intracellular hydrogen peroxide level and prevents copper-induced apoptosis. Biochem Biophys Res Commun 323: 218-222.

Nogales E (2000): Structural insights into microtubule function. Annu Rev Biochem $\underline{69}$, 277302

Oesch B, Westaway D, Walchli M, McKinley MP, Kent SB, Aebersold R, Barry RA, Tempst P, Teplow DB, Hood LE (1985): A cellular gene encodes scrapie PrP 27-30 protein. Cell $\underline{40,}$ 735-746

Oltvai ZN, Milliman CL, Korsmeyer SJ (1993): Bcl-2 heterodimerizes in vivo with a conserved homolog, Bax, that accelerates programmed cell death. Cell $\underline{74,}$ 609-619

Opferman JT, Korsmeyer SJ (2003): Apoptosis in the development and maintenance of the immune system. Nat Immunol 4, 410-415

Orrenius S, Zhivotovsky B, Nicotera P (2003): Regulation of cell death: the calciumapoptosis link. Nat Rev Mol Cell Biol 4, 552-565

Paitel E, Alves da Costa C, Vilette D, Grassi J, Checler F (2002): Overexpression of PrPc triggers caspase 3 activation: potentiation by proteasome inhibitors and blockade by anti-PrP antibodies. J Neurochem $\underline{83,1208-1214,}$ 
Pammer J, Weninger W, Tschachler E (1998): Human keratinocytes express cellular prionrelated protein in vitro and during inflammatory skin diseases. Am J Pathol $\underline{153,1353-}$ 1358

Pan KM, Baldwin M, Nguyen J, Gasset M, Serban A, Groth D, Mehlhorn I, Huang Z, Fletterick RJ, Cohen FE (1993): Conversion of alpha-helices into beta-sheets features in the formation of the scrapie prion proteins. Proc Natl Acad Sci U S A 90, 1096210966

Parkin ET, Watt NT, Hussain I, Eckman EA, Eckman CB, Manson JC, Baybutt HN, Turner AJ, Hooper NM (2007): Cellular prion protein regulates beta-secretase cleavage of the Alzheimer's amyloid precursor protein. Proc Natl Acad Sci U S A 104, 11062-11067

Pauly PC, Harris DA (1998): Copper stimulates endocytosis of the prion protein. J Biol Chem 273, 33107-33110

Pellerin L, Magistretti PJ (1994): Glutamate uptake into astrocytes stimulates aerobic glycolysis: a mechanism coupling neuronal activity to glucose utilization. Proc Natl Acad Sci U S A $\underline{91,}$ 10625-10629

Pellerin L, Bergersen LH, Halestrap AP, Pierre K (2005): Cellular and subcellular distribution of monocarboxylate transporters in cultured brain cells and in the adult brain. $\mathrm{J}$ Neurosci Res 79, 55-64

Peters PJ, Mironov A Jr, Peretz D, van Donselaar E, Leclerc E, Erpel S, DeArmond SJ, Burton DR, Williamson RA, Vey M, Prusiner SB (2003): Trafficking of prion proteins through a caveolae-mediated endosomal pathway. J Cell Biol 16, 703-717

Pisani A, Bonsi P, Calabresi P (2004): Calcium signaling and neuronal vulnerability to ischemia in the striatum. Cell Calcium 36, 277-284

Plagemann PG, Gregory KF, Wroblewski F (1960): The electrophoretically distinct forms of mammalian lactic dehydrogenase. 1. Distribution of lactic dehydrogenase. 1. Distribution of lactic dehydrogenases in rabbit and human tissue. J Biol Chem $\underline{235}$, 2282-2287

Prado MA, Alves-Silva J, Magalhaes AC, Prado VF, Linden R, Martins VR, Brentani RR (2004): PrPc on the road: trafficking of the cellular prion protein. J Neurochem $\underline{88}$, 769-781

Prusiner SB (1982): Novel proteinaceous infectious particles cause scrapie. Science 216, 136144 
Prusiner SB (1989): Scrapie prions. Annu Rev Microbiol 43, 345-374

Prusiner SB (1991): Molecular biology of prion diseases. Science 252, 1515-1522

Prusiner SB (1993): Genetic and infectious prion diseases. Arch Neurol 무, 1129-1153

Prusiner SB (1998): Prions. Proc Natl Acad Sci U S A 95, 13363-13383

Prusiner SB, DeArmond SJ (1987). Prions causing nervous system degeneration. Lab Invest 56, 349-363

Prusiner SB, McKinley MP, Bowman KA, Bolton DC, Bendheim PE, Groth DF, Glenner GG (1983). Scrapie prions aggregate to form amyloid-like birefringent rods. Cell $\underline{35}$, 349358

Qin K, Yang DS, Yang Y, Chishti MA, Meng LJ, H. Kretzschmar A, Yip CM, Fraser PE, Westaway D (2000): Copper(II)-induced conformational changes and protease resistance in recombinant and cellular PrP. Effect of protein age and deamidation. J Biol Chem 275, 19121-19131

Ramljak S: Physiological function of the cellular prion protein (PrPC): protein profiling study in two cell culture systems. Mathematisch-Naturwissentschaftliche Dissertation Göttingen 2007.

Ramljak S, Asif AR, Armstrong VW, Wrede A, Groschup MH, Buschmann A, SchulzSchaeffer W, Bodemer W, Zerr I (2008): Physiological role of the cellular prion protein (PrPc): protein profiling study in two cell culture systems. J Proteome Res $\underline{7}$, 2681-2695

Reilly CE (2000): Nonpathogenic prion protein (PrPc) acts as a cell-surface signal transducer. J Neurol 247, 819-820

Riek R, Hornemann S, Wider G, Billeter M, Glockshuber R, Wuthrich K (1996): NMR structure of the mouse prion protein domain $\operatorname{PrP}(121-321)$. Nature $\underline{382,}$ 180-182

Roucou X, Giannopoulos PN, Zhang Y, Jodoin J, Goodyer CG, LeBlanc A (2005): Cellular prion protein inhibits proapoptotic Bax conformational change in human neurons and in breast carcinoma MCF-7 cells. Cell Death Differ 12, 783-795 
Rutishauser D, Mertz KD, Moos R, Brunner E, Rulicke T, Calella AM, Aguzzi A (2009): The comprehensive native interactome of a fully functional tagged prion protein. PLoS One $\underline{4,4446}$

Sakudo A, Lee DC, Saeki K, Matsumoto Y, Itohara S, Onodera T (2003): Tumor necrosis factor attenuates prion protein-deficient neuronal cell death by increases in antiapoptotic Bcl-2 family proteins. Biochem Biophys Res Commun 310, 725-729

Sales N, Rodolfo K, Hassig R, Faucheux B, Di Giamberardino L, Moya KL (1998): Cellular prion protein localization in rodent and primate brain. Eur J Neurosci 10, 2464-2471

Schmidt H, Otto M, Niedmann P, Cepek L, Schroter A, Kretzschmar HA, Poser S (2004): CSF lactate dehydrogenase activity in patients with Creutzfeldt-Jakob disease exceeds that in other dementias. Dement Geriatr Cogn Disord 17, 204-206

Schmitt-Ulms G, Legname G, Baldwin MA, Ball HL, Bradon N, Bosque PJ, Crossin KL, Edelman GM, DeArmond SJ, Cohen FE, Prusiner SB (2001): Binding of neural cell adhesion molecules (N-CAMs) to the cellular prion protein. J Mol Biol 314, 12091225

Schmitz M, Greis C, Ottis P, Silva CJ, Schulz-Schaeffer WJ, Wrede A, Koppe K, Onisko B, Requena JR, Govindarajan N, Korth C, Fischer A, Zerr I (2014): Loss of Prion Protein Leads to Age-Dependent Behavioral Abnormalities and Changes in Cytoskeletal Protein Expression. Mol Neurobiol.

Schurr A, Dong WQ, Reid KH, West CA, Rigor BM (1988): Lactic acidosis and recovery of neuronal function following cerebral hypoxia in vitro. Brain Res $\underline{438}, 311-314$

Schurr A, Payne RS, Miller JJ, Rigor BM (1997): Brain lactate, not glucose, fuels the recovery of synaptic function from hypoxia upon reoxygenation: an in vitro study. Brain Res $\underline{744}$, 105-111

Schurr A, Payne RS, Miller JJ, Tseng MT, Rigor BM (2001): Blockade of lactate transport exacerbates delayed neuronal damage in a rat model of cerebral ischemia. Brain Res 895, 268-272

Semenza GL, Jiang BH, Leung SW, Passantino R, Concordet JP, Maire P, Giallongo A (1996): Hypoxia response elements in the aldolase A, enolase 1, and lactate dehydrogenase A gene promoters contain essential binding sites for hypoxia-inducible factor 1. J Biol Chem 271, 32529-32537 
Shi B, Triebe D, Kajiji S, Iwata KK, Bruskin A, Mahajna J (1999): Identification and characterization of baxepsilon, a novel bax variant missing the $\mathrm{BH} 2$ and the transmembrane domains. Biochem Biophys Res Commun 254, 779-785

Shmakov AN, McLennan NF, McBride P, Farquhar CF, Bode J, Rennison KA, Ghosh S (2000): Cellular prion protein is expressed in the human enteric nervous system. Nat Med 6, 840-841

Shyng SL, Huber MT, Harris DA (1993): A prion protein cycles between the cell surface and an endocytic compartment in cultured neuroblastoma cells. J Biol Chem 268, 1592215928

Shyu WC, Lin SZ, Chiang MF, Ding DC, Li KW, Chen SF, Yang HI, Li H (2005a): Overexpression of PrPC by adenovirus-mediated gene targeting reduces ischemic injury in a stroke rat model. J Neurosci 25, 8967-8977

Shyu WC, Chen CP, Saeki K, Kubosaki A, Matusmoto Y, Onodera T, Ding DC, Chiang MF, Lee YJ, Lin SZ, Li H (2005b): Hypoglycemia enhances the expression of prion protein and heat-shock protein 70 in a mouse neuroblastoma cell line. J Neurosci Res $\underline{80,887-}$ 894

Spampanato C, De Maria S, Sarnataro M, Giordano E, Zanfardino M, Baiano S, Carteni M, Morelli F (2012): Simvastatin inhibits cancer cell growth by inducing apoptosis correlated expression. Int J Oncol 40, 935-941

Sparkes RS, Simon M, Cohn VH, Fournier RE, Lem J, Klisak I, Heinzmann C, Blatt C, Lucero M, Mohandas T (1986): Assignment of the human and mouse prion protein

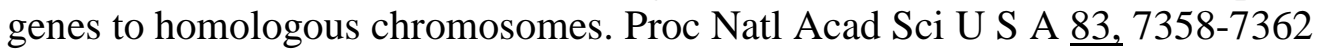

Spielhaupter C, Schatzl HM (2001): PrPC directly interacts with proteins involved in signaling pathways. J Biol Chem 276, 44604-44612

Spudich A, Frigg R, Kilic E, Kilic U, Oesch B, Raeber A, Bassetti CL, Hermann DM (2005): Aggravation of ischemic brain injury by prion protein deficiency: role of ERK-1/-2 and STAT-1. Neurobiol Dis 20, 442-449

Stahl N, Borchelt DR, Hsiao K, Prusiner SB (1987): Scrapie prion protein contains a phosphatidylinositol glycolipid. Cell $\underline{51,229-240}$

Stahl N, Baldwin MA, Teplow DB, Hood L, Gibson BW, Burlingame AL, Prusiner SB (1993): Structural studies of the scrapie prion protein using mass spectrometry and amino acid sequencing. Biochemistry $\underline{32,}$ 1991-2002 
Stella R, Cifani P, Peggion C, Hansson K, Lazzari C, Bendz M, Levander F, Sorgato MC, Bertoli A, James P (2012): Relative quantification of membrane proteins in wild-type and prion protein (PrP)-knockout cerebellar granule neurons. J Proteome Res $\underline{11,523-}$ 536

Strom A, Diecke S, Hunsmann G, Stuke AW (2006): Identification of prion protein binding proteins by combined use of far-Western immunoblotting, two dimensional gel electrophoresis and mass spectrometry. Proteomics $\underline{6}, 26-34$

Strom A, Wang GS, Reimer R, Finegood DT, Scott FW (2007): Pronounced cytosolic aggregation of cellular prion protein in pancreatic beta-cells in response to hyperglycemia. Lab Invest $\underline{87,139-149}$

Sunyach C, Jen A, Deng J, Fitzgerald KT, Frobert Y, Grassi J, McCaffrey MW, Morris R (2003): The mechanism of internalization of glycosylphosphatidylinositol-anchored prion protein. Embo J 22, 3591-3601

Taylor DR, Hooper M (2006): The prion protein and lipid rafts. Mol Membr Biol 23, 89-99

Tsujimoto Y, Croce CM (1986). Analysis of the structure, transcripts, and protein products of bcl-2, the gene involved in human follicular lymphoma. Proc Natl Acad Sci U S A $\underline{83}$, 5214-5218

Van Delft MF, Huang DC (2006): How the Bcl-2 family of proteins interact to regulate apoptosis. Cell Res 16, 203-213

Vassallo N, Herms J (2003): Cellular prion protein function in copper homeostasis and redox signalling at the synapse. J Neurochem $\underline{86}, 538-544$

Vey M, Pilkuhn S, Wille H, Nixon R, DeArmond SJ, Smart EJ, Anderson RG, Taraboulos A, Prusiner SB (1996): Subcellular colocalization of the cellular and scrapie prion proteins in caveolae-like membranous domains. Proc Natl Acad Sci U S A $\underline{93}$, 1494514949

Walz R, Amaral OB, Rockenbach IC, Roesler R, Izquierdo I, Cavalheiro ES, Martins VR, Brentani RR (1999): Increased sensitivity to seizures in mice lacking cellular prion protein. Epilepsia 40, 1679-1682

Walz R, Castro RM, Velasco TR, Carlotti CG Jr, Sakamoto AC, Brentani RR, Martins VR (2002): Cellular prion protein: implications in seizures and epilepsy. Cell Mol Neurobiol 22, 249-257 
Watts JC, Huo H, Bai Y, Ehsani S, Jeon AH, Shi T, Daude N, Lau A, Young R, Xu L, Carlson GA, Williams D, Westaway D, Schmitt-Ulms G (2009): Interactome analyses identify ties of PrP and its mammalian paralogs to oligomannosidic N-glycans and endoplasmic reticulum-derived chaperones. PLoS Pathog 5, 1000608

Weise J, Crome O, Sandau R, Schulz-Schaeffer W, Bahr M, Zerr I (2004): Upregulation of cellular prion protein (PrPc) after focal cerebral ischemia and influence of lesion severity. Neurosci Lett $\underline{372,146-150}$

Weise J, Sandau R, Schwarting S, Crome O, Wrede A, Schulz-Schaeffer W, Zerr I, Bahr M (2006): Deletion of cellular prion protein results in reduced Akt activation, enhanced postischemic caspase-3 activation, and exacerbation of ischemic brain injury. Stroke 37, 1296-1300

Westergard L, Christensen HM, Harris DA (2007): The cellular prion protein $(\operatorname{PrP}(C))$ : its physiological function and role in disease. Biochim Biophys Acta 1772, 629-644

Wilson MC, Meredith D, Fox JE, Manoharan C, Davies AJ, Halestrap AP (2005): Basigin (CD147) is the target for organomercurial inhibition of monocarboxylate transporter isoforms 1 and 4: the ancillary protein for the insensitive MCT2 is EMBIGIN (gp70). J Biol Chem 280, 27213-27221

Yin XM, Oltvai ZN, Korsmeyer SJ (1994): BH1 and BH2 domains of Bcl-2 are required for inhibition of apoptosis and heterodimerization with Bax. Nature 369, 321-323

Yuan J, Yankner BA (2000). Apoptosis in the nervous system. Nature 407, 802-809

Zafar S, von Ahsen N, Oellerich M, Zerr I, Schulz-Schaeffer WJ, Armstrong VW, Asif AR (2011): Proteomics approach to identify the interacting partners of cellular prion protein and characterization of Rab7a interaction in neuronal cells. J Proteome Res $\underline{10}$, 3123-3135

Zafar S, Asif AR, Ramljak S, Tahir W, Schmitz M, Zerr I (2014): Anchorless 23-230 PrPC interactomics for elucidation of PrPC protective role. Mol Neurobiol 49, 1385-1399

Zanata SM, Lopes MH, Mercadante AF, Hajj GN, Chiarini LB, Nomizo R, Freitas AR, Cabral AL, Lee KS, Juliano MA, de Oliveira E, Jachieri SG, Burlingame A, Huang L, Linden R, Brentani RR, Martins VR (2002): Stress-inducible protein 1 is a cell surface ligand for cellular prion that triggers neuroprotection. Embo J 21, 3307-3316

Zhou M, Demo SD, McClure TN, Crea R, Bitler CM (1998): A novel splice variant of the cell death-promoting protein BAX. J Biol Chem 273, 11930-11936 
Zipfel GJ, Babcock DJ, Lee JM, Choi DW (2000): Neuronal apoptosis after CNS injury: the roles of glutamate and calcium. J Neurotrauma 17, 857-869

Zomosa-Signoret V, Arnaud JD, Fontes P, Alvarez-Martinez MT, Liautard JP (2008): Physiological role of the cellular prion protein. Vet Res $\underline{39,} 9$ 
